\title{
Management and leadership education for medical residents : evaluating needs and developing an educational intervention
}

Citation for published version (APA):

Berkenbosch, L. (2014). Management and leadership education for medical residents : evaluating needs and developing an educational intervention. [Doctoral Thesis, Maastricht University]. Maastricht University. https://doi.org/10.26481/dis.20140630lb

Document status and date:

Published: 01/01/2014

DOI:

10.26481/dis.20140630lb

Document Version:

Publisher's PDF, also known as Version of record

Please check the document version of this publication:

- A submitted manuscript is the version of the article upon submission and before peer-review. There can be important differences between the submitted version and the official published version of record.

People interested in the research are advised to contact the author for the final version of the publication, or visit the DOI to the publisher's website.

- The final author version and the galley proof are versions of the publication after peer review.

- The final published version features the final layout of the paper including the volume, issue and page numbers.

Link to publication

\footnotetext{
General rights rights.

- You may freely distribute the URL identifying the publication in the public portal. please follow below link for the End User Agreement:

www.umlib.nl/taverne-license

Take down policy

If you believe that this document breaches copyright please contact us at:

repository@maastrichtuniversity.nl

providing details and we will investigate your claim.
}

Copyright and moral rights for the publications made accessible in the public portal are retained by the authors and/or other copyright owners and it is a condition of accessing publications that users recognise and abide by the legal requirements associated with these

- Users may download and print one copy of any publication from the public portal for the purpose of private study or research.

- You may not further distribute the material or use it for any profit-making activity or commercial gain

If the publication is distributed under the terms of Article 25fa of the Dutch Copyright Act, indicated by the "Taverne" license above, 


\section{Management and leadership education for medical residents}

Evaluating needs and developing an educational intervention

Lizanne Berkenbosch 
The research reported here was carried out at Maastricht University at the School of Health Professions Education in the Netherlands.

Lay out by: $\quad$ Ilse Stronks, persoonlijkproefschrift.nl

Cover design: $\quad$ Nick Liefhebber, Liefhebber Graphic Design

Printed by: I I I I $\quad$ skamp Drukkers B.V., Enschede, the Nederlands

ISBN: $\quad$ 978-94-6259-215-5

Copyright (c) 2014 L. Berkenbosch, Utrecht, the Netherlands. 


\title{
Management and leadership education for medical residents
}

Evaluating needs and developing an educational intervention

\author{
PROEFSCHRIFT
}

ter verkrijging van de graad van doctor aan de Universiteit Maastricht, op gezag van de Rector Magnificus, Prof. Dr. L.L.G. Soete, volgens het besluit van het College van Decanen,

in het openbaar te verdedigen op

maandag 30 juni 2014 om 16:00 uur

door

Lizanne Berkenbosch 


\section{Promotores}

Prof. dr. A.J.J.A. Scherpbier

Prof. dr. I.C. Heyligers

Prof. dr. L.J.I. Zimmermann

\section{Copromotor}

Dr. J.O. Busari 


\section{TABLE OF CONTENTS}

$\begin{array}{lll}\text { Chapter } 1 \text { General Introduction } & 7\end{array}$

Chapter 2 Physicians as managers of health care delivery and 15 the implications for postgraduate medical training: a literature review.

Teach Learn Med. 2011 Apr;23(2):186-96

Chapter 3 How Dutch medical residents perceive their competency as manager in the revised postgraduate medical curriculum.

Postgrad Med J 2011;87:1032 680-687

Chapter 4 Medical residents perceptions of the need for management education in the postgraduate curriculum: a preliminary study.

Int J Med Educ. 2010; 1:76-82

Chapter 5 How Dutch medical specialists perceive the competencies and training needs of medical residents in healthcare management.

Medical Teacher 2013; 35: e1090-e1102

Chapter 6 Medical residents' perceptions of their competencies and training needs in health care management: an international comparison.

BMC Medical Education 2013, 13:25

Chapter 7 A pilot study of a practice management training module for medical residents Accepted for publication in BMC Medical Education

Chapter 8 Summary and General discussion

Dankwoord (Acknowledgements) 



\section{Chapter 1}

General Introduction

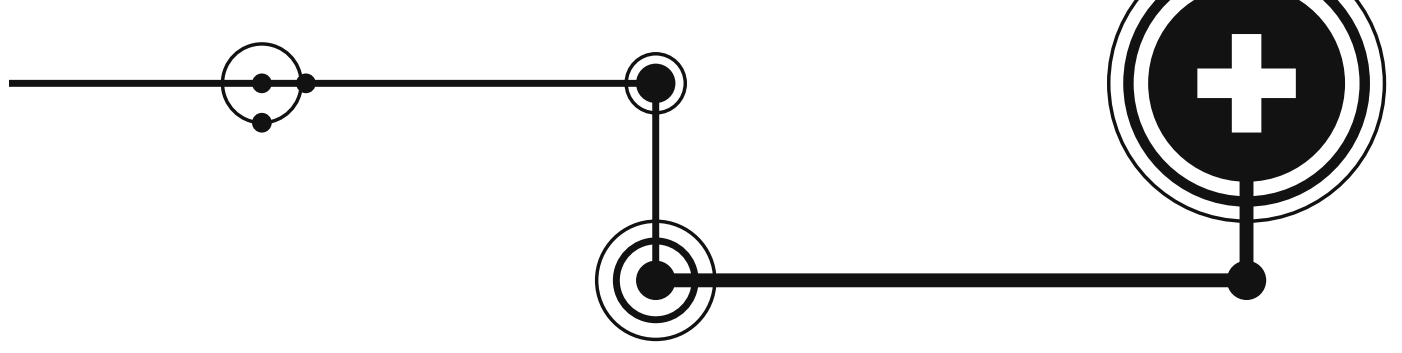




\section{THE EVOLUTION OF MEDICAL EDUCATION}

Over the last decades the nature of health care delivery has changed substantially. With our growing understanding of life sciences and with new technologies emerging every day, the practice of medicine has become more complex. In this complex environment doctors can no longer work alone but are part of multidisciplinary teams. Also, the focus of physicians can not only be on providing medical care of the highest standards anymore, but they have to be aware of the accompanying costs. They face an increasing sense of accountability and a decreasing appreciation of professionals and various authorities. Ultimately, these changes do not only affect physicians, but all stakeholders in this system (patients, hospitals, governments and insurance agencies) (1-7).

Medical schools and hospitals are increasingly being asked to respond to the needs of this changing environment and to be attentive of the results of its educational undertakings $(5,8,9)$. Against this background several institutions in many countries reviewed their goals and their approach in educating future physicians. In the past the emphasis was always on gaining as much medical knowledge as possible. However, in the complex modern health care environment other competencies are also deemed essential for giving the best medical care possible. In America, the Accreditation Council for Graduate Medical Education (ACGME) (responsible for the accreditation of postgraduate medical training programs in the USA) set up six general competencies residents must acquire during their postgraduate medical training namely; patient care, medical knowledge, practice-based learning and improvement, interpersonal and communication skills, and systems-based practice (10-12).

In Canada the changes highlighted above formed the basis for the Royal College of Physicians and Surgeons of Canada's (RCPSC) CanMEDS initiative (the RCPSC is responsible for setting residency training, examination, and accreditation standards across the country). They developed a framework of key competencies, organized around seven physician roles namely Medical Expert, Communicator, Collaborator, Health Advocate, Manager, Scholar, and Professional $(1,8,13)$. Many countries, recognizing the described problems, adopted the CanMEDS framework, including Denmark, Australia, and the Netherlands (14-16).

\section{COMPETENCY-BASED EDUCATION IN THE NETHERLANDS}

Similar to the situation in other countries, competencies such as communication and collaboration have been found to be as important as substantive medical knowledge in the Netherlands as well (17). Recognizing the need for a different kind of doctor, the CanMEDS 
framework was adopted in the Netherlands in 2005 (16,18).

One of the key competencies described in the CanMEDS framework is the physician's role as manager. The CanMEDS framework defines the manager's role as follows: "As managers, physicians are integral participants in healthcare organizations, organizing sustainable practices, making decisions about allocating resources, and contributing to the effectiveness of the healthcare system." "Within this competency physicians are able to:

1. Participate in activities that contribute to the effectiveness of their healthcare organizations and systems;

2. Manage their practice and career effectively;

3. Allocate finite healthcare resources appropriately;

4. Serve in administration and leadership roles, as appropriate."(13)

In the modern health care environment described above, the manager's role seems to be of increasing importance. Some even argue that physicians are the only ones capable of changing the healthcare system in such a way that not only costs are reduced but also innovation is stimulated and the quality of care improved. Most reform proposals are imposed from the outside and are solely designed in an attempt to reduce the increasing healthcare costs by for example restricting services and forcing health care providers to accept lower pay. Physicians are responsible for patient flow (outpatient care, hospitalization, discharge and transfers) but also for clinical decisions such as diagnosis, additional tests and treatment selection. They are therefore not only accountable for the costs made but also for the quality of care delivered. To improve those two aspects physicians should take up their role as health care managers and take the lead in reform, thereby changing their historically sole focus on patient care towards the whole spectrum of healthcare delivery $(6,19,20)$. In the Netherlands, where the healthcare system has moved from a framework of price regulation to one of regulated market forces, physicians themselves now have to take part in negotiations with insurers and hospital management more than they used to do in the past (7). In this context the manager's role seems to be of even greater importance in the Netherlands.

\section{GENERAL PROBLEM DEFINITION}

A tentative literature search for information about the amount of attention given to the manager's role in Dutch medical education yielded little information. This was surprising, particularly because we assumed that the manager's role was an important competency 


\section{Chapter 1}

for modern doctors. In the light of those findings the aim of this dissertation was twofold:

- To find out what is known about the manager's role in the international literature and to investigate if these findings also apply to the Dutch situation.

- To design and develop a medical management training intervention based on the findings resulting from the research that will be necessary to complete aim 1.

\section{THESIS OUTLINE}

In order to fulfill the aims of our research, a total of six studies were conducted and will be described briefly here to provide an outline of the dissertation. In Chapter $\mathbf{2}$ we performed a literature review to identify what is known on the current status of management education in the postgraduate medical curriculum, the need (if any) for management training in undergraduate and postgraduate medical trainees and to find out if there are training programs available that have been specifically designed to develop management competencies. In Chapter 3 we investigated how Dutch medical residents perceive their own competency as medical managers and in Chapter 4 we performed a needs assessment to discover if Dutch residents have a need for medical managerial education and what this education should look like. Chapter 5 builds on the findings of chapters 3 and 4 and uses the findings of these studies to investigate among medical specialists how they perceive the managerial competencies of their residents and if they feel that residents should be taught in this subject. The topic of interest in Chapter 6 is to find out if the results we found among the Dutch medical residents are comparable to that of their colleagues abroad and if a longer duration of the implementation of the CanMEDS framework and mandatory management education have an influence on these perceptions. We therefore conducted the same questionnaire, translated into English, among Danish, Canadian and Australian residents. In Chapter 7 we combine the knowledge gained from our earlier research in setting up and evaluating a management training intervention for medical residents. In Chapter 8 the main findings of Chapters 2 to 7 are summarized and discussed. Finally, suggestions are presented for future research in this area. 


\section{REFERENCES}

1. Frank JE. The CanMEDS 2005 physician competency framework. Better standards. Better physicians. Better care. Ottawa: The Royal College of Physicians and Surgeons of Canada; 2005 [cited 2013 July 18]. Available from: http://www.royalcollege.ca/ portal/page/portal/rc/common/documents/ canmeds/resources/publications/frame work_full_e.pdf.

2. Brooks JP. Suggestions for management training of residents. Physician executive. 1996 Mar;22(3):26-8. PubMed PMID: 10155972.

3. Daugird AJ, Spencer DC. The perceived need for physician management training. The Journal of family practice. 1990 Mar;30(3):348, 51-2. PubMed PMID: 2307950.

4. Davies C. Changing practice in health care. Postgraduate medical journal. 2001 Mar;77(905):145-7. PubMed PMID: 11222820. Pubmed Central PMCID: 1741946 .

5. Halpern R, Lee MY, Boulter PR, Phillips RR. A synthesis of nine major reports on physicians' competencies for the emerging practice environment. Academic medicine : journal of the Association of American Medical Colleges. 2001 Jun;76(6):606-15. PubMed PMID: 11401803.

6. Swanwick T, McKimm J. What is clinical leadership...and why is it important? The clinical teacher. 2011 Mar;8(1):22-6. PubMed PMID: 21324068.

7. (KNMG) TRDMA. Medical professionalism: KNMG manifesto Utrecht: The Royal Dutch Medical Association (KNMG); 2007 [cited 2013 July 18]. Available from: http://knmg. artsennet.nl/Publicaties/KNMGpublicatie/ Medical-professionalism-KNMGmanifesto-2007.htm.
8. Frank JR, Danoff D. The CanMEDS initiative: implementing an outcomes-based framework of physician competencies. Medical teacher. 2007 Sep;29(7):642-7. PubMed PMID: 18236250.

9. Severs M, Crane S. Challenges in medical education - what the doctor ordered? Postgraduate medical journal. 2000 Oct;76(900):599-600. PubMed PMID: 11009572. Pubmed Central PMCID: 1741758.

10. Lurie SJ, Mooney CJ, Lyness JM. Measurement of the general competencies of the accreditation council for graduate medical education: a systematic review. Academic medicine : journal of the Association of American Medical Colleges. 2009 Mar;84(3):301-9. PubMed PMID: 19240434.

11. The Accreditation Council for Graduate Medical Education. History of medical education accreditation: The Accreditation Council for Graduate Medical Education; 2007 [cited 2013 July 18]. Available from: http://www.acgme.org/acgmeweb/About/ ACGMEHistory.aspx.

12. Leach DC. Building and assessing competence: the potential for evidencebased graduate medical education. Quality management in health care. 2002 Fall;11(1):39-44. PubMed PMID: 12455341.

13. Royal College of Physicians and Surgeons of Canada. The CanMEDS Framework: Royal College of Physicians and Surgeons of Canada

14. 2005 [cited 2013 July 18]. Available from: http://www.royalcollege.ca/portal/page/ portal/rc/canmeds/framework.

15. Ministry of Health. The future specialist. Report from the Specialist Commission. Copenhagen: Ministry of Health, 2000. 


\section{Chapter 1}

16. Confederation of Postgraduate Medical Education Councils. Background to the Australian Curriculum Framework for Junior Doctors 2012 [cited 2013 July 18]. Available from: http://curriculum.cpmec.org.au/ background.cfm.

17. Reenen van R S-vDV. Modernisering medische vervolgopleidingen: nieuw kaderbesluit CCMS (Dutch) 2009 [cited 2013 July 18]. Available from: http:// knmg.artsennet.nl/artikel/Moderniseringmedische-vervolgopleidingennieuwkaderbesluit-CCMS.htm.

18. (KNMG) TRDMA. Op weg naar competentiegericht opleiden (Dutch) [cited 2013 July 18]. Available from: http://knmg. artsennet.nl/Opleiding-en-Registratie/ Project-MMV-Home/Rubrieken/Waaromcompetentiegericht.htm.

19. Scheele F, Teunissen P, Van LuijkS, Heineman $E$, Fluit $L$, Mulder $H$, et al. Introducing competency-based postgraduate medical education in the Netherlands. Medical teacher. 2008;30(3):248-53. PubMed PMID: WOS:000255991300004. English.

20. Bohmer RMJ. The Four Habits of High-Value Health Care Organizations. New Engl J Med. 2011 Dec 1;365(22):2045-7. PubMed PMID: WOS:000297499000002. English.

21. Porter ME, Teisberg EO. How physicians can change the future of health care. Jama-J Am Med Assoc. 2007 Mar 14;297(10):1103-11. PubMed PMID: WOS:000244865200024. English. 




\section{Chapter 2}

\section{ABSTRACT \\ Background}

As increasing demands on health care services are posing new challenges to practicing physicians worldwide, physicians have to extend existing and develop new competencies in various domains of their profession. Management and leadership is one of these domains, and relevant competencies have been incorporated in many new competencybased (postgraduate) training programs. Among trainee physicians and clinical educators, however, good understanding remains scant in relation to the definition and content of the physician's competency as manager.

\section{Summary}

One objective of this article is to identify the specific knowledge, skills, and attitudes required for the development of managerial competencies in physicians. The article also establishes both the extent to which competency-based curricula are successful in equipping medical trainees with managerial competencies and the availability of programs specifically designed to develop these competencies. We reviewed publications retrieved through a PubMed search using relevant keywords, combined with the "related articles" function and a manual search of the references of the retrieved articles. Forty relevant articles were selected. They addressed residents' needs for management education and described the design, implementation, and evaluation of management education curricula. Most of the studies were conducted in North America and within the family medicine specialty. The most commonly taught topics were financial and management concepts and quality assurance. In all studies, training resulted in improved knowledge about management issues. All curricula were evaluated positively despite the use of different educational methods.

\section{Conclusions}

Management education in health care appears to be generally considered essential and necessary. There is, however, no clear consensus as to when in the medical education continuum, how, and for how long management education should be provided. 


\section{BACKGROUND}

In the last 10 years, the increasing demands on health care delivery in many countries have significantly influenced the structure of health care systems and the strategies for health care reform. These demands arose, in part, from increased expectations for higher standards of service by health care consumers, the demand for cost effective and efficient health care delivery systems by health care funders, and government and policymakers' demands for increased accountability and transparency in the way care services are being provided throughout the continuum of care (1). In response to these developments, several medical institutions and professional bodies have engaged in continuing efforts to improve and maintain excellence in the delivery of health care by tailoring their services (at the point of care) to patients' needs and by devoting extra attention to scientific research and innovation (2). Consequences for medical training programs have occurred as well. An important educational innovation has been the CanMEDS framework for postgraduate training developed by the Royal College of Physicians and Surgeons of Canada (3), which comprises physician competencies described as seven physician roles: medical expert, communicator, collaborator, manager, health advocate, professional, and scholar. Two characteristic features of this framework are the shift in emphasis from content-based to competency-based training and the revised objective of the training program, that is, to ensure that (graduating) physicians are equipped with the necessary competencies to function effectively in the changing context of health care delivery $(4,5)$. Since the introduction of the CanMEDS framework, other countries in Europe, North America, and Australia have embarked upon similar initiatives to revise their national postgraduate medical programs (3,6-9).

Although the initial catalyst for reform in medical education was born out of consumers' need for specific "critical" skills (i.e., clinical) in physicians, the increasing pressures from patients, payers, and regulators on the health care delivery system have also shaped the educational reform process. This is reflected in the gradual expansion of desired physician competencies to also encompass practice (or care) management and other life/ society domains, such as health care systems, health care organization, population health, patient-physician communication, ethics, and quality assurance and improvement (10). In a synthesis, Halpern et al. identified and classified as "care management" 10 medical domains considered to be important for the practicing physician (11). The term "care management" has subsequently provided an operational description for how physicians' managerial skills could be translated into clinical responsibilities. 


\section{Chapter 2}

\section{OBJECTIVES}

According to the definition of competency as manager that is currently used in many postgraduate medical curricula, "physicians are integral participants in healthcare organizations, organizing sustainable practices, making decisions about allocating resources, and contributing to the effectiveness of the healthcare system" (3,6-9). The CanMEDS framework states,

Physicians should be able to interact with their work environment as individuals, as members of teams or groups, and as participants in the health system locally, regionally or nationally. ... Physicians function as Managers in their everyday practice activities involving co-workers, resources and organizational tasks, such as care processes, and policies as well as balancing their personal lives. ... They require the ability to prioritize, effectively execute tasks collaboratively with colleagues, and make systematic choices when allocating scarce healthcare resources. The Manager Role describes the active engagement of all physicians as integral participants in decision-making in the operation of the healthcare system. (Competency as manager, core CanMEDS 2005 framework)

Information is sparse on the current understanding of the competency as manager among trainee physicians and clinical educators. A major question is whether in postgraduate curricula the competency as manager is currently defined comprehensively enough to inform the development of training programs that equip trainees with the management skills and knowledge they need to meet the ongoing changes and challenges in the delivery of health care. It is also unclear what implications would arise for postgraduate medical programs if specific training programs were designed for the manager role, and we know little about the effects of the incorporation in medical curricula of dedicated modules on management training.

We reviewed the literature to examine whether and how the competency as manager has been defined and incorporated into (postgraduate) medical curricula and to identify effects of training in this competency on the performance of graduated physicians and the implications this may have for medical institutions. We also sought information about which specific knowledge, skills, and attitudes are required to develop managerial competencies in trainee physicians and about existing programs specifically designed to train these competencies. 


\section{METHODS}

Search Strategy

We searched PubMed using string combinations of the following keywords: Care management, Students, Residency, Curriculum, Education, and CanMEDS, as well as the Mesh search string "Practice Management"[Mesh] AND "Education, Medical, Undergraduate"[Mesh] OR "Education, Medical, Graduate"[Mesh]) OR "Education, Medical, Continuing"[Mesh]. Our search was limited to articles published in English and included papers published from 1970 onward, because we aimed to obtain a thorough understanding of the subject and did not know how much information was available. We used the PubMed function "related articles" for every useful article that was found to determine whether we had missed any relevant articles. For the same purpose we examined the references of all the articles retrieved by the initial search. To qualify for inclusion in the review, articles had to focus on management training for medical students, residents, or fellows.

\section{RESULTS}

Based on the relevance of the title and analysis of the abstract we made an initial selection of 58 articles. After careful reading and content assessment by two of the authors, 18 articles were excluded because they did not focus on practice management.

\section{Practice Management}

We clustered the 40 articles into four main categories, although most articles showed some degree of overlap of content. The four categories contained articles describing a needs assessment (Category 1), addressing the design and implementation of a management curriculum (Category 2), evaluating participants' knowledge before and after a management training program (Category 3), and evaluating a management curriculum (Category 4; Table 1).

\section{Countries and Clinical Specialties}

We identified the countries and the specialties where the articles originated. The majority was from North America (33 from the United States and 4 from Canada), and Australia, England, and India contributed 1 study each. Eight articles were from family medicine, one of the first specialties to introduce practice-management training during the residency period $(12,13)$. Eight articles originated in university settings. They dealt with the implementation of a management curriculum during medical school (14-16), the 


\section{Chapter 2}

Table 1. Summary of the categories on management education

\begin{tabular}{|c|c|}
\hline Category & Summary of findings \\
\hline \multirow[t]{8}{*}{$\begin{array}{l}\text { 1. Articles describing } \\
\text { needs assessment }\end{array}$} & $\begin{array}{l}\text { - Management education during medical school or residency period is } \\
\text { essential }(18,19,23-29) \text {. }\end{array}$ \\
\hline & $\begin{array}{l}\text { - Gaps were identified in the managerial skills, -knowledge and -training of } \\
\text { residents }(18,23,24,26,27,29) \text {. There was a desire for specific management } \\
\text { education on practical issues (23). }\end{array}$ \\
\hline & $\begin{array}{l}\text { - Most studies did not report any prior or specific deficiency in the } \\
\text { knowledge and/or management skills of the trainees before they were } \\
\text { carried out }(19,20,22,24,25,28) \text {. }\end{array}$ \\
\hline & $\begin{array}{l}\text { - Residents had the need to be able to function in a variety of work } \\
\text { environments, be adaptable to continual changes, recognize the nature } \\
\text { of conflicts and develop the necessary skills to deal with these situations } \\
\text { (23). Also to be able to negotiate physician compensation, plan clinical } \\
\text { programs, look after oneself and career, initiate innovation and lead } \\
\text { change (26). }\end{array}$ \\
\hline & $\begin{array}{l}\text { - Senior medical students, residents and fellows needed skills to be able to } \\
\text { perform insurance coding and claims, contract negotiation with preferred } \\
\text { health maintenance or provider organizations, practice accounting and } \\
\text { taxing (18). }\end{array}$ \\
\hline & $\begin{array}{l}\text { - Program directors felt that residents demonstrated poor organizational } \\
\text { skills (20) and were inadequately trained in management skills (25). }\end{array}$ \\
\hline & $\begin{array}{l}\text { - Preferred educational methods (25-29) included interactive learning } \\
\text { methods, workshops, small group tutoring and mentorships(26,27). }\end{array}$ \\
\hline & $\begin{array}{l}\text { - Residents, physicians and practice plan administrators felt practice } \\
\text { management education should be included in the curriculum of the } \\
\text { residency training (29). }\end{array}$ \\
\hline \multirow[t]{5}{*}{$\begin{array}{l}\text { 2. Design of the } \\
\text { management training } \\
\text { program }\end{array}$} & $\begin{array}{l}\text { - The design of the management training curricula was influenced by the } \\
\text { nature of the national training programs e.g. CanMEDS(26,30), ACGME } \\
(23,31-34) \text {, other programs or individual initiatives(14-16,22,24,35-41). }\end{array}$ \\
\hline & $\begin{array}{l}\text { - Aim of curricula was to develop physician's competencies in business } \\
\text { principles of finance and personnel supervision, office procedures and } \\
\text { routines, organizational and leadership skills, and effective utilization of } \\
\text { time and resources }(22,23,26,30,33,35,38,40,42-44) \text {. }\end{array}$ \\
\hline & $\begin{array}{l}\text { - There was no consensus on the length, duration and timing of } \\
\text { management training for both the under- and postgraduate medical } \\
\text { curriculum. }\end{array}$ \\
\hline & $\begin{array}{l}\text { - Most articles reported implementing a management training curriculum } \\
\text { during residency }(17,21-24,26,31,32,34-47) \text {, during both the residency and } \\
\text { fellowship period }(30,33) \text { or during medical school (14-16). }\end{array}$ \\
\hline & $\begin{array}{l}\text { - Length and duration of the curricula on the management training ranged } \\
\text { from hours till years e.g. from the play length of a board game (22) to } \\
\text { sessions of approximately an hour, once a month for four years (23). }\end{array}$ \\
\hline
\end{tabular}


Table 1. Continued

\begin{tabular}{|c|c|}
\hline Category & Summary of findings \\
\hline & $\begin{array}{l}\text { - Most articles described the implementation of a management curriculum } \\
\text { using interactive methods such as workshops }(14,15,26,30,36,37,43) \text {, } \\
\text { lectures with group discussions }(14-16,23,24,26,30-35,41,44,46,47) \text {, } \\
\text { simulated practice }(35,36,46) \text { or preceptorships where the resident is } \\
\text { assigned to a physician executive and observes management meetings } \\
\text { and has tutorials with managers }(32,35,40,47) \text {. }\end{array}$ \\
\hline & $\begin{array}{l}\text { - Other methods described included a board game (22) and a computer } \\
\text { program (17). }\end{array}$ \\
\hline & $\begin{array}{l}\text { - There was a lot of variation in the professional background of the } \\
\text { management instructors. }\end{array}$ \\
\hline & $\begin{array}{l}\text { - Some institutions relied on their own faculty members to educate their } \\
\text { students or residents }(30,37,41,46) \text {. }\end{array}$ \\
\hline & $\begin{array}{l}\text { - Others (also) contracted outside content experts e.g. former insurance } \\
\text { company director to cover managed care }(24,26,31,33-36,38,39,50) \text {. }\end{array}$ \\
\hline & $\begin{array}{l}\text { - Most commonly taught topics were finance related, management } \\
\text { related, quality assurance, legal issues, personnel, and organizational skills } \\
\text { \& time management. }\end{array}$ \\
\hline \multirow{3}{*}{$\begin{array}{l}\text { 3. Knowledge } \\
\text { assessment before } \\
\text { and after training }\end{array}$} & $\begin{array}{l}\text { - Ten articles performed knowledge assessments to evaluate the effect of } \\
\text { the educational intervention in the participants. }\end{array}$ \\
\hline & $\begin{array}{l}\text { - The methods of assessing the training programs and acquired } \\
\text { knowledge of the participants varied a lot in the articles. }\end{array}$ \\
\hline & $\begin{array}{l}\text { - Despite the differences, all articles reported improvement in knowledge } \\
\text { on health care management issues among the participants. }\end{array}$ \\
\hline \multirow{4}{*}{$\begin{array}{l}\text { 4. Evaluation of } \\
\text { the management } \\
\text { curriculum }\end{array}$} & $\begin{array}{l}\text { - Twenty-two articles described a management curriculum that was } \\
\text { subjectively evaluated by its participants or by their program directors. }\end{array}$ \\
\hline & $\begin{array}{l}\text { - All curricula were evaluated positively despite the differences in level and } \\
\text { functions of participants and the instructional methods applied. }\end{array}$ \\
\hline & $\begin{array}{l}\text { - In two of the studies, the participants felt that the management course } \\
\text { should be implemented in the core curriculum. }\end{array}$ \\
\hline & $\begin{array}{l}\text { - Three other articles that also described an increase in the participants' } \\
\text { interest in management topics on completion of the curriculum }(22,30,36) \text {. }\end{array}$ \\
\hline
\end{tabular}


Chapter 2

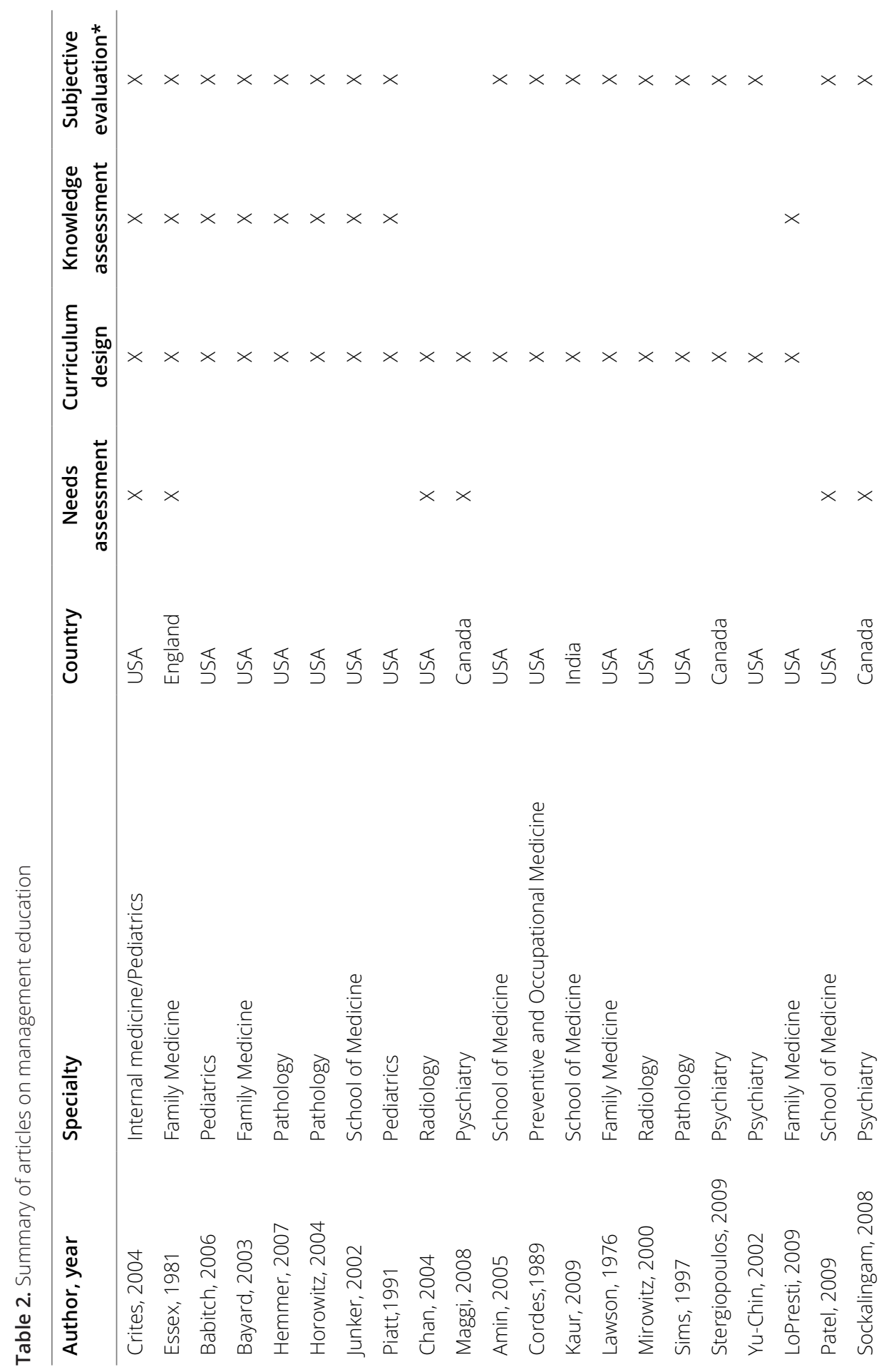




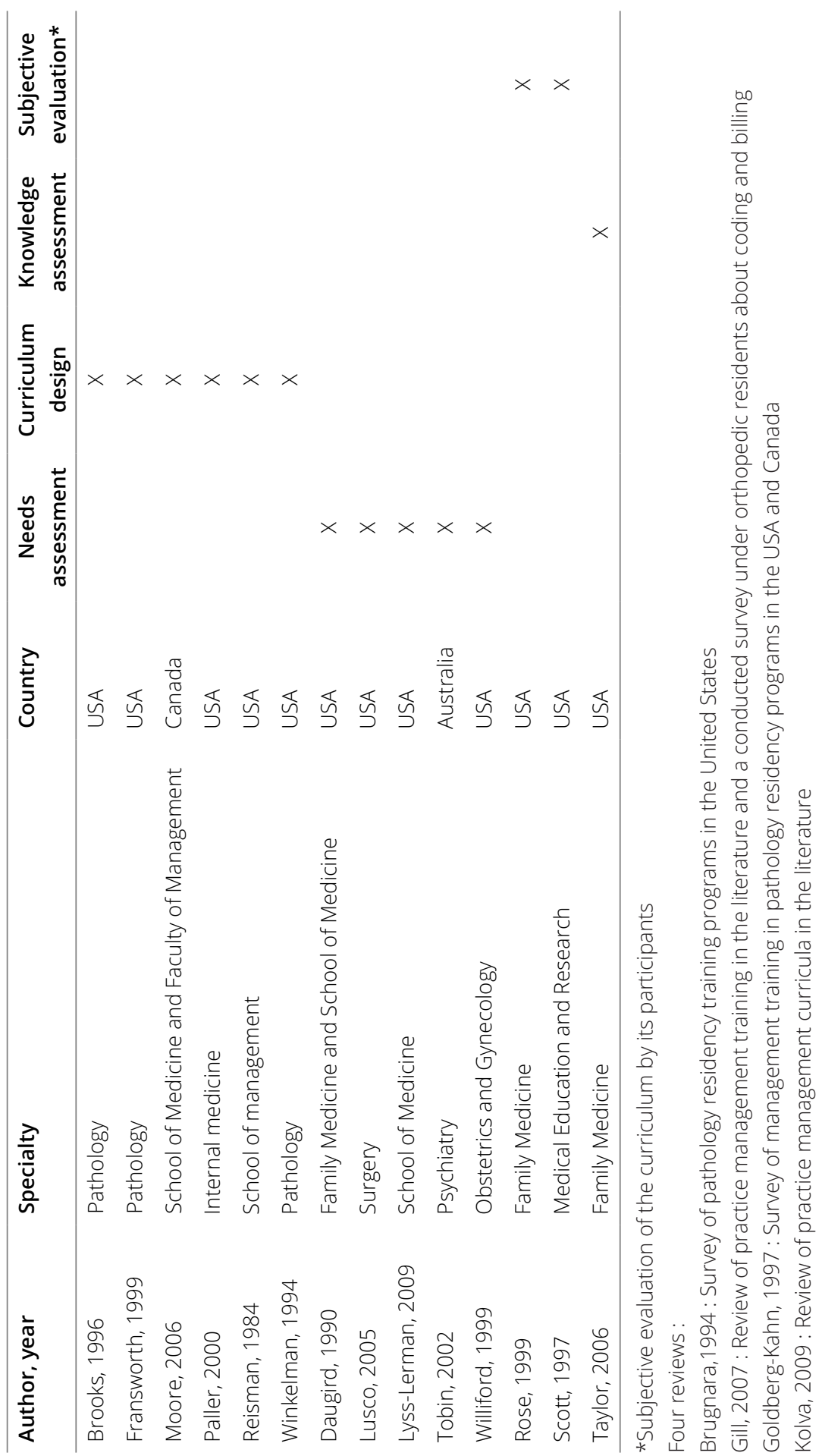




\section{Chapter 2}

development of a management curriculum for physicians (17), and needs assessment among graduated medical students $(18,19)$ and program directors of 10 specialties $(20)$. One article described the implementation of a management curriculum for medical students, residents, and health leaders (21). There were also reports of research of practice management in other specialties including pathology $(n=8)$, psychiatry $(n=5)$, pediatrics $(n=3)$, radiology $(n=2)$, and internal medicine ( $n=2$; Table 2$)$.

\section{Articles describing needs assessments}

Of the reviewed articles, 11 concerned needs assessments, although the focus was not always specifically on practice management (Table 3$)(20,22)$. If this was the case however, it was invariantly concluded that management education was essential during both medical school and the residency period (18,19,23-29). Needs assessments involved different groups: residents and fellows (7 articles), program directors ( 2 articles), and medical students (1 article).

Four articles assessed perceived deficiencies in residents' management roles in addition to their needs $(18,24,26,27)$. All articles on residents' needs in relation to the manager role reported gaps in residents' managerial skills, knowledge, or training $(18,23,24,26,27,29)$ and a desire for management education focused on specific practical issues (23).

Most needs assessment studies did not report any prior or specific deficiency in trainees' management knowledge and/or skills $(19,20,22,24,25,28)$ although some revealed a need among residents to be able to function in a variety of work environments, be adaptable to continual change, and be capable of recognizing the nature of conflicts and develop the necessary skills to deal with them (23). Daugerd et al. reported that senior medical students, residents, and fellows needed skills to deal with insurance coding and claims, contract negotiations with preferred health maintenance organizations or provider organizations, and practice accounting and taxes (18). Sockalingem identified a need among psychiatry residents to be able to negotiate physician compensation, plan programs, look after self and career, develop innovation, and lead change (26). Two articles reported program directors' perceptions that residents demonstrated poor organizational skills (20) and inadequate management skills (25).

Five articles, which in addition to training needs, evaluated preferences for educational methods (25-29), found that interactive learning methods, workshops, small-group tutoring, and mentoring were the educational strategies of choice $(26,27)$. Scheduling of management training in the curriculum was addressed in two articles. A study among 58,294 graduated medical students showed that students were not satisfied with the 


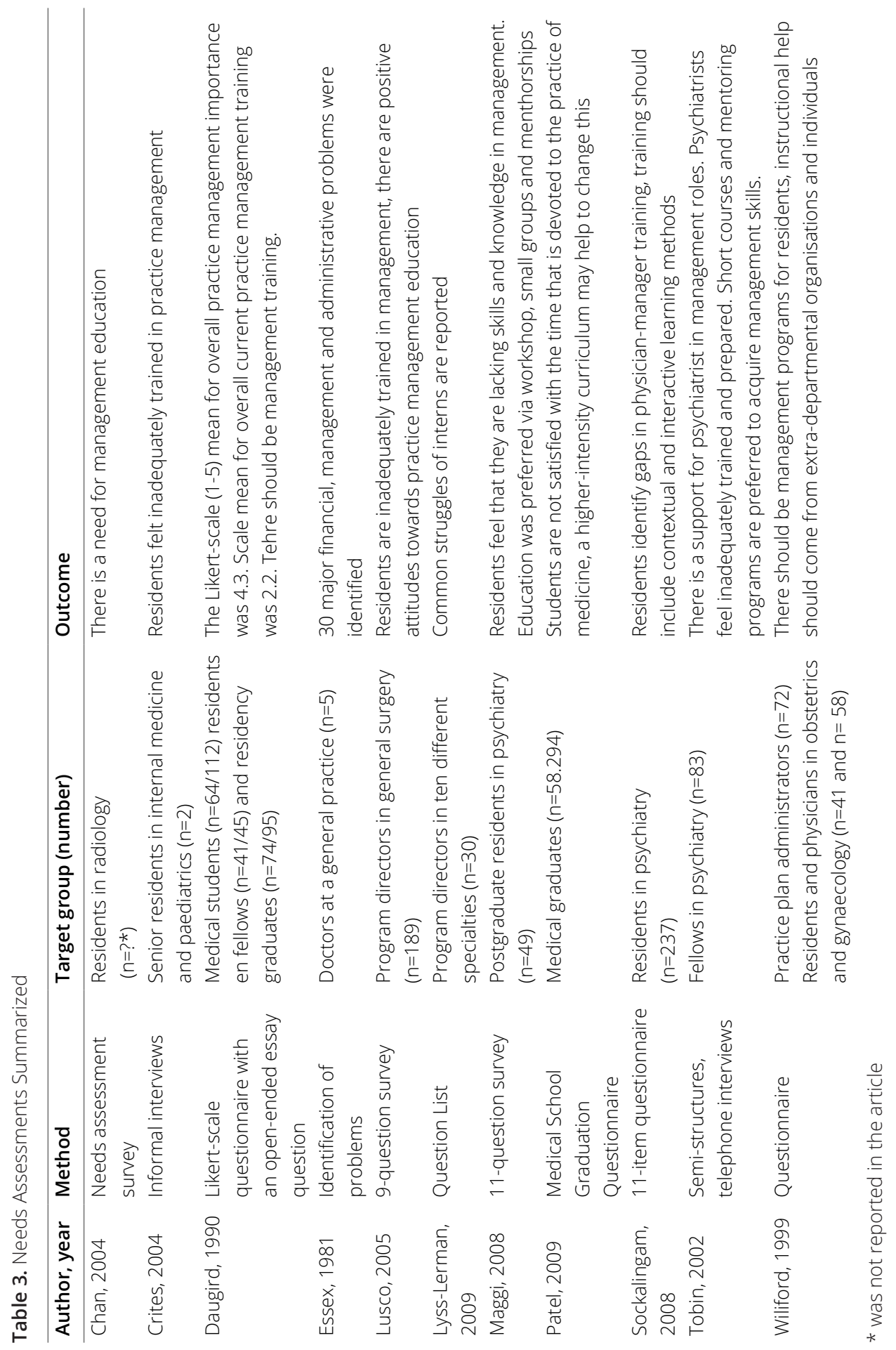




\section{Chapter 2}

amount of time devoted to medical economics during medical school (19), and a study among residents, physicians, and practice plan administrators revealed the unanimous view that practice management education should be included in residency curricula (29).

\section{Design of management training programs}

In many of the articles we reviewed, the design of management training curricula was influenced by existing national training programs, such as the CanMEDS competencies $(26,30)$, and the competencies developed by the Accreditation Council for Graduate Medical Education (ACGME) in the United States (23,31-34), whereas other articles referred to a variety of other programs and individual initiatives (14-16,22,24,35,41). Most articles were rather vague about training objectives, which were generally formulated as offering participants better preparation for the entrepreneurial aspects of medicine. In so far as curriculum goals were clearly defined, they referred to the development of physician competencies in relation to business principles of finance and personnel supervision, office procedures and routines, organizational and leadership skills, and effective utilization of time and resources. These goals were to be achieved through educational objectives defining knowledge, skills, and attitudes to be mastered by residents by the end of the practice management curriculum $(22,23,26,30,33,35,38,40,42-44)$.

\section{Length, Duration, and Timing of training programs}

The reviewed articles showed no consensus regarding the timing in the overall curriculum, the length of individual training sessions, or the total duration of management training programs. Most articles reported on management training during residency (17,2124,26,31,32,34-47), but others reported programs during both the residency and fellowship periods $(30,33)$ as well as during medical school (14-16). One article described several projects aimed at providing knowledge on management and leadership competencies to the medical community, ranging from a short management program for medical students and residents to a master course for hospital chief executive officers, heads of departments, and other senior medical professionals (21).

The length of the curricula varied from hours to years, in other words, from the play length of a board game (22) to a 4-year program with monthly sessions lasting approximately 1 hour (23). In Brugnara's study in the United States, 61 of 138 respondents stated that they were offered a formal training curriculum in management during pathology residency training, with an average annual number of 26.8 ( \pm 4.9 SE) teaching hours dedicated to management. In response to a question about the appropriateness of the amount of time for management training, 64\% of 113 respondents wanted more time, whereas $31.8 \%$ thought the amount of time was appropriate. The group desiring more training received 
management training during an annual average of $21.4 \pm 34.1 \mathrm{hr}(n=40)$, but annual training time was $37.8 \pm 50.3(n=22) \mathrm{hr}$ in the group that considered training time to be appropriate (48).

\section{Educational Methods}

Most of the reviewed articles described the implementation of a management curriculum using interactive methods, ranging from workshops $(14,15,26,30,36,37,43)$, lectures with group discussions $(14-16,23,24,26,30-35,41,44,46,47)$ and simulated practice $(35,36,46)$ to preceptorships with residents being assigned to a physician executive, observing management meetings and taking part in discussions and tutorials with managers $(32,35,40,47)$. In a study reviewing 176 pathology residency programs, the most commonly used instructional methods were apprenticeships/mentorship and lectures, followed by reading assignments, consultation of non-pathologist consultants, independent study, and tutoring (49). Other training methods were a board game (22) and a computer program (17).

\section{Management Lecturers and Instructors}

We found marked variation in the professional backgrounds of management instructors. Some curricula relied on their own faculty members $(30,37,41,46)$, whereas others (also) contracted outside content experts, assuming that these would offer more interesting and complete coverage of topics $(24,26,31,33-36.38,39,50)$. In one case, for example, a former insurance company director was contracted to cover managed care and a financial planner taught personal finance and investment.

\section{Topics of the Educational Programs}

We summarized the topics covered by the different educational programs (curricula, computer programs, etc.) by counting the number of times a certain topic was referred to in the articles we reviewed (Table 4). The most commonly taught topics were finance related (13 programs), management related (13 programs), quality assurance (13 programs), legal issues (12 programs), personnel issues (12 programs), and organizational skills and time management (12 programs). Customer satisfaction and patient safety received the least attention.

\section{Knowledge assessment before and after training}

Ten articles evaluated the effects of an educational intervention (Table 5), that is, nine training programs/curricula $(15,24,31,33,34,36,40,46,51)$ and one board game (22). The studies used different methods to assess participants' knowledge on completion of training. 


\section{Chapter 2}

Table 4. Number of times topics were covered

\begin{tabular}{lc}
\hline Topics & Number \\
\hline Financial concepts & 13 \\
Management concepts & 13 \\
Quality (quality versus costs, quality improvement, etc) & 13 \\
Legal issues (risk management, malpractice, government issues, etc) & 12 \\
Personnel & 12 \\
Organizational skills, time management (planning etc) & 12 \\
Leadership & 11 \\
Technology, informatics & 10 \\
Health care insurances & 9 \\
Communication skills & 9 \\
Medical reimbursement (coding and billing, etc) & 8 \\
Career options (CV's, interviews, self-care etc.) & 8 \\
Setting up a (group)practice & 8 \\
Health care delivery systems & 5 \\
Health reform, health change & 5 \\
Teamwork & 5 \\
Personal finances, loan and malpractice insurance & 4 \\
Managed care & 3 \\
Marketing & 4 \\
Knowledge and/or skills management; research (evidenced based medicine, etc.) & 3 \\
Contract negotiations & 3 \\
Health care rationing, health care economics & 4 \\
Customess ethics & 3 \\
Patient safety & 3 \\
& 3 \\
& 4 \\
\hline
\end{tabular}

Five articles used subjective pre- and post-self-assessment tests (15,34,36,40,51), 4 articles used an objective test with questions assessing knowledge before and after the curriculum $(22,31,33,46)$, and 1 article did both (24). The number of questions in the knowledge tests ranged from one question before and after each lecture (34) to 65 questions pre- and posttest (22). Some objective examinations contained multiple-choice questions, others used yes/no questions. All self-assessments asked residents to indicate their perceived knowledge or comfort with various topics on a 5-point Likert scale. Despite wide variation in training methods and knowledge assessments, all articles reported improvement in participants' knowledge of health care management issues after the training program. 


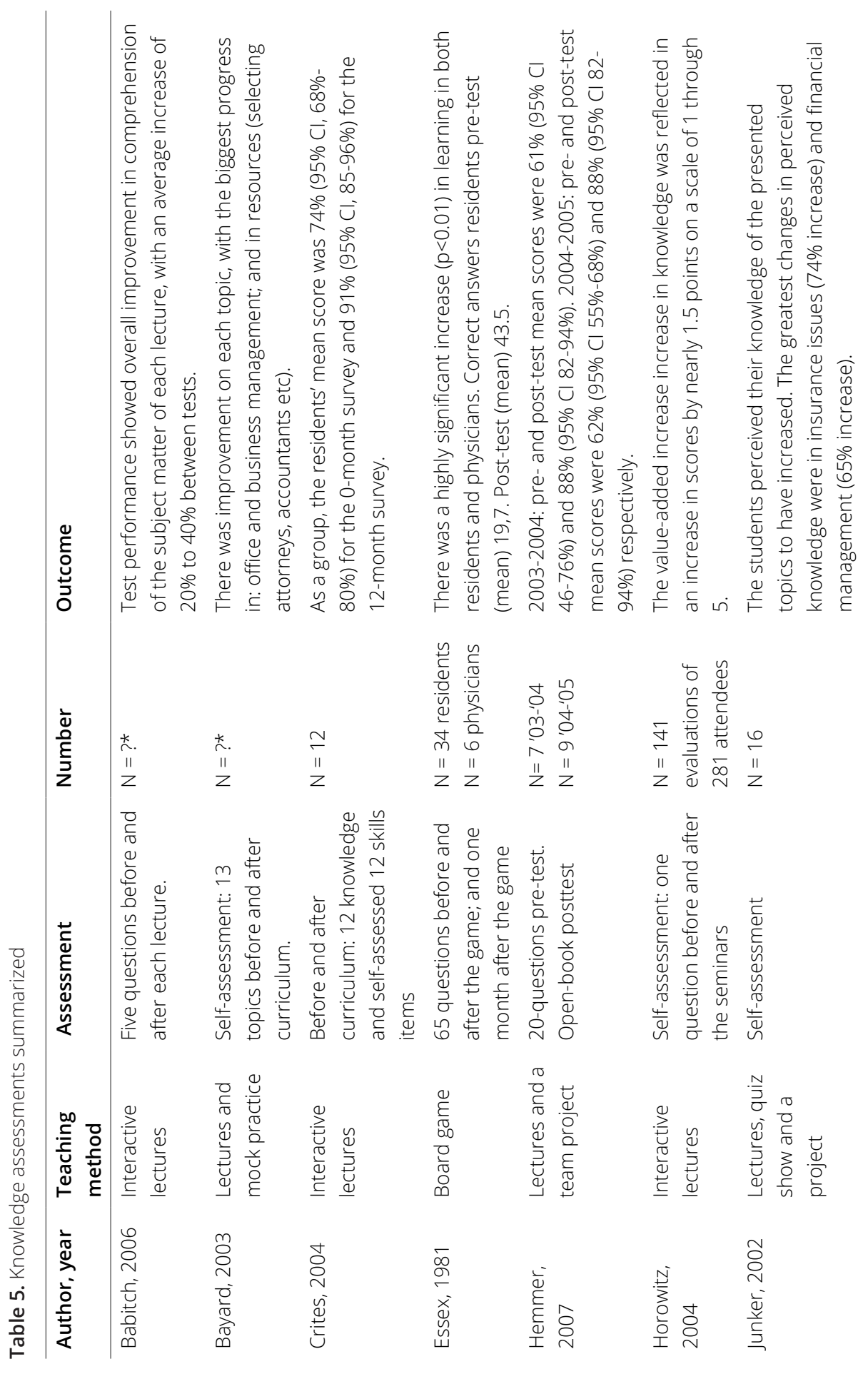




\section{Chapter 2}

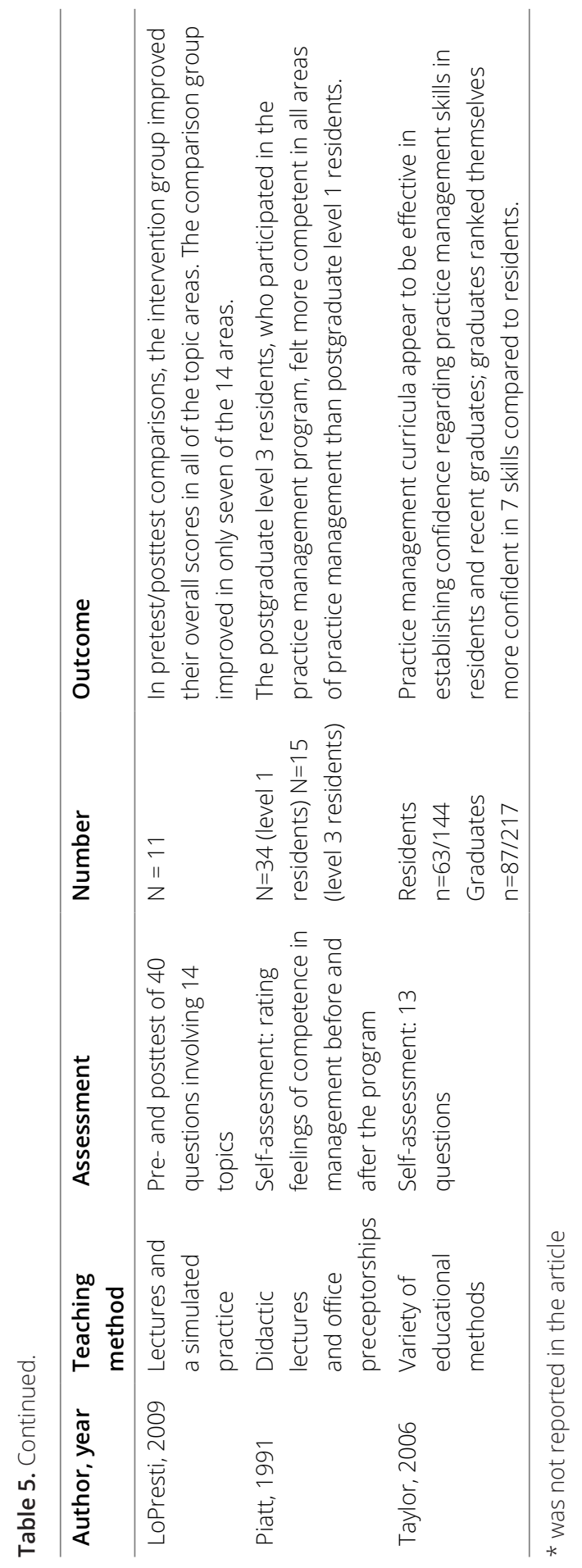




\section{Evaluation of management curricula}

Twenty-two articles described management curricula that were subjectively evaluated by the participants or the program directors. Participants differed in degree and function. Fifteen articles examined evaluation outcomes of residents and fellows, 2 looked at evaluation outcomes of medical students $(16,19)$, and 2 at evaluation outcomes of medical directors and CEOs $(12,50)$. Fifteen evaluation studies used Likert scale items, some with additional open-ended questions to elicit more detailed comments on curriculum content as well as suggestions for improvement $(16,36,43)$. Four articles did not report how subjective feedback was obtained $(14,35,39,40)$. All curricula received positive evaluations despite differences in participants and educational methods.

In two evaluations, participants were specifically asked if they thought the management course should be incorporated into the core curriculum and both studies reported general assent to this proposal $(24,30)$. The study by Crites involved 12 residents rating statements on a 5-point Likert scale. The statement "I would be interested in expanding my primary care curriculum to include more practice management education" received a high mean rating of 4.67. In the study reported by Mirowitz, 36 residents and fellows participating in a management-training program indicated that a core curriculum in health policy and practice should be repeated in the future, with the majority ( $n=23,74 \%)$ reporting a strong agreement with this statement. Three other articles described similar increases in participants' interest in management topics on completion of a management curriculum $(22,30,36)$.

\section{DISCUSSION}

The aim of this review was to examine in how far the competency as "manager" has been defined and incorporated in the (revised) curricula of (postgraduate) medical training programs. First, we were interested in establishing whether the competency as manager, which is currently included in many postgraduate medical curricula, is defined in a manner that is sufficient and comprehensive enough to create programs that provide trainees' adequate preparation for their role as "physician manager." Second, we were interested in identifying the effects, if any, of managerial skills training on graduate physicians' performance and the implication this may have (had) for medical training programs. Our goal was also to highlight the specific knowledge, skills, and attitudes that are required to develop managerial competencies as well as identify existing programs specifically designed to develop these competencies in trainee physicians. 


\section{Chapter 2}

The most striking finding in our review was that practically all the articles on care (or practice) management were from the United States and Canada. Apparently, management and management education are considered important aspects of health care delivery and education in North America and less so outside this continent. However, we have no positive evidence of a lack of awareness of the importance of management aspects in European institutions. All we have is a paucity of published studies. What is clear, however, is that further studies are needed, especially in Europe (and probably in Africa and Asia), to clearly define the needs of trainee physicians and appropriate methods for health care management training throughout the continuum of health professional education.

Another interesting observation from this review is that a majority of the studies was conducted in family medicine, suggesting that, in this specialty in particular, management is considered a crucial aspect of training (22). This is understandable when one realizes that many primary care physicians have to set up and run their own (private) clinics and thus need to be equipped with good managerial skills and knowledge. Unfortunately, it was difficult to identify a clear definition of the competency as manager used in these programs, let alone compare it with the definitions underlying many new competencybased postgraduate training programs (3,6-9). What we also observed was that management education seems to be of particular interest within psychiatry, radiology, and pathology, as these specialties yielded the highest number of studies besides family medicine. An explanation could be that residents in these specialties engage in more technical and management-related activities during their training and thus have more opportunities to develop their managerial skills. As Horowitz et al. argued, pathologists tend to have more hands-on experience with managing a team and are probably more focused on improving their skills in this area (34). However, it could also be that, by necessity, these disciplines require their residents to interact more with the health care system, thus making this material more meaningful and/or relevant to them.

We know that health care delivery and educational systems in the United States and Canada differ from those in most European countries. This is exemplified by differences in health insurance schemes. Although many countries in Europe have a single payer national health insurance scheme (52,53), health care in the United States is financed by different sources, including commercial health care insurance, Medicaid, Medicare, and individual out-of-pocket payments. We believe that the strong interest in management training in the United States may be closely linked to the existence of different payment schemes as well as the intricacies of the system of managed care that was introduced in the 1980s (54). "Managed care," in the U.S. context, encompasses a variety of different 
financial and organizational arrangements around the delivery of care services. It links the responsibility for care delivery to a defined population (e.g., enrollees of a managed care plan) with the process of covering the costs, for example, insurance or financing mechanism or the assumption of financial risk. At its onset, managed care focused on managing the cost of health care delivery through a utilization-control mechanism. However, the increasing development of vertically integrated systems in the U.S. health care environment emphasized the need for an efficient managed care structure that not only controlled costs but efficiently linked outpatient, inpatient, home, and longterm care in a single coordinated system. Lurie argued that these developments have had implications for medical education in the United States because managed care physicians must know about non-office-based approaches in caring for their patients (55). Eight domains of knowledge were, as a result, found to be necessary for physicians to practice competently in managed care environments: epidemiological thinking, human behavior, organizational behavior, information systems, quality measurement and improvements, health systems financing and delivery, ethics, and systems-based care (55).

With respect to the educational methods used to teach health care management, many of the reviewed articles reported the implementation of a management curriculum, mostly during the residency period, and combining didactic and interactive teaching methods. This combined approach seemed to be preferred generally, despite considerable variety in the timing, length of sessions, and duration of training programs. Regardless of which training methods were used, all of the evaluated management training programs reported positive experiences of participants with respect to the curriculum and increased knowledge about management principles. It remains unclear, however, whether it was the instructors or the trainees that gave rise to the reported preference for didactic teaching. It also remains uncertain whether "didactic teaching" is the most effective teaching strategy compared with other methods like the board game and computer-assisted training.

One should be cautious in interpreting these findings however, considering that the number of participants in the studies was low, the curriculum and knowledge assessments subjective, and the statistical information meager. Furthermore, it is difficult to assess the comparative effectiveness of the various instructional methods, as there is no uniformity in the design, structure, and evaluation of the various studies. It is also difficult to pinpoint the best moment(s) during the medical curriculum to schedule formal management training programs and to define the frequency and length of such sessions. Bearing these limitations in mind and based on the analysis of the reviewed articles, there is considerable evidence pointing to the conclusion that medical residents are currently insufficiently prepared for 


\section{Chapter 2}

their managerial tasks and would probably benefit from the inclusion in the curriculum of dedicated training in management skills. In developing such an intervention, we would recommend the use of the most preferred methods of instruction, that is, formal didactic teaching and interactive teaching (workshop) sessions, as well as inclusion of at least the following topics: health care finance, organization and policy in health care, negotiation skills, group practice, and career planning. The program instructors should be experienced physician managers as well as nonmedical content experts. Training should preferably be scheduled during residency training, and the program should consist of different modules spread over the whole length of the training period. These recommendations are also in line with the preliminary findings of an ongoing survey among Dutch medical residents regarding their perceived needs for training in managerial competencies and their preparation as physician managers by the current programs.

\section{CONCLUSION}

From this review, it is clear that much work remains to be done before undergraduate and postgraduate medical training programs can be said to deliver physicians that are well prepared for the management aspects of medical practice. Although North American institutions devoted more attention to management training, there is even there an overriding sense that extra attention should be paid to the preparation of trainees for their care (practice) management tasks. In contrast to the situation in North America, there appears to be a lack of formal reporting on care or practice management programs in European medical institutions. Family medicine is the specialty with the most experience in training residents in management skills, although it is obvious that these competencies are equally crucial for practitioners in other specialties.

Furthermore, there appears to be insufficient evidence in the literature to demonstrate a clear impact of specific training modalities for management skills on the outcome of care at the end point of service or on the professional competencies of graduates who participated in management programs. Nonetheless, across the board, we found reports of improvement in the knowledge and confidence of those who participated in care management training programs. We believe that management-training programs should be formally incorporated into the curricula of all medical schools. Although the review does not offer evidence to support any specific recommendations for the ideal training program, there seems to be an overall preference for a curriculum during the residency period, which combines didactic and interactive teaching methods. 


\section{REFERENCES}

1. Porter, ME and Teisberg, E O. 2006. Redefining health care: Creating valuebased competition on results, 71-95. Boston: Harvard Business School Press.

2. Bohmer, R MJ. 2009. Designing care: Aligning the nature and management of health care, 98-102. Boston: Harvard Business Press.

3. Canada RCoPaSo. 2009. CanMEDS 2005 Framework., Ottawa, Canada: Royal College of Physicians and Surgeons of Canada.

4. Bohmer, R MJ and Knoop, C I. 2007. The challenge facing the U.S. healthcare delivery system, 606-609. Boston: Harvard Business School.

5. Stephenson, J. 2009. Doctors in management. British Medical Journal, 339: 45-95.

6. Education ACfGM. 2010. Accreditation Council for Graduate Medical Education. Outcome project, Chicago: Accreditation Council for Graduate Medical Education.

7. van Reenen, $\mathrm{R}$ and Schelfhout-van Deventer, V. 2009. Framework for the Dutch Specialist Training Programs. Kaderbesluit Centraal College Medische Specialismen (Dutch)., Utrecth, the Netherlands: Koninklijke Nederlandsche Maatschappij tot bevordering der Geneeskunst.

8. Association, A M. 2005. Prevocational medical education and training, Barton: Australian Medical Association.

9. Council, G M. 2010. About the foundation programme, London: General Medical Council.

10. Frohna, J, Kalet, AKachur, E. 2004. Assessing residents competency in care management: Report of a consensus conference. Teaching and Learning in Medicine, 16: 77-84.

11. Halpern, R, Lee, M, Boutler, P and Phillips, R. 2001. A synthesis of nine major reports on physicians' competencies for the emerging practice environment. Academic Medicine, 76: 606-15.
12. Rose, E A, Neale, A V and Rathur, W A. 1999. Teaching practice management during residency. Family Medicine, 31: 107-13.

13. Kolva, D E, Barzee, K A and Morley, C P. 2009. Practice management residency curricula: A systematic literature review. Family Medicine, 41: 411-9.

14. Amin, A N. 2005. A business of medicine curriculum for medical students. Medical Education, 39: 510-1.

15. Junker, J A, Miller, T and Davis, M S. 2002. Practice management: A third-year clerkship experience. Family Medicine, 34: 87-9.

16. Kaur, $N$ and Singh, T. 2009. Introducing medical students to health care management. Medical Education, 43: 10901.

17. Reisman, A, Mathur, K and Mulcahy, E. 1984. The Case Western Reserve University practice management game: A painless way for physicians to learn managerial skills. Journal of Health Administration Education, 2: 65-74.

18. Daugird, A J and Spencer, D C. 1990. The perceived need for physician management training. Journal of Family Practice, 30(348): 351-2.

19. Patel, M S, Lypson, $M L$ and Davis, M M. 2009. Medical student perceptions of education in health care systems. Academic Medicine, 84: 1301-6.

20. Lyss-Lerman, P, Teherani, A, Aagaard, E, Loeser, H, Cooke, M and Harper, G M. 2009. What training is needed in the fourth year of medical school? Views of residency program directors. Academic Medicine, 84: 823-9.

21. Moore, K, Patel, H, Razack, S, Snell, L and Taylor, L. 2006. Management and leadership development programs for the medical community at McGill University. McGill Journal of Medicine, 9: 74-7. 


\section{Chapter 2}

22. Essex, B and Jackson, R N. 1981. Moneymed: A game to develop management skills in general practice. Journal Royal College of General Practitioners, 31: 735-9.

23. Chan, S. 2004. Management education during radiology residency: Development of an educational practice. Academic Radiology, 11: 1308-17.

24. Crites, G E and Schuster, R J. 2004. A preliminary report of an educational intervention in practice management. BMC Medical Education, 4: 15

25. Lusco, $\vee C$, Martinez, S A and Polk, H C. 2005. Jr. Program directors in surgery agree that residents should be formally trained in business and practice management. American Journal of Surgery, 189: 11-3.

26. Maggi, J D, Stergiopoulos, V and Sockalingam, S. 2008. Implementing a new physician manager curriculum into a psychiatry residency training program: The change process, barriers and facilitators. Psychiatric Quarterly, 79: 21-31.

27. Sockalingam, S, Stergiopoulos, V and Maggi, J. 2008. Residents' perceived physicianmanager educational needs: A national survey of psychiatry residents. Canadian Journal of Psychiatry, 53: 745-52.

28. Tobin, M and Edwards, J L. 2002. Are psychiatrists equipped for management roles in mental health services?. Australian and New Zealand Journal of Psychiatry, 36: 4-8.

29. Williford, L E, Ling, F W, Summitt, R L Jr. and Stovall, T G. 1999. Practice management in obstetrics and gynecology residency curriculum. Obstetrics and Gynecology, 94: 476-9.

30. Mirowitz, S A. 2000. Development and assessment of a radiology core curriculum in health care policy and practice. Academic Radiology, 7: 540-50.
31. Babitch, L A. 2006. Teaching practice management skills to pediatric residents. Clinical Pediatrics (Phila), 45: 846-9.

32. Cordes, D H, Rea, D F, Rea, J and Vuturo, A. 1989. A program of management training for residents. Academic Medicine, 64: 45-6.

33. Hemmer, P R, Karon, B S, Hernandez, J S, Cuthbert, C, Fidler, M E and Tazelaar, H D. 2007. Leadership and management training for residents and fellows: A curriculum for future medical directors. Archives of Pathology and Laboratory Medicine, 131: 610-4.

34. Horowitz, R E, Naritoku, W and Wagar, E A. 2004. Management training for pathology residents: A regional approach. Archives of Pathology and Laboratory Medicine, 128: 59-63.

35. Aluise, J J. 1977. The physician as manager. "What" and "how" of practice management education. Journal of Family Practice, 4: 305-11.

36. Bayard, M, Peeples, C R, Holt, J and David, D J. 2003. An interactive approach to teaching practice management to family practice residents. Family Medicine, 35: 622-4.

37. Brooks, J P. 1996. Suggestions for management training of residents. Physician Executive, 22: 26-8.

38. Farnsworth, J R and Weiss, R L. 1999. A mentor-based laboratory management elective for residents. American Journal of Clinical Pathology, 111: 156-60.

39. Lawson, J G and McConnell, J W. 1976. Teaching practice management in a family practice residency. Journal of Medical Education, 51: 858-60.

40. Piatt, J P, Bartley, D L, Jacobson, A D and Rimsza, M E. 1991. Practice management training for pediatric residents. American Journal of Diseases of Children, 145: 299301. 
41. Winkelman, J W and Brugnara, C. 1994. Management training for pathology residents. II. Experience with a focused curriculum. American Journal of Clinical Pathology, 101: 564-8.

42. Sims, KL and Darcy, T P. 1997. A leadershipmanagement training curriculum for pathology residents. American Journal of Clinical Pathology, 108: 90-5.

43. Stergiopoulos, V, Maggi, J and Sockalingam, S. 2009. Teaching the physician-manager role to psychiatric residents: Development and implementation of a pilot curriculum. Academic Psychiatry, 33: 125-30.

44. Yu-Chin, R. 2002. Teaching administration and management within psychiatric residency training. Academic Psychiatry, 26: 245-52.

45. Gill, J B and Schutt, R C Jr. 2007. Practice management education in orthopaedic surgical residencies. Journal of Bone and Joint Surgery, American Volume, 89: 216-9.

46. LoPresti, L, Ginn, P and Treat, R. 2009. Using a simulated practice to improve practice management learning. Family Medicine, 41: 640-5.

47. Paller, M S, Becker, T, Cantor, B and Freeman, S L. 2000. Introducing residents to a career in management: The physician management pathway. Academic Medicine, 75: 761-4.

48. Brugnara, C, Fenton, T and Winkelman, JW. 1994. Management training for pathology residents. I. Results of a national survey. American Journal of Clinical Pathology, 101: 559-63.

49. Goldberg-Kahn, B, Sims, K L and Darcy, T P. 1997. Survey of management training in United States and Canadian pathology residency programs. American Journal of Clinical Pathology, 108: 96-100.
50. Scott, H M, Tangalos, E G, Blomberg, R A and Bender, C E. 1997. Survey of physician leadership and management education. Mayo Clinic Proceedings, 72: 659-62.

51. Taylor, M L, Mainous, A G III, Blue, A V and Carek, P J. 2006. How well are practice management curricula preparing family medicine residents?. Family Medicine, 38: 275-9.

52. Muiser, J. 2007. The new Dutch health insurance scheme: Challenges and opportunities for better performance in health financing. World Health Organisation Discussion Paper, 3

53. Robinson, R and Dixon, A. 1999. Health care systems in transition: United Kingdom, Copenhagen, Denmark: European Observatory on Health Care Systems.

54. Amara, R and Foundation, R. 2003. Health and health care 2010: The forecast, the challenge (2nd ed.), Jossey-Bass.

55. Lurie, N. 1996. Preparing physicians for practice in managed care environments. Academic Medicine, 71: 1044-9. 



\section{Chapter 3}

How Dutch medical residents perceive their competency as manager in the revised postgraduate medical curriculum.

Berkenbosch L, Brouns JWM, Heyligers I, Busari JO

Postgrad Med J 2011;87:1032 680-687

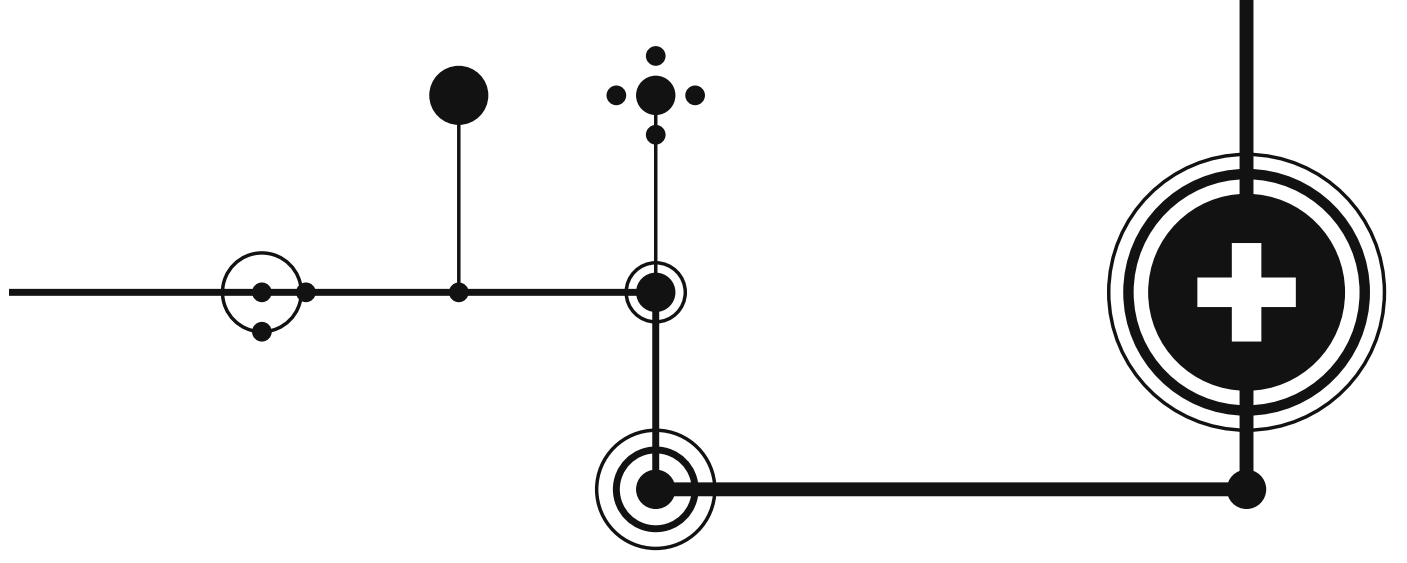




\section{Chapter 3}

\section{ABSTRACT Introduction}

In 2005, competency based training was introduced into the curriculum of the postgraduate training of Dutch medical residents. The role as manager is one of the seven competencies and, compared to the other roles, it is presently thought to receive little attention during training. The goal of this study was to investigate medical residents' understanding of this competency and how they perceive their role as manager.

\section{Methods}

In October 2009, 506 residents from different specialties in four teaching hospitals were invited via email to participate in the study. A 29-item Likert scale questionnaire was designed to investigate residents perceived healthcare management skills and knowledge in four management areas.

\section{Results}

177 of 506 residents (35\%) responded to the survey. More than half of the residents (106/177, 60\%) did not feel confident in their (contract) negotiating skills and 56\% (98/175) stated that they lacked sufficient knowledge of how the Dutch healthcare system is financed and organised. The residents were most confident in their ability to handle feedback (151/177, 85\%), medical information data registration (168/173, 97\%), and how to allocate healthcare resources based on evidence based principles (143/173, 83\%).

\section{Conclusion}

These results demonstrate that residents in the Netherlands perceive their knowledge and skills in certain essential medical management concepts to be inadequate. The results suggest that a course in medical management should be considered as a mandatory part of the curricula of residency training programmes. 


\section{INTRODUCTION}

In the last couple of years, notable changes have been observed in the manner and pace at which the education and practice of medicine has developed in many countries. A couple of factors thought to have contributed to these changes include the increased competition and commercialisation within the healthcare industry, the decline in professional autonomy, the increased dependency and associated costs of healthcare technology, and the shifting trend towards large organisational structures in healthcare delivery. As a result, professional competencies such as leadership, teamwork and other organisational skills are becoming increasingly important for physicians to be able to function effectively in this rapidly changing healthcare environment. The educational reform process in many medical training programmes is one of the various interventions designed to address these changes. The objective of most reforms is to ensure that upon graduation, junior physicians are equipped with the set of competencies that will allow them to function efficiently in a modern healthcare environment. The first of these initiatives was the CanMEDS framework by the Royal College Physicians and Surgeons of Canada (RCPSC) (1). Seven competencies were described in this framework (ie, medical expert, communicator, collaborator, manager, health advocate, professional, and scholar) (figure 1). It was believed that the highest quality of care possible could be guaranteed if physicians were guided by these standards, combined with individual best practices and continuing professional development. Other countries in Europe, North America and Australia have since embarked upon similar initiatives and also revised the curriculum of their national postgraduate medical programmes (2-4).
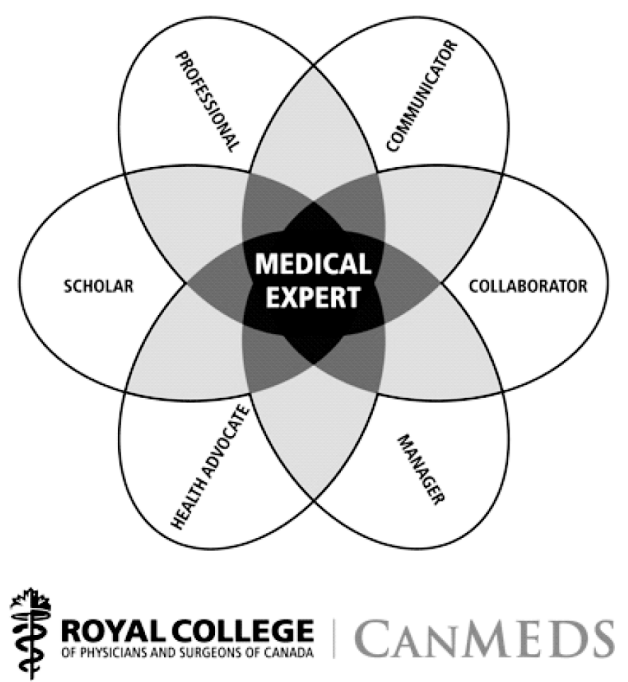

Figure 1. The seven professional competencies for specialist physicians 


\section{Chapter 3}

In 2005, competency based training was formally introduced into the Dutch postgraduate medical curriculum (see table 1 for details on the Dutch medical training programme). Seven professional competencies (similar to the CanMEDs roles) were outlined in the training programmes (5). We observed, however, that the competency as manager seemed to receive little attention when compared to the other professional competencies in the curricula. Also, it was difficult to assess residents' competencies as medical managers objectively since the only known method for evaluating this competency in the Netherlands was the portfolio. A possible reason for this could be the fact that the Dutch Central College of Medical Specialists was only responsible for recommending the general guidelines for the new competency based curriculum, while the different medical specialties had the freedom to interpret these recommendations as it applied to their disciplines and translate the competencies into concepts and skills that could be taught and evaluated as they deemed fit. Finally, in cases where it occurred, the objective documentation of residents' managerial competencies in portfolios took place sporadically and frequently in a non-standardised fashion (6).

In a recent study that investigated physicians' perceived competencies and preparedness for practice, 42 Dutch paediatricians were asked to rank the competencies they felt that their professional training best prepared them in. The results showed that they felt that they were trained best in the competency as 'medical expert' and least as 'manager' (7). Although these paediatricians graduated as far back as 1985, not much seems to have changed since then as there is still no mandatory management training in the Dutch postgraduate medical training programme. Furthermore, other studies have shown that medical residents do not feel well prepared to manage clinical practices after their training (8-16); in a recent review we conducted, we discovered that there is a need for specific modules in management training in the postgraduate medical curriculum (17). We therefore decided to investigate the perceived knowledge and competency of medical residents in their role as (physician) managers and also to identify if certain variables such as gender, specialty, previous management education or experience and hospital training setting (university vs district teaching hospitals) influenced these perceptions.

\section{METHODS \\ Designing the survey}

In October 2009, we designed a survey that was based on the findings of the literature review we conducted on the need for management education during the residency training (17). In that review we described 10 articles that assessed residents' knowledge of 
Residents' perceived management competency

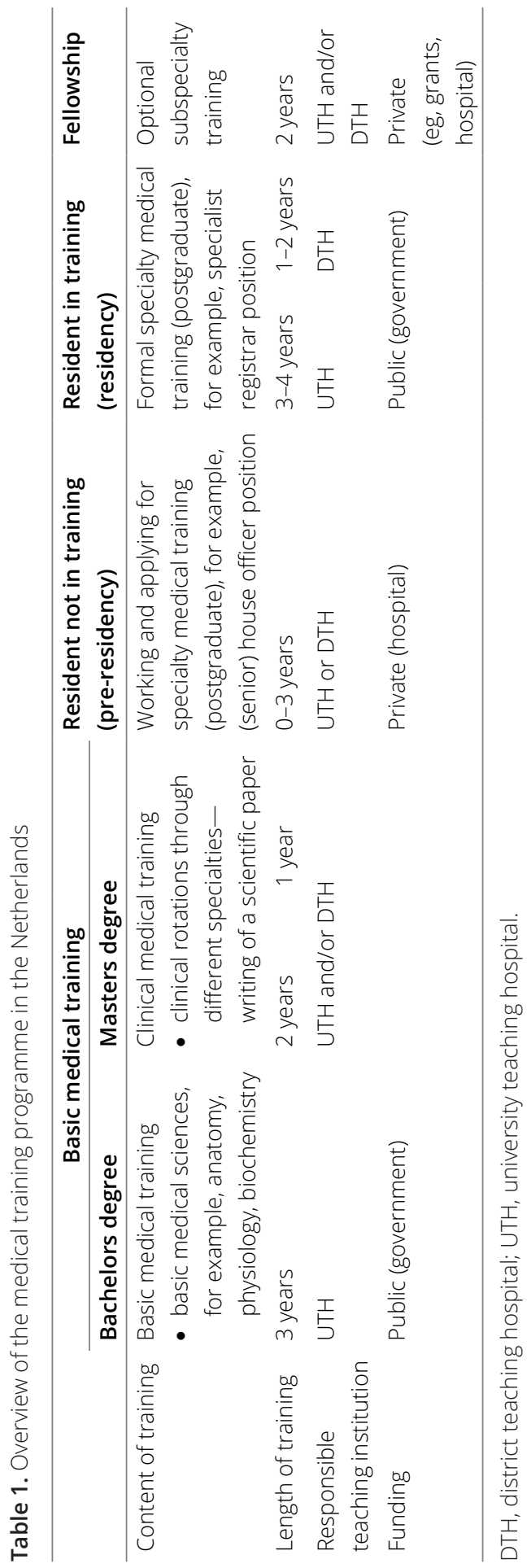




\section{Chapter 3}

managerial principles as an indicator of the effect of a managerial educational intervention. Five articles used subjective pre- and post-self assessment tests (9,18-21), while four articles used an objective test with questions that assessed management knowledge before and after the curriculum (22-25). One article did both (26). We used these studies as a guideline for developing our survey. A 46 item questionnaire was prepared and sent to an expert panel consisting of two clinical educators (internal medicine and paediatrics), a resident, two educationalists, and an educational psychologist for comments. Based on the feedback we received, the questionnaire was revised and a number of items rephrased or eliminated. The final questionnaire consisted of 29 items that covered four areas of practice management: 1. the balance between patient care and personal development; 2. effectively operating within the healthcare setting; 3. allocating finite healthcare resources appropriately; and 4. using information technology to deliver optimal healthcare. The respondents were asked to rank their perceived level of competency on a five point Likert scale, with 1: completely agreeing, and 5: completely disagreeing with a statement. We also asked the residents to fill in their demographic characteristics: age, gender, years of work experience, specialty (surgical vs non-surgical specialties), hospital (university vs district teaching hospitals), previous management experience (e.g., a previously held job or having served as an executive member in their residency association, etc.) and previous management education (this could range from discussing coding and billing once a month to an actual course of a couple of days), as we were interested in knowing whether these variables had significant influence on their perceived management knowledge and skills.

\section{Data collection}

We emailed this survey to all residents in the Atrium Medical Centre, Heerlen and Maastricht University Medical Centre, Maastricht. We also sent the survey to the Paediatric residents and Obstetrics and Gynaecology (ObGyn) residents in the Academic Medical Centre, Amsterdam, and University Medical Centre Groningen, Groningen. As the study was a web based survey (using the survey monkey web application), links to the questionnaire were sent to all participants by email, and they could fill in the questionnaire anonymously. The duration of the survey was 3 months and reminders were sent by email twice during this period. Before starting the survey, we obtained ethical approval from our hospital's research and ethics committee. We also obtained the approval of the local resident associations and, where applicable, the approval of the directors of the residency training programmes or the equivalent. 


\section{Data analysis}

Analysis were performed using SPSS, version 15. Cronbach's a analysis was used to test the reliability of our questionnaire. The mean of the perceived levels of competency and percentages per rank were calculated for each of the practice management skill items. We used independent $t$ tests to determine statistically significant differences in mean scores based on previously described characteristics-for example, gender and specialty. We also performed a multiple regression analysis to determine which variables significantly influenced the mean overall scores of the residents.

\section{RESULTS}

A total of 506 residents were approached via email to participate in the survey. Of this total, 177 questionnaires were returned (overall response rate 35.0\%). One hundred and sixtyeight residents filled in the questionnaire completely. The dropout rate (failure to complete the survey) was $5.1 \%(n=9)$. One respondent stated that he did not fill in his demographic characteristics due to the fear of losing anonymity. The others failed to provide a reason for not completing the questionnaire.

The Cronbach's a score was 0.87 for the entire questionnaire. The corrected item total correlations were above 0.3 .

\section{Residents' characteristics}

The mean age of the residents was 30.3 years (SD 3.0). Sixty-seven per cent (112/168) of the respondents were female. Residents from 19 different specialties completed the survey, with Paediatrics (36/168, 21.4\%), ObGyn (31/168, 18.5\%), Internal Medicine (24/168, 14.3\%), and Anaesthesiology (15/168, 8.9\%) being the largest response groups. The average years of work experience was 4.3 years (SD 2.6). Fifteen respondents had not started the formal residency programme. The residents in the formal residency training had a mean of 3.0 years (SD 1.6). Eighty-seven per cent (147/168) of the respondents reported not having any formal management training at their current workplace, while 58.3\% (98/168) reported to have had some previous experience in a management function-for example, in their sorority, previous (holiday) jobs, sports club, committees, etc (table 2).

\section{Perceived levels of knowledge and competency}

In general, the residents rated their perceived competency moderately (mean 2.59; SD 0.37). The overall result of the survey is summarised in table 3.

In the first area, 'the resident finds a balance between patient care and personal development in his work', more than half of the residents did not feel competent enough in 


\section{Chapter 3}

Table 2. Residents' characteristics

\begin{tabular}{|c|c|c|}
\hline \multicolumn{3}{|l|}{ Number of residents: 168} \\
\hline \multirow[t]{2}{*}{ Gender } & Male & $56(33.3 \%)$ \\
\hline & Female & $112(66.7 \%)$ \\
\hline Age & Mean & 30.3 year (SD 3.0) \\
\hline \multirow[t]{20}{*}{ Specialty } & Anesthesiology & $15(8.9 \%)$ \\
\hline & Clinical genetics & $3(1.8 \%)$ \\
\hline & Clinical chemistry & $1(0.6 \%)$ \\
\hline & Dermatology & $6(3.6 \%)$ \\
\hline & Emergency department & $4(2.4 \%)$ \\
\hline & Ear, nose and throat & $3(1.8 \%)$ \\
\hline & ObGyn & $31(18.5 \%)$ \\
\hline & Internal medicine & $24(15.3 \%)$ \\
\hline & Medical rehabilitation & 1 (0.6\%) \\
\hline & Neurology & $4(2.4 \%)$ \\
\hline & Neurosurgery & $3(1.8 \%)$ \\
\hline & Ophthalmology & $5(3.0 \%)$ \\
\hline & Orthopedics & 5 (3.0\%) \\
\hline & Pathology & $5(3.0 \%)$ \\
\hline & Pediatrics & $36(21.4 \%)$ \\
\hline & Psychiatry & $2(1.2 \%)$ \\
\hline & Radiology & $8(4.8 \%)$ \\
\hline & Surgery & $4(2.4 \%)$ \\
\hline & Urology & $3(1.8 \%)$ \\
\hline & Non-compliance* & $5(3.0 \%)$ \\
\hline \multirow[t]{2}{*}{ Years of work experience } & Mean & 4.3 years (SD 2.6) \\
\hline & Non-compliance* & 1 \\
\hline \multirow{3}{*}{$\begin{array}{l}\text { Number of years in residency } \\
\text { training }\end{array}$} & Mean & 3.0 years (SD 1.6) \\
\hline & Not in training & 15 \\
\hline & Non-compliance* & 2 \\
\hline \multirow[t]{2}{*}{ Previous management training } & Yes & $26(15.5 \%)$ \\
\hline & No & $142(84.5 \%)$ \\
\hline \multirow{2}{*}{$\begin{array}{l}\text { Previous experience in a } \\
\text { management functiont }\end{array}$} & Yes & $98(58.3 \%)$ \\
\hline & No & $70(41.7 \%)$ \\
\hline \multirow{2}{*}{$\begin{array}{l}\text { Management training at current } \\
\text { workplace }\end{array}$} & Yes & $21(12.5 \%)$ \\
\hline & No & $147(87.5 \%)$ \\
\hline \multirow[t]{5}{*}{ Desired future workplace } & Academic hospital & $44(26.2 \%)$ \\
\hline & Peripheral hospital & $94(56.0 \%)$ \\
\hline & Private practice & $12(7.1 \%)$ \\
\hline & Otherwise & $3(1.8 \%)$ \\
\hline & Don't know yet & $50(29.8 \%)$ \\
\hline
\end{tabular}

\footnotetext{
* The resident didn't answer the question, or his answer wasn't usable

t This could be a function in an association, committee, sports club etc

ObGyn: obstetrics and gynaecology
} 
Table 3. Overall results

\begin{tabular}{lccccccc}
\hline & Mean & $\mathbf{1}$ & $\mathbf{2}$ & $\mathbf{3}$ & $\mathbf{4}$ & $\mathbf{5}$ & $\#$ \\
\hline $\begin{array}{l}\text { Area one: The resident finds a balance between patient care and personal development in his } \\
\text { work }\end{array}$ & 2.58 (SD 0.85) & $5 \%$ & $51 \%$ & $29 \%$ & $14 \%$ & $2 \%$ & $0 \%$ \\
\hline 1. Create career opportunities & 2.62 (SD 0.86) & $6 \%$ & $45 \%$ & $32 \%$ & $16 \%$ & $1 \%$ & $0 \%$ \\
2. Negotiate personal ambitions & 2.64 (SD 0.94) & $7 \%$ & $44 \%$ & $28 \%$ & $18 \%$ & $2 \%$ & $0 \%$ \\
3. Personal financial situation & 3.55 (SD 0.87) & $2 \%$ & $10 \%$ & $28 \%$ & $51 \%$ & $9 \%$ & $0 \%$ \\
4. Negotiate working conditions & 2.41 (SD 0.87) & $13 \%$ & $48 \%$ & $24 \%$ & $15 \%$ & $0 \%$ & $0 \%$ \\
5. Time management & 2.60 (SD 0.90) & $9 \%$ & $42 \%$ & $31 \%$ & $18 \%$ & $1 \%$ & $0 \%$ \\
6. Patient care vs practice requirements & 2.60 (SD 0.89) & $7 \%$ & $46 \%$ & $27 \%$ & $20 \%$ & $0 \%$ & $0 \%$ \\
7. Patient care vs personal life & 2.08 (SD 0.55) & $9 \%$ & $76 \%$ & $12 \%$ & $2 \%$ & $0 \%$ & $0 \%$ \\
8. Handling received feedback & 2.59 (SD 0.69) & $2 \%$ & $46 \%$ & $42 \%$ & $10 \%$ & $0 \%$ & $0 \%$ \\
9. Giving feedback & rif
\end{tabular}

Area two: The resident functions effectively in the health care setting

\begin{tabular}{|c|c|c|c|c|c|c|c|}
\hline 10. Organization healthcare system & 3.45 (SD 0.89) & $1 \%$ & $15 \%$ & $28 \%$ & $50 \%$ & $6 \%$ & $1 \%$ \\
\hline 11. Organization specialist department & 3.89 (SD 0.77) & $1 \%$ & $5 \%$ & $19 \%$ & $57 \%$ & $18 \%$ & $1 \%$ \\
\hline 12. Requirements as specialist & 3.47 (SD 0.82) & $1 \%$ & $11 \%$ & $35 \%$ & $45 \%$ & $7 \%$ & $1 \%$ \\
\hline 13. Leadership skills & 2.46 (SD 0.70) & $3 \%$ & $54 \%$ & $34 \%$ & $7 \%$ & $1 \%$ & $1 \%$ \\
\hline 14. Managing a ward & $2.22(S D 0.70)$ & $10 \%$ & $63 \%$ & $22 \%$ & $4 \%$ & $1 \%$ & $1 \%$ \\
\hline 15. Dealing with conflicts & 2.28 (SD 0.64) & $6 \%$ & $64 \%$ & $24 \%$ & $5 \%$ & $0 \%$ & $1 \%$ \\
\hline 16. Rights and duties & 2.51 (SD 0.75) & $4 \%$ & $52 \%$ & $32 \%$ & $11 \%$ & $0 \%$ & $1 \%$ \\
\hline 17. Reportage in medical files & 2.38 (SD 0.74) & $5 \%$ & $62 \%$ & $23 \%$ & $9 \%$ & $1 \%$ & $1 \%$ \\
\hline 18. Mistake made myself & 2.47 (SD 0.75) & $2 \%$ & $61 \%$ & $24 \%$ & $11 \%$ & $1 \%$ & $1 \%$ \\
\hline 19. Mistakes made by others & 2.67 (SD 0.80) & $2 \%$ & $47 \%$ & $33 \%$ & $16 \%$ & $1 \%$ & $1 \%$ \\
\hline 20. Improving quality processes & 2.62 (SD 0.87) & $6 \%$ & $45 \%$ & $29 \%$ & $18 \%$ & $1 \%$ & $1 \%$ \\
\hline 21. Leading a committee & 2.70 (SD 0.91) & $9 \%$ & $31 \%$ & $41 \%$ & $16 \%$ & $2 \%$ & $1 \%$ \\
\hline
\end{tabular}

Area three: The resident allocates finite healthcare resources appropiately

\begin{tabular}{llllllll}
\hline 22. Allocating resources based on EBM & 2.10 (SD 0.59) & $9 \%$ & $72 \%$ & $15 \%$ & $1 \%$ & $1 \%$ & $2 \%$ \\
23. Allocating resources based on availability & 2.35 (SD 0.70) & $4 \%$ & $64 \%$ & $22 \%$ & $7 \%$ & $1 \%$ & $2 \%$ \\
24. Allocating resources based on costs & 2.58 (SD 0.86) & $3 \%$ & $55 \%$ & $20 \%$ & $18 \%$ & $1 \%$ & $2 \%$ \\
25. Protecting patients' interests & 1.97 (SD 0.60) & $17 \%$ & $68 \%$ & $11 \%$ & $1 \%$ & $1 \%$ & $2 \%$
\end{tabular}

Area four: The resident uses information technology appropriately to deliver optimal health care and to maintain and keep up medical knowledge

\begin{tabular}{lcc|c|cccc}
\hline 26. Using information technology & 2.06 (SD 0.87) & $24 \%$ & $51 \%$ & $16 \%$ & $5 \%$ & $2 \%$ & $2 \%$ \\
27. Updating medical knowledge & 1.77 (SD 0.56) & $27 \%$ & $68 \%$ & $2 \%$ & $1 \%$ & $1 \%$ & $2 \%$ \\
28. Eligible for medical training & 2.31 (SD 0.80) & $11 \%$ & $56 \%$ & $22 \%$ & $9 \%$ & $1 \%$ & $2 \%$ \\
29. Coding and billing & 2.98 (SD 1.03) & $5 \%$ & $33 \%$ & $28 \%$ & $26 \%$ & $7 \%$ & $2 \%$ \\
\hline
\end{tabular}

\#: No response

Shaded box: median

For area and question specification: see appendix 1

1: Completely agrees, 2: Agrees, 3: Neutral, 4: Disagrees, 5: Completely disagrees 


\section{Chapter 3}

their negotiating skills_for example, contract negotiation (90/177, 51\% disagree; 16/177, 9\% completely disagree). Forty-two per cent (75/177) rated their competency in giving feedback to their colleagues 'neutrally', while 85\% (151/177) felt competent in seeking and handling feedback.

In the second section, 'the resident functions effectively in the healthcare setting', more than $50 \%$ of the respondents stated that they lacked enough knowledge on how the Dutch healthcare system was organised and financed, on how their specialty's department was organised and financed, and what will be expected of them when they become medical specialists. Forty-one per cent (72/175) rated their competency in leading committees or meetings neutrally. They felt competent in their skills of managing their wards (111/175, $63 \%$ agree; 17/175, 10\% completely agree) and dealing with conflicts on the workplace (114/175, 65\% agree; 10/175, 6\% completely agree).

The residents felt competent in all domains of the third section, 'the resident allocates finite healthcare resources appropriately'. The large majority stated that they would advocate in their patient interests even if they had to defy their supervisors. Eighty-three per cent (143/173) agreed that they allocate healthcare resources using evidence based principles such as guidelines or protocols.

In the fourth section, 'the resident uses information technology appropriately', one third (58/173) of the respondents felt competent in their coding and billing skills, one third (49/173) was neutral, and the other third (46/173) did not feel competent enough in that area. Ninety-seven per cent (168/173) felt competent in their ability to find medical resources (books, internet, databases, etc) to keep their medical knowledge up to date.

\section{Factors influencing perceived knowledge and competency}

University versus district hospitals

When we compared the residents based on which hospital they worked at, we saw that the residents at the university hospitals $(n=120)$ rated themselves on average to be more competent on the items "I know how to handle my personal financial situation and what I can expect in the future" (mean university 2.53 (SD 0.87) vs district 2.89 (SD 1.04); p=0.018) and "I know how to lead or participate in a committee or meeting" (mean university 2.54 (SD 0.86) vs district 3.08 (SD 0.92); $p=0.000$ ). Residents from the district teaching hospitals $(n=53)$ scored better on the item "I know how to use information technology in patient care appropriately (e.g., online databases)" (mean university 2.15 (SD 0.86) vs district 1.85; $p=0.035)$. 


\section{Residents' perceived management competency}

Surgical versus non-surgical specialties

The residents who worked in a non-surgical specialty $(n=109)$ rated their perceived knowledge and skills higher on one question; "I know which rights and duties I have to fulfil being a doctor (eg, health law)" (mean non-surgical 2.43 (SD 0.76) vs surgical 2.71 (SD 0.74); $p=0.026$ ). The residents from surgical specialties $(n=55)$ ranked their competency higher on the following four questions: "I know how to manage my ward effectively" (mean nonsurgical 2.34 (SD 0.71) vs surgical 2.07 (SD 0.66); p=0.019), "I take the costs of healthcare resources into account when allocating them" (mean non-surgical 2.70 (SD 0.92) vs surgical 2.42 (SD 0.71); $p=0.034$ ), "I know how to reimburse and code my work (coding and billing)" (mean non-surgical 3.19 (SD 1.05) vs surgical 2.53 (SD 0.81); $p=0.000$ ), and "I know how to lead or participate in a committee or meeting" (mean non-surgical 2.84 (SD 0.92) vs surgical 2.53 (SD 0.79); $p=0.031$ ).

\section{Gender}

When comparing the means of the residents based on their gender, men ( $n=56)$ scored their perceived knowledge and skills higher on four questions: "I am well aware of how to create career opportunities" (mean men 2.30 (SD 0.74) vs women 2.73 (SD 0.88); p=0.001), "I know how the Dutch healthcare system is organised and financed" (mean men 3.29 (SD 0.91 ) vs women 3.57 (SD 0.76); $p=0.033$ ), "I know how to lead or participate in a committee or meeting" (mean men 2.41 (SD 0.85) vs women 2.88 (SD 0.88); $p=0.001$ ), and "I know where I can find medical resources (books, internet, databases) to keep up my medical knowledge" (mean men 1.62 (SD 0.49) vs women 1.85 (SD 0.57); $p=0.014$ ). The female residents ( $n=112$ ) did not rank their competency significantly higher on any question.

\section{Previous management experience}

We also asked the residents if they had some previous experience in a management function. Residents who had such experience scored significantly better on 10 questions, as is shown in table 4. There were no questions on which the residents without this experience scored better.

\section{Previous management education}

The residents who had previous management education $(n=26)$ rated themselves higher on one question in comparison with the residents who did not have previous education ( $\mathrm{n}=142$ ): "I am capable of giving feedback to my colleagues" (mean previous education 2.35 (SD 0.63) vs no education 2.65 (SD 0.69); $p=0.038$ ). 


\section{Chapter 3}

Table 4. Significant differences based on previous experience

\begin{tabular}{|c|c|c|c|}
\hline Question & p Value & Experience & Mean \\
\hline \multirow[t]{2}{*}{ 1. Create career opportunitities } & 0.019 & No & 2.77 (SD 0.89) \\
\hline & & Yes & $2.46(S D 0.81)$ \\
\hline \multirow[t]{2}{*}{ 2. Negotiate personal ambitions } & 0.031 & No & 2.80 (SD 0.84) \\
\hline & & Yes & 2.51 (SD 0.85) \\
\hline \multirow[t]{2}{*}{ 9. Giving feedback } & 0.006 & No & 2.77 (SD 0.76) \\
\hline & & Yes & 2.48 (SD 0.60) \\
\hline \multirow[t]{2}{*}{ 10. Organization healthcare system } & 0.001 & No & 3.73 (SD 0.74) \\
\hline & & Yes & 3.30 (SD 0.83) \\
\hline \multirow[t]{2}{*}{ 11. Organization specialist department } & 0.003 & No & 4.10 (SD 0.66) \\
\hline & & Yes & 3.76 (SD 0.77) \\
\hline \multirow[t]{2}{*}{ 13. Leadership requirements } & 0.024 & No & 2.60 (SD 0.75) \\
\hline & & Yes & 2.36 (SD 0.63) \\
\hline \multirow[t]{2}{*}{ 15. Dealing with conflicts } & 0.034 & No & $2.41(S D 0.71)$ \\
\hline & & Yes & 2.19 (SD 0.57) \\
\hline \multirow[t]{2}{*}{ 20. Improving quality processes } & 0.000 & No & 2.93 (SD 0.89) \\
\hline & & Yes & 2.44 (SD 0.77) \\
\hline \multirow[t]{2}{*}{ 21. Leading a committee } & 0.000 & No & 3.10 (SD 0.82) \\
\hline & & Yes & 2.45 (SD 0.85) \\
\hline \multirow[t]{2}{*}{ 27. Finding medical resources } & 0.032 & No & 1.89 (SD 0.60) \\
\hline & & Yes & 1.69 (SD 0.51) \\
\hline
\end{tabular}

Previous experience: $\mathrm{n}=98$,

No previous experience: $\mathrm{n}=70$

Table 5. Influence of independent variables on mean scores

\begin{tabular}{lccccc}
\hline & \multicolumn{2}{c}{$\begin{array}{c}\text { Unstandardised } \\
\text { coefficients }\end{array}$} & & $\begin{array}{c}\text { Standardised } \\
\text { coefficients }\end{array}$ & Significance \\
\cline { 2 - 3 } & $\beta$ & SE & & $\beta$ & SE \\
\hline (Constant) & 2330 & 0.192 & & & 0.000 \\
Gender & 0.088 & 0.058 & & 0.117 & 0.134 \\
Specialty & 0.036 & 0.057 & & 0.049 & 0.522 \\
Previous education & 0.052 & 0.077 & & 0.054 & 0.499 \\
Previous management experience & 0.187 & 0.059 & & 0.262 & $0.002^{*}$ \\
Hospital & -0.018 & 0.060 & & -0.024 & 0.760 \\
Work experience & -0.10 & 0.011 & & -0.069 & 0.373 \\
\hline
\end{tabular}

${ }^{*} \mathrm{p}<0.05$. 


\section{Multiple regression analysis}

As is shown in table 5, the only variable which had an overall significant influence on perceived management competency was having had previous management experience ( $p=0.002$ ). On the overall questionnaire residents who had such an experience rated their perceived management competency to be higher.

\section{DISCUSSION}

The residents who participated in this study rated their confidence in their management competency overall as moderate (mean 2.59; SD 0.37). The other findings, however, demonstrated a perceived lack of knowledge and skills in some essential management areas. The only variable that significantly influenced the overall perceived competence in a positive way was when the residents had previous management experience.

The residents scored their competency on their coding and billing abilities and on their contract negotiating skills as low. As a large number of patients are coded and billed by residents in practice, it is crucial that this is done correctly as this may have negative financial consequences for the clinical department. Effective negotiating skills are also important in many clinical settings_-for example, in contract negotiations, patient contacts, nurse-physician interactions, and in deliberations with peers. The respondents also rated their knowledge of the Dutch healthcare system poorly, including the way it was organised and financed. The perceived lack of knowledge of their national healthcare systems may suggest a possible shortcoming of the Dutch basic medical curriculum. This is especially important when one considers that a good understanding of the (financial) organisation of healthcare systems and of the individual medical departments is a prerequisite for engaging in innovative and cost effective healthcare practices.

About a third of the residents rated their perceived ability to engage in career negotiations, provide feedback to others, and operate adequately in leadership roles neutrally. They also gave neutral ratings on their knowledge of healthcare law, their perceived ability to lead healthcare teams or committees, and how to handle medical errors made by others effectively. Although the residents rated their competencies in these areas neutrally, we consider this still to be insufficient considering how important it is to be able to initiate reflection and provide feedback to peers and other members of the healthcare team when errors are made. It is equally important that residents feel comfortable in their leadership roles as departments function more efficiently with competent and confident leaders. In 


\section{Chapter 3}

contrast to their perceptions on giving feedback, the respondents felt more competent in handling received feedback, working with medical information databases, and allocating healthcare resources efficiently based on evidence based principles. The latter two findings are not surprising since a lot of attention is devoted to the use of medical information technology in the Dutch basic medical curriculum.

Using independent t tests, we saw that all the variables produced at least one question where there was a significant difference in the means between the groups. The variable that stood out most was whether residents had previous management experience. The residents who had this experience ranked their competency higher on 10 of the 29 questions. This suggests that participating in extracurricular managerial activities in the undergraduate years (probably) improves perceived competency as physician managers. The multiple regression analysis confirmed this finding. Only the variable "previous management experience" had significant influence on how the residents scored their competency. This is remarkable, as previous management education and work experience were of no significant influence on their overall perceived competency. The results suggest that current management courses and individual prior work experience are not sufficient enough to increase residents' perceived competency in management tasks.

In 1990 Daugird and Spencer published an article on the perceived need for physician management training among medical students and family practice residents. The respondents were asked which specific management areas they felt they were incompetent or inadequately trained in. The most cited areas included: insurance coding and billing, Health Maintenance Organization (HMO) or Preferred Provider Organization (PPO) participation and contracts, practice accounting, and taxes (8). Although this study was conducted 20 years ago (among family practice residents), the results of our study showed similar findings, with our respondents indicating problems with coding and billing and poor knowledge of the healthcare system. In another management study by Sockalingam et al among Canadian psychiatry residents, the respondents reported the highest perceived knowledge levels for models of mental health delivery and the Mental Health Act. In the perceived skill domains, the residents reported the highest perceived skill levels in the areas of working in teams, and negotiating and resolving conflict. The lowest perceived levels of management knowledge and skills were in programme planning, principles of quality improvement, reading and understanding financial statements, budgeting and innovation, and leading change (27). The Dutch residents in our study also scored their management competencies in resolving conflicts to be adequate, and in fact felt more competent in leading change (quality improvement) when compared to the residents in 
the Canadian study. One should be cautious in comparing these results however, since Sockalingam et al used different descriptors for the domains of management education in their study (27). This also highlights the fact that there is still little consensus on what the manager's role exactly comprises and what we should teach our residents.

There are a few limitations worth mentioning in this study. To begin with, the response rate was low, despite the two reminders we sent to increase the response rate. Studies in the literature do show, however, that most studies that employ electronic questionnaires report an average response rate of 35-50\%, making our rate, though low, still acceptable (28-30). Another point worth mentioning is the fact that we only measured perceived knowledge and skills in our survey and it is possible that if measured objectively, the respondents' actual skills and knowledge would have been scored differently. Finally, this study focused on residents in four hospitals in the Netherlands. One may argue that the residents in other hospitals that were left out may have had more management training in their programmes and might therefore rate their competencies higher than our respondents did. However, this effect is likely to be minimal, as we know that there is currently no formal management training (course) in the revised curriculum of the postgraduate training programme in the Netherlands.

\section{CONCLUSIONS}

This study of residents' perceptions of their practice management skills suggests that medical residents rate their overall competency moderately. There are a number of areas where they feel they lack adequate managerial knowledge or skills. Although we did not measure the objective knowledge and skills of the respondents in this study, our research suggests that a course in medical management should be considered as a mandatory part of the curricula of residency training programmes. 


\section{REFERENCES}

1. Royal College of Physicians and Surgeons of Canada. The CanMEDS Physician Competency Framework. 2010. http:// rcpsc.medical.org/canmeds/ (accessed 20 Apr 2011).

2. General Medical Council. About the foundation programme. 2010. http:// www.gmc-uk.org/education/postgraduate/ regulation.asp (accessed 18 Feb 2010).

3. Australian Medical Association. Prevocational Medical Education and Training. 2005. http://www.ama.com.au/ node/2181 (accessed 18 Feb 2010).

4. Accreditation Council for Graduate Medical Education. Accreditation Council for Graduate Medical Education. Outcome project. 2010. http://www.acgme.org/ Outcome (accessed 18 Feb 2010).

5. Reenen van R, Schelfhout-van Deventer V. Framework for the Dutch Specialist Training Programs. Kaderbesluit Centraal College Medische Specialismen (Dutch). 2009. http:// knmg.artsennet.nl/artikel/Moderniseringmedische-vervolgopleidingen-nieuwkaderbesluit-CCMS.htm (accessed 18 Feb 2010).

6. Koninklijke Nederlandse Maatschappij tot bevordering der Geneeskunst. Landelijke opleidingsplannen per specialisme. 2011. http://knmg.artsennet. nl/Opleiding-en-Registratie/Modernisering/ Opleidingsplannen/Landelijke-plannen. htm(accessed 10 May 2011).

7. Busari JO, Verhagen EA, Muskiet FD. The influence of the cultural climate of the training environment on physicians' self-perception of competence and preparedness for practice. BMC Med Educ 2008:8:51.

8. Daugird AJ, Spencer DC. The perceived need for physician management training. J Fam Pract 1990;30:351-2.
9. Taylor ML, Mainous AG 3rd., Blue AV, et al. How well are practice management curricula preparing family medicine residents? Fam Med 2006;38:275-9.

10. Stone MA. Family physicians' evaluation of the practice management education received during residency training. Fam Med 1994;26:101-5.

11. Breitwieser D, Adye W, Arvidson M. Resident evaluation of current practice management training. J Fam Pract 1981;13:1063-4.

12. Mayo F, Wood M, Marsland DW, et al. Graduate follow-up in the Medical College of Virginia/Virginia Commonwealth University family practice residency system. J Fam Pract 1980;11:731-42.

13. Geyman JP, Cherkin DC, Deisher JB, et al. Graduate follow-up in the University of Washington family practice residency network. J Fam Pract 1980;11:743-52.

14. Ciriacy EW, Bland CJ, Stoller JE, et al. Graduate follow-up in the University of Minnesota affiliated hospitals residency training program in family practice and community health. J Fam Pract 1980;11:719-30.

15. Hecht RC, Farrell JG. Graduate followup in the University of Wisconsin family practice residency programs. J Fam Pract 1982;14:549-55.

16. Carek PJ, Abercrombie S, Baughman O, et al. Graduate survey of the South Carolina Area Health Education Consortium family practice residency programs. I S C Med Assoc 2001;97:250-3.

17. Busari JO, Berkenbosch $L$, Brouns J. Physicians as managers of health care delivery and the implications for postgraduate medical training: a literature review. Teach Learn Med 2011;23:186-96. 
18. Junker JA, Miller T, Davis MS. Practice management: a third-year clerkship experience. Fam Med 2002;34:87-9.

19. Horowitz RE, Naritoku W, Wagar EA. Management training for pathology residents: a regional approach. Arch Pathol Lab Med 2004;128:59-63.

20. Bayard M, Peeples CR, Holt J, et al. An interactive approach to teaching practice management to family practice residents. Fam Med 2003;35:622-4.

21. Piatt JP, Bartley $D L$, Jacobson $A D$, et al. Practice management training for pediatric residents. Am J Dis Child 1991;145:299-301.

22. Essex B, Jackson RN. Moneymed: a game to develop management skills in general practice. J R Coll Gen Pract 1981;31:735-9.

23. Babitch LA. Teaching practice management skills to pediatric residents. Clin Pediatr (Phila) 2006;45:846-9.

24. Hemmer PR, Karon BS, Hernandez JS, et al. Leadership and management training for residents and fellows: a curriculum for future medical directors. Arch Pathol Lab Med 2007;131:610-14.

25. LoPresti L, Ginn P, Treat R. Using a simulated practice to improve practice management learning. Fam Med 2009;41:640-5.

26. Crites GE, Schuster RJ. A preliminary report of an educational intervention in practice management. BMC Med Educ 2004;20:15.

27. Sockalingam S, Stergiopoulos V, Maggi J. Residents' perceived physician-manager educational needs: a national survey of psychiatry residents. Can J Psychiatry 2008;53:745-52.

28. Greenlaw C, Brown-Welty S. A comparison of web-based and paper-based survey methods: testing assumptions of survey mode and response cost. Eval Rev 2009;33:464-80.
29. Sheehan K. E-mail survey response rates: a review. J Comp Mediated Commun 2001;6:1-20.

30. Assessment Do II. Response rates. 2010. http://www.utexas.edu/academic/diia/ assessment/iar/teaching/gather/method/ survey-Response.php (accessed 6 May 2010). 
Chapter 3

\section{APPENDIX 1}

\section{Personalia}

- Age:

- Gender:

- Male

- Female

- Year of graduation:

- I studied Medicine at the following institution:

- I work within the following specialty:

- I have the following amount of years of work experience as a physician:

- Currently I am in my _ year of training of my chosen specialty (zero when not in training)

- Besides Medicine I also undertook a(n) education/curriculum/course which contributes to my functioning as a Manager:

- No

- Yes, namely:

- I had the following experiences which can contribute to my functioning as a manager:

- None

- Yes, namely (sorority/study club/sports club/commission/job):

- During my training, focussed time has been spent on the management role of physicians.

- No

- Yes, namely (describe training, course):

- Desired work location after finishing my training:

- Academic Hospital

- Peripheral Hospital

- Private (family) practice

- Family medicine practice

- I don't know yet

- Other: 


\section{Questionnaire}

On a scale of 1 to 5, choose the response you feel to be most accurate regarding your knowledge or skills on the following topics, if:

$1=$ I totally agree

$2=1$ agree

$3=$ Neutral

4 = disagree

$5=1$ totally disagree

The resident finds a balance between patient care and personal development in his work.

This includes setting priorities, time management and utilizing self-evaluation skills to balance patient care, practice requirements, outside activities and personal life I am well aware of how to create career opportunities.

- I know how to negotiate on my personal ambitions (working part-time, PhD project)

- I know how to handle my personal financial situation and what I can expect in the future.

- I know how to negotiate on my salary and my working conditions.

- I am adept at estimating time requirements for daily tasks and time management and as a result, I am capable of finishing my job requirements on time.

- I am capable of setting priorities between providing patient care and practice requirements, such as administrative tasks.

- I am capable of setting priorities between patient care and my personal life.

- I know how to handle feedback from my supervisors

- I am capable of giving feedback to my colleagues.

The resident functions effectively in the health care setting

This means that the resident understands the roles and responsibilities of specialists, the organizations they work in, and how the healthcare system functions. They are capable of working collaboratively with others in the organization, leading a practice and participating in the management systems within the organization such as hospital committees or national representative functions.

- I know how the Dutch healthcare system is organised and financed

- I know how my specialist department is organised and financed

- I know what is expected of me when I am a specialist (leadership, administrative tasks, meetings, finance)

- I know how to function in my position as a leader for other medical personnel (nurses etc.) 


\section{Chapter 3}

- I know how to manage my ward effectively

- I know how to deal with conflicts at my workplace

- I know which rights and duties I have to fulfil being a doctor (for example, health law)

- I know what has to be reported in a medical file to avoid legal problems]

- I know how to deal with medical mistakes I made myself

- I know how to deal with medical mistakes made by others

- I participate actively in evaluating and improving systematic quality processes (for example, improving patient safety)

- I know how to lead or participate in a committee or meeting

The resident allocates finite healthcare resources appropriately

Although the interests of the patient are always of most importance, consideration has to be made towards effectiveness, efficiency and access in the just allocation of healthcare resources.

- I allocate healthcare resources (additional research, treatments) based on evidencebased medicine, guideline or protocol

- I take into account when allocating health care resources that they are finite (waiting lists).

- I take the costs of healthcare resources into account when allocating them.

- I stand up for my patient, when I feel that the amount of care he/she receives isn't enough, even when I have to challenge my supervisor

The resident uses information technology appropriately to deliver health care optimal and to maintain and keep up medical knowledge

This is the use of patient-related databases, the use of electronic information and knowing how to use medical information systems to deliver optimal healthcare and to maintain and keep up medical knowledge.

- I know how to use information technology in patient care appropriately (for example, work with electronic medical file and online databases)

- I know where I can find medical resources (books, internet, databases) to keep up my medical knowledge

- I know when I am eligible for medical training

- I know how to reimburse and code my work (coding and billing). 




\section{(9)}

\section{Chapter 4}

Medical residents perceptions of the need for management education in the postgraduate curriculum: a preliminary study.

Brouns JWM, Berkenbosch L, Ploemen-Suijker FD, Heyligers I, Busari JO Int J Med Educ. 2010; 1:76-82 


\section{Chapter 4}

\section{ABSTRACT \\ Objectives}

The curriculum of the new post-graduate medical training program in the Netherlands is comprised of seven competencies that residents should possess upon graduation. In this new curriculum however, the competency as manager receives relatively little attention. In this preliminary study we investigated the residents' need for management training and tried to identify the preferred form of intervention to develop these management skills.

\section{Methods}

A survey was designed to investigate the perceived needs of residents for management training and the preferred form of training intervention. A total of 506 residents in four Dutch teaching hospitals were invited to participate in a web-based survey. Results were using descriptive statistics, Chi-square tests and Fisher's exact tests.

\section{Results}

A total of 177 residents responded to the survey. Of the respondents, 85\% $(n=146)$ reported a need for management training. The preferred management topics included negotiation skills, practice partnerships, knowledge of the health care system and career planning. The preferred training method was a workshop given by medical specialists or extramural content experts. The best timing for training was determined to be during residency.

\section{Conclusions}

Dutch medical residents reported a need for management training. While this study justifies an intervention for training management skills in residents, more research is required to design appropriate programs that consider the preferences of residents. 


\section{INTRODUCTION}

In many countries, the professional training of medical specialists has been redesigned so that upon completion, junior physicians are equipped with the attitudes, skills and knowledge that would enable them to function efficiently in their communities. The first of these changes was the innovative framework for the education of essential competencies in physicians developed by the Royal College Physicians and Surgeons of Canada. In addition to improving patient care, the aim of this initiative was to define the competencies trainee doctors should possess upon graduation, as well as to monitor and appraise the competencies of practicing physicians. The competencies in this framework included the roles as medical expert, communicator, collaborator, manager, health advocate, professional and scholar (1).

In January 2005, competency-based training was introduced into the curriculum of all postgraduate medical training programs in the Netherlands. Similar to the CanMEDS competency framework, this new curriculum included seven competencies that residents were required to possess upon graduation. The physician's role as manager was one of these competencies, which compared to the other competencies in the undergraduate and postgraduate training programs, appeared to receive relatively little attention. The sparse amount of specific (medical) management training modules during the undergraduate and residency period reflects this point. We also examined the perceptions of medical residents on their role as manager and found out that they lacked adequate knowledge and skills of certain essential medical management concepts. This is remarkable however, when one considers that the possession of good management skills and knowledge is important for effective medical practice. We also found out that during medical school there were no specific trainings available in medical management and during the residency period some were available sporadically, but not mandatory (2). It is not unthinkable though, that certain management topics (e.g. communication, allocating health resources, using information technology) might be woven through the content of other competencies in the reformed postgraduate curriculum, while specific management topics such as negotiation skills, managing a ward, organisation of the health care system, career planning, time management might be missing entirely.

In a recent review by Busari and colleagues, a literature search was conducted to study two issues on management education in the postgraduate medical curriculum (3). The objective of this review was first, to identify if there was a need for management training among undergraduate and postgraduate medical trainees; and secondly to find out if 


\section{Chapter 4}

there were training programs available, specifically designed to develop management competencies during the medical training programs. In this review, six studies were found in which a needs assessment was performed among residents, fellows or physicians. All of these studies reported a need for management training by the respondents (4-9). Results of others studies also showed that management training had already been incorporated into the curricula of some medical programs. Most of these studies were conducted in North America and Canada and within the family medicine specialty. Although there was no consensus on the duration, timing and educational method for management training in these studies, all of the programs were evaluated positively $(5,10-24)$.

With the knowledge that specific management training in the Dutch postgraduate medical training is sparse and the findings (in North America and Canada) as described above that there is a need for management training in the medical curricula, the authors of this study decided to investigate if there was a need for training in management skills among Dutch medical residents. We also wanted to know what the preferred form of intervention would be to develop these competencies in residents during their training. In addition, we were interested in ascertaining if there was any significant relationship between the need for management training and variables such as gender, specialty, training environment, prior managerial experiences and years of clinical experience.

\section{METHODS}

A questionnaire based on the findings of the review of Busari and colleagues was designed to collect data in this study (3). A first draft of the questionnaire, in which a broad variety of questions were included, was sent by email to an expert panel of clinical educators and residents for feedback. Using the feedback received, the questionnaire was revised by modifying or dropping some of the items. The definitive questionnaire consisted of two parts: a first part that examined the residents perceived needs for management training and a second part that assessed the personal characteristics (see Appendix 1).

The items in the needs assessment section investigated the preferred management topics (content), the preferred method of instruction, when the training should take place (timing), the length of the training (duration) and the preferred venue for the training (location). In total, twenty-nine items were included in the questionnaire that comprised of a mix of 5-point Likert-scale-questions, yes/no-questions, open-ended questions and multiplechoice questions. 
Medical residents from different specialties in four different teaching hospitals in the Netherlands were solicited, by email, to participate in the survey. The institutions in which residents were working included the Atrium Medical Centre Heerlen (a district teaching hospital) and Maastricht University Medical Center, Academic Medical Centre Amsterdam and University Medical Centre Groningen (university teaching hospitals). In the hospitals in Heerlen and Maastricht, residents in all the specialties were approached. In Amsterdam and Groningen, on the other hand, only those working in paediatric and obstetrics \& gynaecology specialties were approached. The choice for these two specialties in these centres was purely due to logistical reasons. Prior to starting the survey, ethical approval from the hospitals research and ethics committee was obtained. We also sought for and obtained the approval of the local resident associations and, where applicable, the approval of the directors of the residency training programs or the equivalent. Using the 'Survey Monkey' web-application, links to the questionnaire were sent to all of the participants by email to complete anonymously. Residents had the duration of three months to respond to the questionnaire and during this period reminders were sent to them twice.

We used the Statistical Package for the Social Sciences (SPSS) to analyze the data. Descriptive statistics were used to present the demographic distribution of the participants and the pattern of the responses to the items. Chi-square and Fisher's exact tests were used to assess relationships between the perceived needs for management training and variables such as gender (male versus female), specialty (surgical versus non-surgical), training location (academic versus district teaching hospital), prior experience with managerial tasks and/or training (yes versus no) and the years of clinical experience.

\section{RESULTS}

\section{Baseline Characteristics}

Of the 506 residents we approached, 177 residents responded to our survey, yielding a response rate of 35\%. Of the 177 returned questionnaires, 170 were used for further analysis as 7 residents did not answer the questionnaire completely. The majority of the respondents were female (67\%); the specialties with the most responses included paediatrics (21\%), obstetrics \& gynaecology (18\%) and internal medicine (14\%). A majority of the residents (84\%) had no prior experience with management training while more than half of them reported to have had experience with managerial tasks in the past (58\%). These experiences included managerial tasks 1) during their undergraduate university period (e.g. in fraternities/sororities and sports club), 2) during their current employment 


\section{Chapter 4}

(e.g. participating in medical committees), and 3) during their PhD-research period. Many (87\%) of the respondents also claimed that there was little or no attention for management training at their current training locations. The baseline characteristics of the residents are shown in table 1.

Table 1. Baseline characteristics of the responding residents ( $n=170)$

\begin{tabular}{|c|c|c|c|c|}
\hline \multicolumn{2}{|l|}{ Characteristic } & \multirow{2}{*}{$\begin{array}{c}\text { No } \\
(\%)\end{array}$} & \multirow{2}{*}{$\begin{array}{c}\text { Mean } \\
(\mathrm{Yr})\end{array}$} & \multirow{2}{*}{$\begin{array}{c}\text { Min - } \\
\text { Max (Yr) }\end{array}$} \\
\hline Gender & Male & & & \\
\hline & Female & $112(67)$ & & \\
\hline & Missing (not answered) & $2(1.1)$ & & \\
\hline Age (year) & & & 30 & $24-39$ \\
\hline \multirow[t]{4}{*}{ Hospital } & Atrium Medical Centre Heerlen & $53(31)$ & & \\
\hline & Medical Academic Centre Maastricht & $72(42)$ & & \\
\hline & Academic Medical Centre Amsterdam & $23(14)$ & & \\
\hline & Medical Academic Centre Groningen & $22(13)$ & & \\
\hline \multirow[t]{20}{*}{ Specialty } & Anesthesiology & $15(8.8)$ & & \\
\hline & Clinical Chemistry & $1(0.6)$ & & \\
\hline & Dermatology & $6(3.5)$ & & \\
\hline & Ear, Nose and Throat Medicine & $3(1.8)$ & & \\
\hline & Emergency Medicine & $4(2.4)$ & & \\
\hline & Internal Medicine & $24(14)$ & & \\
\hline & Medical Genetics & $3(1.8)$ & & \\
\hline & Neurology & $4(2.4)$ & & \\
\hline & Neurosurgery & $3(1.8)$ & & \\
\hline & Obstetrics \& Gynecology & $31(18)$ & & \\
\hline & Ophthalmology & $5(2.9)$ & & \\
\hline & Orthopedics & $5(2.9)$ & & \\
\hline & Pathology Medicine & $5(2.9)$ & & \\
\hline & Pediatrics & $36(21)$ & & \\
\hline & Psychiatry & $2(1.2)$ & & \\
\hline & Radiology & $8(4.7)$ & & \\
\hline & Rehabilitation Medicine & $1(0.6)$ & & \\
\hline & Surgery & $3(1.8)$ & & \\
\hline & Urology & $1.8(3)$ & & \\
\hline & Missing (not answered) & $8(4.7)$ & & \\
\hline \multicolumn{2}{|c|}{ Years of clinical experience by working as a physician } & - & 4.3 & $0-13$ \\
\hline
\end{tabular}


Table 1. Continued

\begin{tabular}{|c|c|c|c|c|}
\hline \multicolumn{2}{|l|}{ Characteristic } & \multirow{2}{*}{$\begin{array}{c}\text { No } \\
(\%) \\
26(15)\end{array}$} & \multirow{2}{*}{$\begin{array}{c}\text { Mean } \\
(\mathrm{Yr})\end{array}$} & \multirow{2}{*}{$\begin{array}{c}\text { Min - } \\
\operatorname{Max}(\mathrm{Yr})\end{array}$} \\
\hline Any previous & Yes & & & \\
\hline management training? & No & $142(84)$ & & \\
\hline & Missing (not answered) & $2(1.2)$ & & \\
\hline \multirow{3}{*}{$\begin{array}{l}\text { Previous experience with } \\
\text { management tasks? }\end{array}$} & Yes & $98(58)$ & & \\
\hline & No & $70(41)$ & & \\
\hline & Missing (not answered) & $2(1.2)$ & & \\
\hline \multirow{3}{*}{$\begin{array}{l}\text { Attention for } \\
\text { management training at } \\
\text { current workplace? }\end{array}$} & Yes & $21(12)$ & & \\
\hline & No & $147(87)$ & & \\
\hline & Missing (not answered) & $2(1.2)$ & & \\
\hline
\end{tabular}

\section{Needs assessment}

Of the 170 residents, 85\% ( $n=145)$ reported a need for management training and 50\% $(n=86)$ agreed or strongly agreed that there was not enough attention for management tasks during their clinical training. The vast majority of the respondents ( $n=164)$ answered the question 'In what topics would you like to be trained?' by selecting their preferred topics (see Figure 1). Most residents chose negotiation skills ( $n=119)$, specialist partnerships $(n=108)$, health care system $(n=97)$ and career opportunities $(n=96)$ as topics they want to be trained in. The topics electronic databases $(n=21)$, cost-effectiveness towards diagnosis and treatment $(n=18)$ and medical computer systems ( $n=13)$ were least frequently chosen. On the question regarding preferred training method, 'workshop' was chosen most often: 143 of the 164 residents that answered this question chose 'workshop' eventually in combination with another preferred training method. The other preferred training methods included interactive training ( $n=64)$, case-based training ( $n=56)$, web-based training $(n=49)$, lectures ( $n=46)$ and discussion groups $(n=42)$, see figure 2 . With respect to the instructor of choice, the residents preferred 'medical specialists' ( $n=140)$ and 'extramural instructor or experts' ( $n=140)$ as training instructors, while only a few chose 'hospital managers' as preferred training instructor $(n=36)$. The most frequently chosen answer to the question 'I would prefer the training venue to be at...' was 'the workplace' $(n=158)$; other answers included 'university location' ( $n=52)$, and 'other' ( $n=13)$.

The residents were also asked how long they felt such management training should last, where it should take place and what the preferred timing for management training should be during the program. On the item that specifically asked how long the training should last, i.e. 'I would like a training that lasts...', 141 of the received responses were eventually 


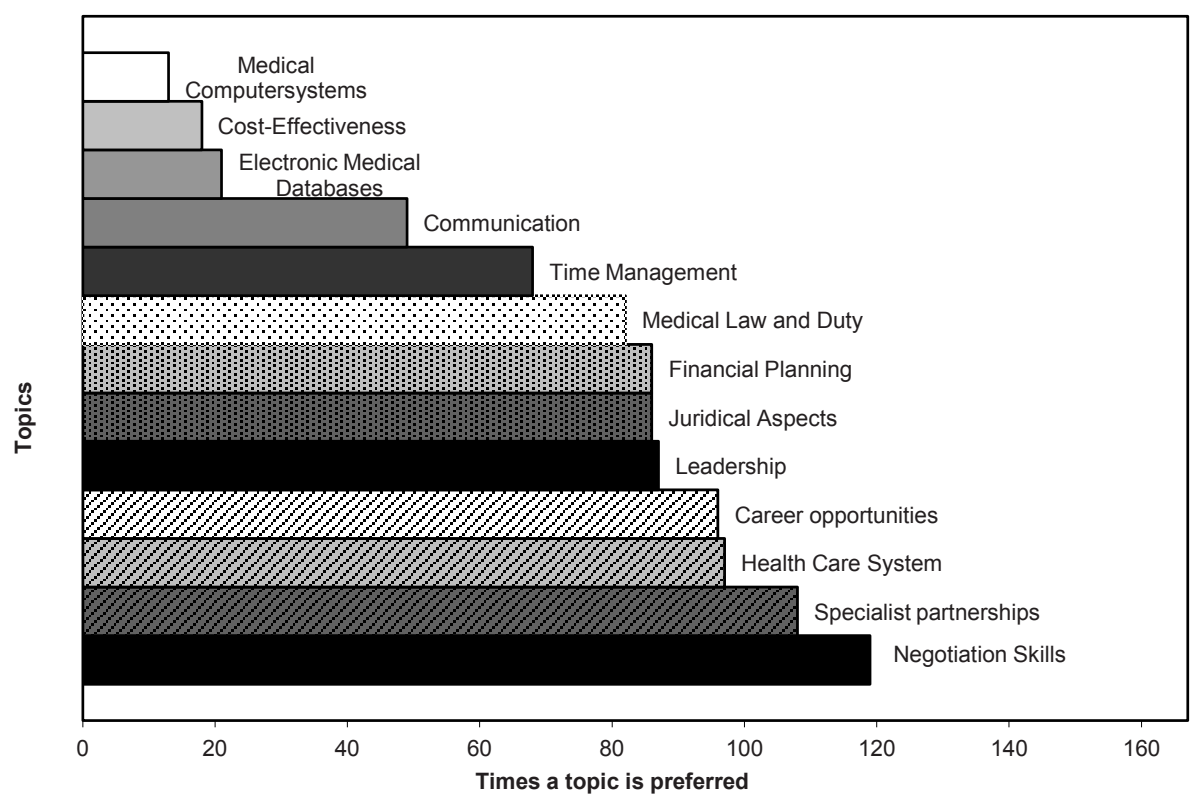

Figure 1. Number of times a topic has been chosen by residents to be trained in ( $\mathrm{n}=164$ residents)

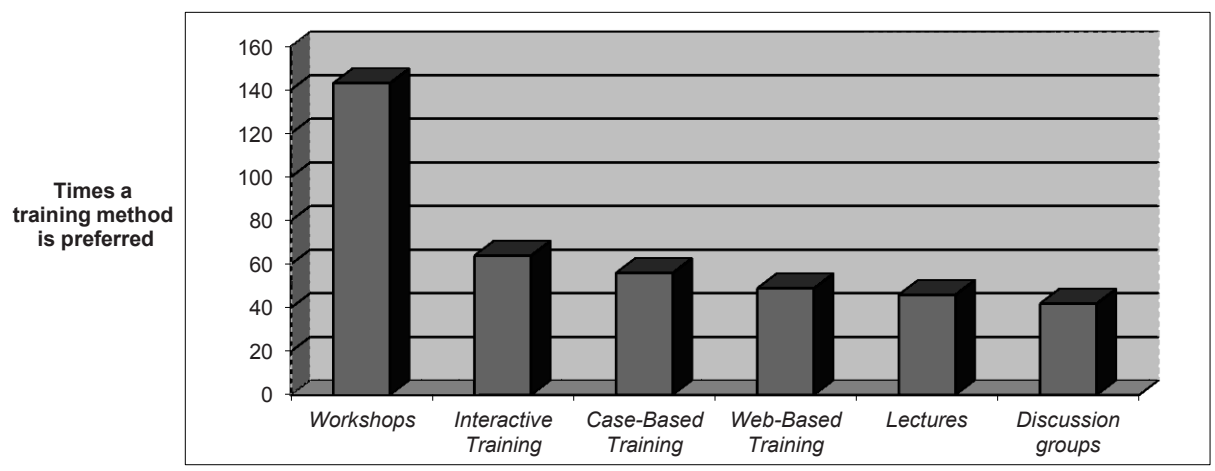

Training Methods

Figure 2. Number of times a topic has been chosen by residents as 'preferred training method' ( $n=164)$

eligible for analysis. This was because some of the data were not properly answered. For example, some respondents filled in the preferred number of hours a single training session should last instead of the number of hours a whole course should last. The respondents' preferred duration of the training ranged from 1 to 400 hours, with a mean of 17 hours. On the question how long the length of the training should be i.e. 'During what 
period a training should take place?', 106 of the 161 submitted responses were useful for analysis. The length of the program that residents preferred most, was one spread over days ( $n=42$ times) or years ( $n=43$ times). A training period spread over months ( $n=19$ times) or weeks ( $n=2$ times) was not a preferred choice. 168 residents answered the question on the timing of training and participating in the training during the residency was the most frequently chosen option ( $n=162)$, see table 2 .

Table 2. Resident's answers to the question "Timing of training..." (n=168 residents)

\begin{tabular}{lc}
\hline Timing of training (during...) & Frequency* \\
\hline Medical school & 42 \\
Pre-residency period & 37 \\
Residency & 163 \\
When working as a Specialist & 32 \\
\hline
\end{tabular}

* Number of times a timing is chosen as 'preferable timing'

Table 3. Analysis of a possible correlation between a need for training and five variables by using Chisquare tests and Fisher's exact tests ( $n=170)$

\begin{tabular}{|c|c|c|c|c|c|}
\hline \multirow[t]{2}{*}{ Variable } & & \multicolumn{2}{|c|}{ Need for Training } & \multirow{2}{*}{$\begin{array}{c}\text { Chi-square } \\
\text { test }(p=)\end{array}$} & \multirow{2}{*}{$\begin{array}{c}\text { Fisher's } \\
\text { exact test } \\
(p=)\end{array}$} \\
\hline & & Yes $(n=)$ & No $(n=)$ & & \\
\hline \multirow[t]{2}{*}{ Gender } & Male & 50 & 6 & & \multirow{2}{*}{0,397} \\
\hline & Female & 93 & 19 & 0,470 & \\
\hline \multirow[t]{2}{*}{ Specialty } & Surgical & 47 & 6 & & \\
\hline & Non-surgical & 90 & 19 & 0,312 & \\
\hline \multirow[t]{2}{*}{ Working Venue } & Academic & 100 & 17 & & \multirow{2}{*}{-} \\
\hline & Rural & 45 & 8 & 0,923 & \\
\hline \multirow{2}{*}{$\begin{array}{l}\text { Experience with training } \\
\text { and/or tasks }\end{array}$} & Yes & 54 & 12 & & \multirow{2}{*}{-} \\
\hline & No & 89 & 13 & 0,334 & \\
\hline \multirow{3}{*}{$\begin{array}{l}\text { Number of years of clinical } \\
\text { work experience }\end{array}$} & Low (0-2 years) & 37 & 7 & \multirow{3}{*}{0,750} & \multirow{3}{*}{-} \\
\hline & Mean (2-5 years) & 59 & 12 & & \\
\hline & High (> 5 years) & 44 & 6 & & \\
\hline
\end{tabular}

Data were analyzed to determine if there was a relationship between the perceived need for management training and gender, specialty, hospital setting, previous experience with management tasks and/or training and the number of years of clinical experience. The p-value of all these variables was $>0.05$, see table 3 . 


\section{Chapter 4}

\section{DISCUSSION}

The purpose of this study was to investigate whether there was a need for management training among Dutch medical residents and if so, what the preferred form of intervention was. We were also interested in knowing if residents' personal characteristics were of any influence on the perceived needs and preferred choice of training in medical or practice management.

The results of our study showed that there was a clear need for management training among Dutch medical residents. This was demonstrated by $85 \%$ of our respondents reporting a need for training in (practice) management skills. Results also revealed that the need for training in management skills was independent of gender, number of years of clinical experience, specialty, training location and prior experience with management training and/or tasks.

The findings of our study showed that in developing their managerial competencies, medical residents had specific preferences for the method of intervention. For example, the preferred method of instruction was the workshop and specialist physician-managers or external content experts were the preferred instructors. The residency period was the moment within the continuum of the medical training that the residents felt they needed training in managerial skills and the suggested average duration for the training was 17 hours, spread over a period of a couple of days to years. It was also interesting to find that the preferred method and timing of the training of residents in our study was similar to that in other studies. For example, Sockalingam and colleagues and Maggi and colleagues found that workshops were the preferred method of learning among psychiatry residents $(6,7)$. Williford and colleagues reported that obstetrics and gynaecology residents felt that management instruction should be designed for residents, fellows and faculty rather than for medical students and interns. Furthermore, the recommended total (mean) duration of the course was 19.54 hours, with a clear preference for designated time for practice management on an annual basis (9).

The respondents in our study also preferred an intervention (i.e. course or training) that dealt with topics on how to develop effective negotiation skills, partnerships with specialist or team practices, career planning skills and better knowledge of health care systems. These findings differed however from those reported by Williford and colleagues. Of the five courses that were ranked in the top ten of potential course topics by residents, former residents and practice executives in their study, only one was similar to ours (e.g. contractual agreements between physicians). The remaining four topics managed care, billing procedures, practice economics and patient record management were different (9). A possible explanation for this difference might be effects of the ongoing changes 
in various health care systems (e.g. introduction of electronic patient record) as well as the reform in residency training programs, as the needs- assessment in Williford and colleagues was conducted in the late 90's (9). Nonetheless, partnerships with specialist or team practices seem to be a topic in which residents still need training.

We also discovered differences between our findings and those of more recent studies on needs assessments. There were some topics that were mentioned in these studies that we did not identify in ours (e.g., physician compensation, program planning and innovation and leading change). A possible explanation for this difference could be the method used in these studies to identify the residents' preferred topics. For example, in the studies by Sockalingam and colleagues and Maggi and colleagues, a questionnaire was developed to address gaps in physician-manager knowledge and skill-areas in psychiatry residents. The preferred topics were subsequently derived from the gaps identified between the residents' knowledge and skills $(6,7)$. In our study, we asked residents directly to select those topics in which they wanted training. Another possible explanation for these differences could be related to the mix of the respondents in the surveys. In our study, residents from different specialties were included in the survey, while in the studies by Sockalingam and colleagues and Maggi and colleagues, only psychiatry students participated in them $(6,7)$.

In addition to the findings described above, there are a few of limitations in our study that are worth mentioning. To begin with, our survey had a relatively low response rate of $35 \%$. On examination of the literature however, we discovered that the reported average response rate for most studies that employed electronic questionnaires was 35-50\% (2527). The possible explanations for the low response rate in our study, include the difficulty we had in reaching and enrolling all the residents in the Atrium Medical Centre in the survey. The first invitation for the survey was sent to their email accounts in the hospital, which turned out not to be in use by most of the residents. As a result, we had to send a second email to their private email accounts to ensure they received the invitation and the link to the questionnaire. Other possible explanations for the low response rate were the heavy workload in the clinics that may have prevented the residents from finding/creating time (or being motivated) to respond to our survey, the lack of incentives for participating in the survey or simply the lack of interest in management education among the medical residents we approached. Bearing this last point in mind, it is important to note that there is a potential risk of non-response bias in our results. Our assumption is that residents who are interested in management training might have been more motivated to participate in our survey than those who were not, making it possible that the need for management training might be more among the general resident population than what our results actually reported (i.e., underreporting bias). 


\section{Chapter 4}

The baseline characteristics of the respondents in our study also showed some notable results worthy of elaboration. First of all, the majority of the residents who participated in the survey were female. This observation reflects the current state of the male to female distribution of trainee physicians in medical institutions in the Netherlands. Secondly, the paediatric, obstetrics \& gynaecology and internal medicine specialties were overrepresented in our survey and can be explained by the fact that we only approached paediatrics and obstetrics \& gynaecology residents in two of the four hospitals. The overrepresentation of internal medicine in the survey however, might be due to the high number of residents that were enrolled within the specialty i.e. volume. However, this cannot be said for the surgical residents who despite a similarly large volume of trainees showed poor participation (i.e., $\mathrm{n}=3$ ). We do not have a clear explanation for why their participation was poor; although we assume that it could be due to a lack of interest in management training by residents in this specialty or them feeling better equipped with managerial skills and knowledge and thus not feeling the need to respond to the questionnaire. Nonetheless, despite the several possible explanations for the wide distribution of responses, we are aware that results of our survey should be interpreted with caution.

The exclusion of family medicine residents in our survey is another limitation, knowing that the development of management competencies of physicians do play an important role in this specialty. It is possible that the perceived need for management training in this survey might have been lower if residents in family medicine were also included in the survey. Our findings should therefore be generalized with caution, as they reflect the perceptions of residents in hospital-based specialties alone.

The open-ended questions regarding the number hours a training intervention should last and the period training should occur were also not clearly stated. Many participants failed to answer this question correctly and again, one should be careful in concluding that the preferred length of training should last 17 hours and be spread over days or years.

A course aimed at developing management skills during the residency program (and taking into account the specific needs of the respondents) is currently being developed in our centre, based on the findings of this survey. One may argue the legitimacy of developing a specific intervention based on the findings of this study alone, since our research focused on the subjective needs and preferences of residents and did not objectively investigate the need for management training or the deficiencies in residents' managerial competencies. For this reason, it might be helpful to increase the validity our findings by examining the perceptions of program directors and specialists-physicians on this topic as well.

Finally, as this is a preliminary study in which a survey was used to assess the perceived need for management education, it does not represent an objective assessment of the 
need for management education among medical residents. Our (subjective) findings indicate that residents find management training to be necessary, but further (objective) research is needed to confirm this. For example, by assessing the quality of specific skills or gaps in residents' managerial competencies or by assessing the perceptions of program directors and specialists-physicians on residents' managerial competencies.

\section{CONCLUSIONS}

This study of medical residents' perceptions of their need for training in practice management skills clearly demonstrates that Dutch medical residents desire formal and structural instruction on this subject. Similar to other findings in the literature, Dutch medical residents report a clear need for management training and prefer a program that covers topics on negotiation skills, specialist partnerships, career planning and health care system. The preferred method of instruction should be a workshop in the hospital environment and with a specialist physician manager or external content expert as training instructor. Furthermore, the training should take place during residency. Despite some limitations of our study, these findings indicate that a management training intervention is necessary during residency. Residents have specific training preferences for such an intervention, which course developers should bear in mind when developing such a program. We believe that more (objective and valid) research on this subject would be helpful in developing specific and effective training interventions. 


\section{REFERENCES}

1. The CanMEDS 2005 competency Framework.Ottawa: Royal College of Physicians and Surgeons of Canada. 2006 [cited 2010 November 11]. Available from: http://rcpsc.

2. medical.org/canmeds/CanMEDS2005/ index.php

3. Berkenbosch L, Brouns JWM, Heyligers I, Busari JO. How Dutch medical residents perceive their competency as manager in the revised postgraduate medical curriculum.

4. Heerlen: Atrium Medical Center and University of Maastricht, Unpublished Article, 2010.

5. Busari JO, Berkenbosch L, Brouns JWM. Physicians as managers of health care delivery and the implications for postgraduate medical training: a literature review. Teach Learn Med. 2010 in press.

6. Chan S. Management education during radiology residency: development of an educational practice. Acad Radiol. 2004;11:1308-17.

7. Crites GE, Schuster RJ. A preliminary report of an educational intervention in practice management. BMC Med Educ. 2004;4:15.

8. Maggi JD, Stergiopoulos $V$, Sockalingam S. Implementing a new physician manager curriculum into a psychiatry residency training program: the change process, barriers and facilitators. Psychiatr Q. 2008;79:21-31.

9. Sockalingam S, Stergiopoulos V, Maggi J. Residents' perceived physician-manager educational needs: a national survey of psychiatry residents. Can J Psychiatry. 2008;53:745-52.

10. Tobin M, Edwards JL. Are psychiatrists equipped for management roles in mental health services? Aust N Z J Psychiatry. 2002;36:4-8.
11. Williford LE, Ling FW, Summitt RL, Jr., Stovall TG. Practice management in obstetrics and gynecology residency curriculum. Obstet Gynecol. 1999;94:476-9.

12. Essex B, Jackson RN. Moneymed: a game to develop management skills in general practice. J R Coll Gen Pract.1981;31:735-9.

13. Babitch LA. Teaching practice management skills to pediatric residents. Clin Pediatr (Phila). 2006;45:846-9.

14. Bayard M, Peeples CR, Holt J, David DJ. An interactive approach to teaching practice management to family practice residents. Fam Med. 2003;35:622-4.

15. Hemmer PR, Karon BS, Hernandez JS, Cuthbert C, Fidler ME, Tazelaar HD. Leadership and management training for residents and fellows: a curriculum for future medical directors. Arch Pathol Lab Med. 2007;131:610-4.

16. Horowitz RE, Naritoku W, Wagar EA. Management training for pathology residents: a regional approach. Arch Pathol Lab Med. 2004;128:59-63.

17. Junker JA, Miller T, Davis MS. Practice management: a third-year clerkship experience. Fam Med. 2002;34:87-9.

18. Amin AN. A business of medicine curriculum for medical students. Med Educ. 2005;39:510-1.

19. Kaur $\mathrm{N}$, Singh $\mathrm{T}$. Introducing medical students to health care management. Med Educ. 2009;43:1090-1.

20. Mirowitz SA. Development and assessment of a radiology core curriculum in health care policy and practice. Acad Radiol. 2000; 7:540-50.

21. Sims KL, DarcyTP.Aleadership-management training curriculum for pathology residents. Am J Clin Pathol. 1997;108:90-5. 
22. Piatt JP, Bartley DL, Jacobson AD, Rimsza ME. Practice management training for pediatric residents. Am J Dis Child. 1991;145:299-301.

23. Brugnara C, Fenton T, Winkelman JW. Management training for pathology residents. I. Results of a national survey. Am J Clin Pathol. 1994;101:559-63.

24. Stergiopoulos V, Maggi J, Sockalingam S. Teaching the physician-manager role to psychiatric residents: and implementation of a pilot curriculum. Acad Psychiatry. 2009;33:125-30.

25. Yu-Chin R. Teaching administration and management within psychiatric residency training. Acad Psychiatry. 2002;26:245-52.

26. Lawson JG, McConnell JW. Teaching practice management in a family practice residency. J Med Educ. 1976;51:858-60.

27. Greenlaw C, Brown-Welty S. A comparison of webbased and paper-based survey methods: testing assumptions of survey mode and response cost. Eval Rev. 2009;33:464-80.

28. Sheehan K. E-mail survey response rates: A review. Journal of Computer Mediated Communication. 2001;6:1-20.

29. Assessment Doll. Response rates. Austin: The University of Texas, 2010. 


\section{Chapter 4}

\section{APPENDIX 1: QUESTIONNAIRE Needs assessment}

- There is not sufficient time given to management responsibilities and management training at my work place.

Answers: I totally agree, I agree, Neutral, I disagree, I totally disagree

- I have a need for training in management competencies.

Answers: Yes, No

- I would prefer extra teaching/training in the following topics (multiple answers possible)...

Answers: Career options, Financial Planning, Negotiation skills e.g. contract negotiation, Time management, Health Care System, Specialist Partnerships, Leadership, Juridical Aspects of Medical Mistakes, Medical Law and Duty, Communication, Medical Cost-effectiveness of Diagnosis and Treatment, Medical Computer Systems, Electronic Medical Databases, Other (please specify), I don't need training

- I would like training which uses the following method (multiple answers possible...) Answers: Lectures, Workshop, Discussion Groups, Interactive training, Case-Based training, Web-Based Training, Other (please specify), I don't need training

- I would prefer the following as an instructor in developing my management competencies... (multiple answers possible...)

Answers: Physician, Extramural Expert, Hospital Manager, Other (please specify), I don't need training

- I would prefer the venue of the training to be at... (multiple answers possible) Answers: My Workplace (e.g. hospital, private practice), A University Location, Other (please specify), I don't need training

- I would like a training that lasts... (fill in 0 hours if you don't need training) Open ended question

- During what period should a training take place? (e.g. during one day, spread during a month, spread during a year)

open ended question

- $\quad$ Timing of training...

Answers: during Medical School, during Pre-Residency Period e.g. Senior House Officer, during Residency, When Working as a Specialist, I don't need training 


\section{Personal Characteristics}

- Gender

Answers: Male, Female

- Age and Medical Training: Age (for example 26 years), Year of Graduation (for example 2006), University (for example Maastricht University)

Open ended questions

- Work experience: I work in the following specialty (for example pediatrics)..., Total years of work experience as a resident/senior house officer (for example 2 years)..., Current training year in your specialty (fill in 0 years if not undergoing training for a certain specialty)...

Open ended questions

- Besides medicine I also undertook a training/curriculum/course which contributes to my functioning as a manager...

Answers: No I have not undertook such training, Yes I undertook the following training/ curriculum/course (please specify)

- I have had experiences which can contribute to my functioning as a manager...

Answers: No I don't have, Yes I have had the following experiences (for example sorority life, study club, sports club, etcetera).

- During my training, focused training has been spent on the management role of physicians...

Answers: No, Yes namely (please specify)

- After finishing my postgraduate medical training, I would like to work in a... (multiple answers possible)

Answers: Teaching (Academic) Hospital, General Hospital, Practice (private or family), I don't know yet, Other (please specify) 



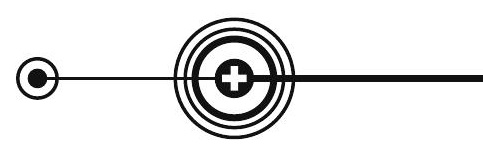

\section{Chapter 5}

How Dutch medical specialists perceive the competencies and training needs of medical residents in healthcare management.

Berkenbosch L, Bax M, Scherpbier A, Heyligers I, Muijtjens A, Busari JO Medical Teacher 2013; 35: e1090-e1102

$€$
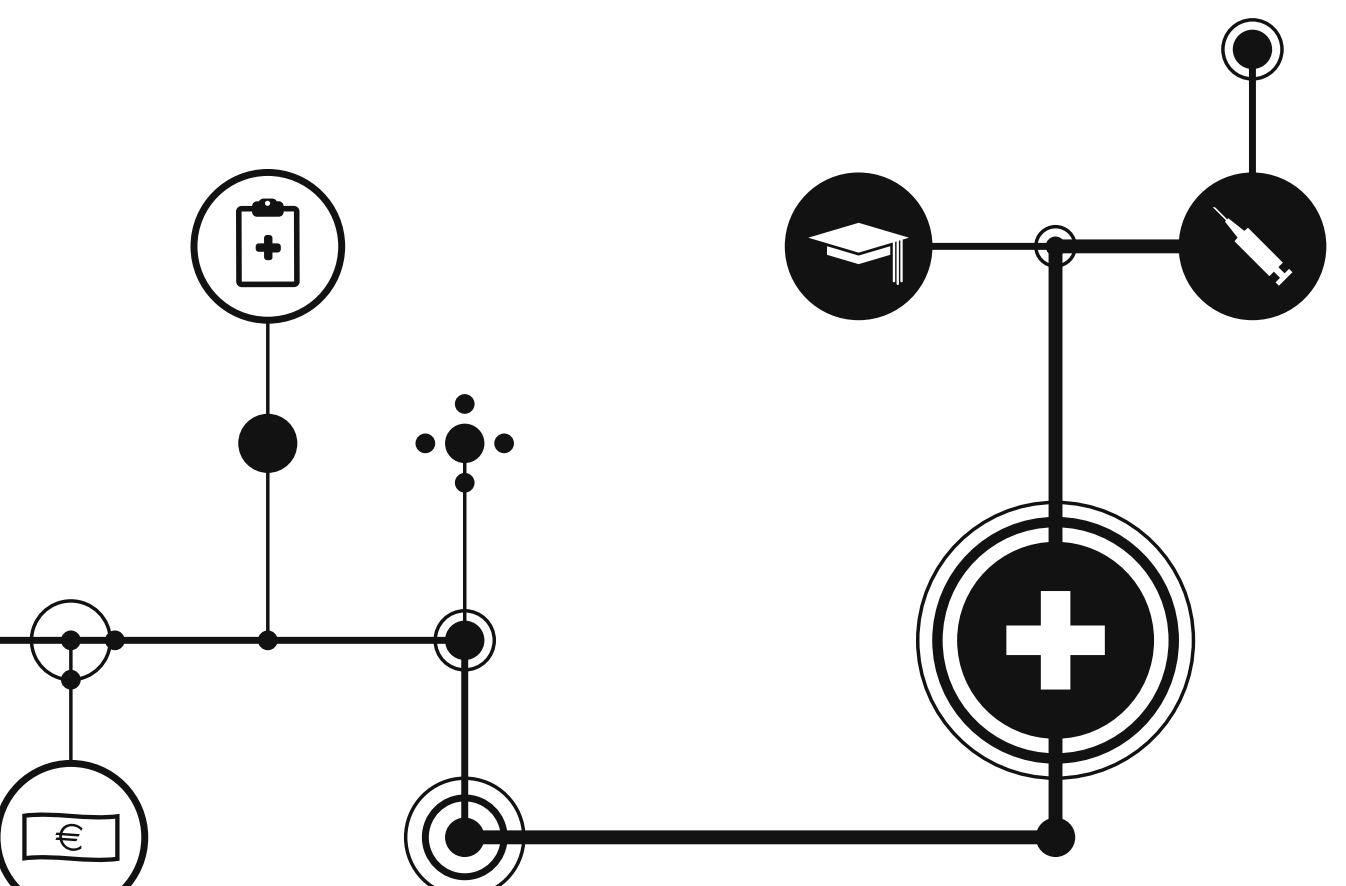


\section{Chapter 5}

\section{ABSTRACT \\ Background}

The Dutch postgraduate medical training has been revised to focus on seven competencies. The role as manager is one of these competencies. Recent studies show that this competency receives little attention during the residency training. In an earlier study we discovered that residents perceived their competency as managers to be moderate.

\section{Aims}

In this study, we investigated how medical specialists perceived the managerial competencies of medical residents and their need for management education.

\section{Methods}

In September 2010, a 46-item questionnaire was designed which examined medical specialists' perceptions of the competency and needs of residents in the field of medical management. Two-hundred-ninety-eight specialists were invited via email to participate.

\section{Results}

Hundred-twenty-nine specialists (43.3\%) responded to our survey. They rated the residents' competencies in contract negotiating skills, knowledge of the healthcare system and specialist department poorly. They felt that residents were competent in updating their medical knowledge. Ninety-four percent reported a need for training in management among residents. Preferred topics were time management and healthcare-organization. The preferred training method was a workshop given during residency by an extramural expert.

\section{Conclusion}

Dutch medical specialists perceive the management competencies of residents in some areas to be inadequate. They feel that training in medical management during residency is necessary. 


\section{INTRODUCTION}

On the first of January 2005, all residency-training programs in the Netherlands formally began using a new competency based curriculum to train their medical residents. Like the CanMEDS framework, the new curriculum comprised seven competencies that residents were expected to possess upon graduation (i.e. medical expert, communicator, collaborator, manager, health advocate, professional and scholar) (1). Six years after its inception however, the physicians' role as manager still appears to receive little attention in both the undergraduate and postgraduate training programs. This is concerning, particularly when one considers that in order to practice effectively, physicians should possess good managerial skills.

The first studies on this subject date back to the late seventies and early eighties and showed that family medicine was one of the first specialties to develop practice-management training during the residency period (2-6). Only in the last 10 to 15 years has there been a broader interest for this subject among other specialties and stakeholders in health care delivery, resulting from the increasing costs and challenges related to access and quality of health care (7-11). Unfortunately, despite these developments, a number of studies still report that physicians do not feel as adequately prepared for their role as managers as for the other roles (12-14). In a recent review that we conducted, we found that when a needs assessment was performed among residents or specialists, they all reported a need for management training. We also discovered that management curricula have been incorporated into the medical programs of several institutions and although there was no consensus on the content, duration, timing and educational methods for management training, all of the implemented programs were evaluated positively (11).

Based on our observation that the role as manager receives sparse attention in the Dutch postgraduate medical training, we decided to investigate the situation in the Netherlands. In 2009 we designed a questionnaire to examine the perceived competence and needs of Dutch medical residents. We found that residents in the Netherlands perceived their knowledge and skills in certain essential medical management concepts to be inadequate. Sixty percent of the respondents did not feel confident in their (contract) negotiating skills and 56\% stated that they lacked sufficient knowledge of how the Dutch healthcare system is financed and organized. About one-third gave neutral ratings in negotiating career prospects, possessing adequate leadership skills, knowledge of the legal aspects of healthcare and how to deal with medical errors (15). The results also showed that the majority (85\%) of the residents reported a need for management training (16). 


\section{Chapter 5}

These results confirmed the findings in the existing literature and our hypothesis that residents in the Netherlands perceive a lack in managerial knowledge and skills and that the majority would like to receive management training. Since our ultimate goal was to develop a management course for Dutch medical residents we wanted to examine the problem from different perspectives. There have been several studies on the management needs of medical specialists $(8,9,17)$, but as far as we know there has been no research on how specialists perceive the management competencies of their residents. We decided to investigate how medical specialists perceived the managerial competencies of medical residents and if they felt that residents lacked specific management skills or knowledge in certain areas. We also wanted to investigate what medical specialists thought a management course for the residents should comprise.

\section{METHODS \\ Designing the survey}

In September 2010, we designed a survey for the medical specialists based on the previous questionnaire for residents $(15,16)$. The questionnaire was modified for the new purpose and for review sent to an expert panel consisting of ten persons of which two were educational psychologists, two were educationalists and six were medical specialists. Based on the feedback we received, we added two questions to the questionnaire (on preventive healthcare and employment of potential colleagues).

The final questionnaire consisted of 30 statements about the management competency of residents which covered four areas of practice management namely: 1. the balance between patient care and personal development, 2. effectively operating within the health care setting, 3. allocating finite healthcare resources appropriately and 4. using information technology to deliver optimal healthcare. The respondents were asked to rank their perceived level of competence of the residents on a 5-point Likert-scale, with 1: completely disagreeing, and 5: completely agreeing with a statement (see appendix 1). There were seven items which assessed how medical specialists perceived the need for management education among medical residents (training variables). This section not only investigated the need for management training for the residents, but also the preferred management topics, the preferred method of instruction, when the training should take place and the length of the training.

Finally there were nine questions about the demographic characteristics of the specialists (background variables) i.e. age, gender, years of work experience, possession of a PhD, specialty (surgical vs. non-surgical specialties), hospital (university vs. district teaching hospitals), previous management experience (e.g. chair(wo)man of a committee) and 
previous management education (e.g. a management course) and if they had management training at their current workplace. We were interested to find out whether some of these background variables were associated with the specialists' perceptions of the management competencies and the management education needs of their residents.

\section{Data collection}

We emailed this survey to all specialists in the Atrium Medical Centre, Heerlen and to specialists in Maxima Medical Centre, Veldhoven and in the Catharina Hospital, Eindhoven. The pediatricians in Maastricht University Medical Centre, Maastricht also received the survey. As the study was a web-based survey (using the Survey Monkey web application) links to the questionnaire were sent to all of the participants by email. They could fill in the questionnaire anonymously. The duration of the survey was six weeks and reminders were sent by email twice in Heerlen and once in Veldhoven and Eindhoven. Prior to starting the survey, we sought for and obtained ethical approval from our hospitals research and ethics committee.

\section{Data analysis}

Analysis was performed using SPSS, version 17. Descriptive statistics were used to present the demographic distribution of the participants. An explorative factor analysis was performed to identify if there were underlying clusters of items (scales) in the questionnaire. Cronbach's alpha analysis was used to test the reliability of the resulting scales and to decide which low-contributing items should be removed from the scale. For the final scales, scale scores were obtained by calculating the mean score of the corresponding items. Whether the specialist's perceptions as expressed by these scale variables are influenced by background variables was investigated using multiple regression analysis. The scale variables formed the dependent variables in the analysis and the background variables were the independent variables. In order to reduce the number of (dummy) variables, we selected the following background variables of interest: Gender, Work experience_ log, Management training, Management experience, Surgical and PhD degree holder. Gender was defined $0=$ Male, and $1=$ Female. Work experience (in years) was expected to have a skewed distribution and was therefore replaced by Work experience_log $=\log _{10}$ (Work experience). Management training was defined as $0=\mathrm{No}$ and $1=\mathrm{Yes}$, Management experience was defined $0=\mathrm{No}$ and $1=$ Yes. The variable "surgical" was used as a binary version of Specialty and defined as follows: Surgical=1 if Specialty=Surgery, Orthopedics, Gynecology, Ear, Nose and Throat or Urology and 0 otherwise. PhD degree holder was defined $0=$ No and $1=$ Yes. The relationship between the perceived need for management training and the background variables mentioned above was investigated by analyzing 


\section{Chapter 5}

the corresponding cross tables using Fisher's exact test to assess the significance of the association.

\section{RESULTS}

A total of 298 specialists were approached via email to participate in the survey. Of this total, 129 questionnaires were returned (overall response rate: 43.3\%). One hundred twenty-one specialists filled in the questionnaire completely. The dropout rate (failure to complete the survey) was $6.0 \%(n=8)$. One of the specialists reported a problem with the questionnaire in the personal characteristics section, which was solved. There were no other reasons given for not completing the questionnaire.

\section{Specialists' characteristics}

The mean age of the specialists was 47.0 years (SD 8.5) (Table 1). Seventy-six percent (92/121) of the respondents were male. Specialists from twenty different specialties completed the survey, with Pediatrics (25/121, 19.4\%), Surgery (14/121, 10.9\%) and Internal Medicine $(12 / 121,9.3 \%)$ being the largest response groups. The average years of work experience was 13.2 years (SD 9.1). Fifty-six percent (68/121) of the respondents reported not to have any formal management training at their current workplace, 51.2\% (62/121) had management training at some point in their career and 72\% (87/121) reported to have had some previous experience in a management or leadership function.

\section{Explorative Factor Analysis}

For the 30 competency items, explorative factor analysis (EFA) was performed using 4-6 factors consisting of principal components analysis and oblique rotation. After removal of ambiguous items (loading difference less than 0.1) and low loading items (loading less than 0.4 ), the EFA was repeated. In the reliability analysis, the resulting scales were investigated for items that did not positively contribute to the reliability. Using these indications three items were removed, and for the remaining set of 27 items a satisfactory 4-factor solution was obtained (explained variance equal to 49\%). Table 2 shows the resulting loadings for this solution (loadings $<0.1$ not shown), a grey background indicating subsets of items associated with each factor (scale). By the content of their corresponding items the four scales were indicated "Leadership and Management", "Organization and Finance", "Operational Management", and "Professional Ethics and Health Law", respectively. The reliability (Cronbach's alpha) of each scale amounted to 0.85, 0.78, 0.72 and 0.81 respectively. 
Table 1. Characteristics

\begin{tabular}{|c|c|c|c|c|c|}
\hline \multirow{2}{*}{ Characteristic } & & \multirow[b]{2}{*}{ Code } & \multicolumn{2}{|c|}{$\begin{array}{l}\text { Responding } \\
\text { specialists } \\
n=121\end{array}$} & \multirow{2}{*}{$\begin{array}{c}\text { Dutch } \\
\text { specialists } \\
\text { n=12,906 } \\
\begin{array}{c}\text { Number } \\
(\%)\end{array}\end{array}$} \\
\hline & & & $\begin{array}{c}\text { Number } \\
(\%)\end{array}$ & $\begin{array}{l}\text { Mean } \\
(S D)\end{array}$ & \\
\hline \multirow[t]{2}{*}{ Gender } & Male & 0 & $92(76.0)$ & & $8,423(65.3)$ \\
\hline & Female & 1 & $29(24.0)$ & & $4,483(34.7)$ \\
\hline Age (years) & & & & $47.0(8.5)$ & \\
\hline \multirow[t]{18}{*}{ Specialty ${ }^{1}$} & Cardiology & 0 & $6(4.7)$ & & $1,039(8.1)$ \\
\hline & Clinical physicist & 0 & $2(1.6)$ & & -5 \\
\hline & Dermatology & 0 & $3(2.3)$ & & $526(4.1)$ \\
\hline & ENT specialist & 1 & $4(3.1)$ & & $527(4.1)$ \\
\hline & Emergency dep. & 0 & $3(2.3)$ & & - \\
\hline & Geriatrics & 0 & $1(0.8)$ & & $197(1.5)$ \\
\hline & Gynecology & 1 & $10(7.8)$ & & $1,050(8.1)$ \\
\hline & Intensive Care & 0 & $3(2.3)$ & & - \\
\hline & Internal medicine & 0 & $12(9.3)$ & & $2,138(16.6)$ \\
\hline & Lung specialist & 0 & $2(1.6)$ & & $595(4.6)$ \\
\hline & Medical rehabilitation & 0 & $5(3.9)$ & & 499 (3.9) \\
\hline & Neurology & 0 & $9(7.0)$ & & $912(7.1)$ \\
\hline & Orthopedics & 1 & $7(5.4)$ & & $717(5.6)$ \\
\hline & Pediatrics & 0 & $25(19.4)$ & & $1,505(11.7)$ \\
\hline & Radiology & 0 & $7(5.4)$ & & $1,148(8.9)$ \\
\hline & Rheumatology & 0 & $3(2.3)$ & & $287(2.2)$ \\
\hline & Surgery & 1 & $14(10.9)$ & & $1,342(10.4)$ \\
\hline & Urology & 1 & $5(3.9)$ & & $424(3.3)$ \\
\hline Work experience (years) & & & & $13.2(9.1)$ & - \\
\hline \multirow{2}{*}{$\begin{array}{l}\text { Previous management } \\
\text { training }\end{array}$} & Yes & 1 & $62(51.2)$ & & - \\
\hline & No & 0 & $59(48.8)$ & & - \\
\hline \multirow{2}{*}{$\begin{array}{l}\text { Previous management } \\
\text { experience }\end{array}$} & Yes & 1 & 87 (71.9) & & - \\
\hline & No & 0 & $34(28.1)$ & & - \\
\hline \multirow{2}{*}{$\begin{array}{l}\text { Management training at } \\
\text { current workplace }\end{array}$} & Yes & 1 & $53(43.8)$ & & - \\
\hline & No & 0 & $68(56.2)$ & & - \\
\hline \multirow[t]{2}{*}{ PhD } & Yes & 1 & $61(50.4)$ & & - \\
\hline & No & 0 & $60(49.6)$ & & - \\
\hline \multirow[t]{4}{*}{ Workplace } & Eindhoven $(\mathrm{DTH})^{2}$ & & $23(17.8)$ & & - \\
\hline & Heerlen (DTH) & & $62(48.1)$ & & - \\
\hline & Maastricht $(\mathrm{UTH})^{3}$ & & $13(10.1)$ & & - \\
\hline & Veldhoven (DTH) & & $31(24.0)$ & & - \\
\hline
\end{tabular}

${ }^{11}=$ Surgical specialty, $0=$ Non-surgical specialty, ${ }^{2}$ District Teaching Hospital, 3 University Teaching Hospital, ${ }^{4}$ As registered in the Netherlands in 2012, ${ }^{-}$= National data on this characteristic was not found 


\section{Chapter 5}

Table 2. Pattern Matrix

\begin{tabular}{|c|c|c|c|c|}
\hline \multirow[t]{2}{*}{ Items } & \multicolumn{4}{|c|}{ Component $^{1}$} \\
\hline & 1 & 2 & 3 & 4 \\
\hline Leadership skills & 0.74 & & & 0.17 \\
\hline Dealing with conflicts & 0.70 & & & \\
\hline Managing a ward & 0.67 & & & \\
\hline Handling received feedback & 0.65 & & -0.12 & \\
\hline Improving quality processes & 0.61 & & 0.13 & \\
\hline Patient care vs. practice requirements & 0.58 & 0.15 & -0.10 & \\
\hline Giving feedback & 0.55 & & -0.19 & -0.19 \\
\hline Time management & 0.53 & & 0.13 & -0.15 \\
\hline Leading a committee & 0.49 & 0.2 & 0.16 & 0.12 \\
\hline Policy new colleagues & 0.46 & & 0.22 & -0.18 \\
\hline Create career opportunities & 0.43 & & & \\
\hline Personal financial situation & & 0.78 & & \\
\hline Organisation specialist department & & 0.73 & & \\
\hline Negotiate working conditions & & 0.72 & & \\
\hline Organisation health care system & 0.21 & 0.62 & & \\
\hline Requirements as specialist & 0.18 & 0.57 & 0.26 & 0.12 \\
\hline Coding and billing & 0.17 & 0.41 & & -0.26 \\
\hline Allocating resources based on availability & & & 0.83 & \\
\hline Allocating resources based on costs & & & 0.78 & \\
\hline Allocating resources based on EBM & 0.30 & -0.22 & 0.52 & -0.18 \\
\hline Eligible for medical training & -0.20 & 0.28 & 0.50 & -0.11 \\
\hline Updating medical knowledge & -0.12 & 0.21 & 0.47 & -0.13 \\
\hline Preventive healthcare & 0.26 & & 0.46 & 0.16 \\
\hline Mistake made myself & & & & -0.85 \\
\hline Reporting in medical files & & & & -0.75 \\
\hline Mistake made by others & & & 0.14 & -0.74 \\
\hline Rights and duties & & 0.14 & 0.11 & -0.65 \\
\hline
\end{tabular}

${ }^{1}$ Component 1: Leadership and Management; Component 2: Organisation and Finance; Component

3: Operational Management, Component 4: Professional Ethics and Health Law

\section{Perceived levels of knowledge and skills}

In general, the specialists perceived the residents' management competency to be moderate with a mean of 2.95 (SD 0.41) (Table 3). From the items in factor one "Leadership and Management" (mean 3.08, SD 0.82) the specialists gave the lowest rating to the residents' abilities to lead or participate in a meeting or committee (mean 2.69, SD 0.75). 
Medical specialists' perceptions

Table 3. Mean and SD of item and scale scores (five-point) and Cronbach's alpha for the scales (N=129)

\begin{tabular}{|c|c|c|c|}
\hline & Mean & SD & $a$ \\
\hline Scale 1: Leadership and Management & 3.08 & 0.82 & $a=0.85$ \\
\hline Leadership skills & 3.25 & 0.77 & \\
\hline Dealing with conflicts & 3.09 & 0.79 & \\
\hline Managing a ward & 3.12 & 0.89 & \\
\hline Handling received feedback & 3.64 & 0.64 & \\
\hline Improving quality processes & 2.98 & 0.81 & \\
\hline Patient care vs. practice requirements & 2.88 & 0.74 & \\
\hline Giving feedback & 3.09 & 0.86 & \\
\hline Time management & 2.81 & 0.78 & \\
\hline Leading a committee & 2.69 & 0.75 & \\
\hline Policy new colleagues & 2.90 & 0.84 & \\
\hline Create career opportunities & 3.40 & 0.69 & \\
\hline Scale 2: Organization and Finance & 2.35 & 0.87 & $a=0.78$ \\
\hline Personal financial situation & 2.61 & 0.87 & \\
\hline Organization within a specialist department & 1.91 & 0.65 & \\
\hline Negotiate working conditions & 2.46 & 0.93 & \\
\hline Organization within health care system & 2.07 & 0.65 & \\
\hline Requirements as specialist & 2.54 & 0.86 & \\
\hline Coding and billing & 2.52 & 0.98 & \\
\hline Scale 3: Operational Management & 3.39 & 0.92 & $a=0.72$ \\
\hline Allocating resources based on availability & 2.96 & 0.83 & \\
\hline Allocating resources based on costs & 2.73 & 0.88 & \\
\hline Allocating resources based on EBM & 3.64 & 0.67 & \\
\hline Eligible for medical training & 3.54 & 0.78 & \\
\hline Updating medical knowledge & 4.14 & 0.86 & \\
\hline Preventive healthcare & 3.30 & 0.76 & \\
\hline Scale 4: Professional Ethics and Health Law & 2.84 & 0.79 & $a=0.81$ \\
\hline Mistake made myself & 2.81 & 0.80 & \\
\hline Mistake made by others & 2.71 & 0.74 & \\
\hline Reporting in medical files & 2.74 & 0.79 & \\
\hline Rights and duties & 3.09 & 0.78 & \\
\hline
\end{tabular}

They gave the highest score to their capabilities to handle received feedback (mean 3.64, SD 0.64).

The factor, "Organization and Finance" had the lowest average score of the four factors (mean 2.35, SD 0.87) and all items within this factor had a lower mean score than the 


\section{Chapter 5}

other items. The lowest scores on average were given to the knowledge of the residents of the organization and financing of specialist departments (mean 1.91, SD 0.65), and their knowledge of the organization and financing of the health care system (mean 2.07, SD 0.65). The specialists gave the highest score, in this section, to their residents' competency to handle their personal financial situation (mean 2.61, SD 0.87).

The third factor "Operational Management" had the overall highest rating (mean 3.39, SD 0.92). The lowest score in this section was given to the residents' abilities to allocate scarce resources based on their costs (mean 2.73, SD 0.88). They gave the highest rating to their competency to keep their medical knowledge up to date (mean 4.14, SD 0.86).

The lowest average score in the last factor "Professional Ethics and Health Law" (mean 2.84 , SD 0.79) was given to the residents' ability to handle mistakes made by others (mean 2.71, SD 0.74). The specialists gave the highest rating to their residents' knowledge of the rights and duties a doctor has to fulfill (mean 3.09, SD 0.78).

\section{Multiple regression analysis}

As presented in Table 4, the only variable which had an overall significant influence on the perceived management competency of residents was whether or not the specialist had a doctorate degree $(b=0.20, p=0.01)$. Overall, these specialists scored the managerial competency of residents higher. This effect is also seen in the factors "Leadership and Management" ( $b=0.18, p=0.045)$, "Operational Management" $(b=0.21, p=0.029)$ and "Professional Ethics and Health Law" (b=0.24, $p=0.043)$. In the last factor the variable "specialty" also had a significant influence on the given score $(b=0.26, p=0.036)$. Surgical specialists rated the residents on average better than their non-surgical colleagues.

Table 4. Multiple Regression Analysis

\begin{tabular}{|c|c|c|c|c|c|c|}
\hline \multirow[t]{2}{*}{ Dependent variable } & \multicolumn{3}{|c|}{$\mathrm{PhD}$} & \multicolumn{3}{|c|}{ Surgical vs. non-surgica } \\
\hline & b & beta & $\mathrm{p}$ & b & beta & $p$ \\
\hline Overall & 0.20 & 0.24 & 0.01 & & & NS \\
\hline Leadership and Management & 0.18 & 0.19 & 0.045 & & & NS \\
\hline Organization and Finance & & & NS & & & NS \\
\hline Operational Management & 0.21 & 0.20 & 0.029 & & & NS \\
\hline Professional Ethics and Health Law & 0.24 & 0.19 & 0.043 & 0.26 & 0.20 & 0.036 \\
\hline
\end{tabular}




\section{Needs assessment}

Of the 123 specialists who answered the question, 94\% ( $n=116)$ reported a need for management training for their residents. One hundred eleven of them agreed that management education would improve the competency of the residents as managers.

Ninety-four percent of the respondents $(n=121)$ answered the question 'In what topics should the residents be trained in?' by selecting their preferred items. Most specialists chose health care system ( $n=98)$, time management ( $n=89)$, leadership ( $n=85)$ and legal aspects of medical errors $(n=83)$. The topics national health $(n=16)$ and medical computer systems ( $n=13$ ) were least frequently chosen, as is shown in figure 1.

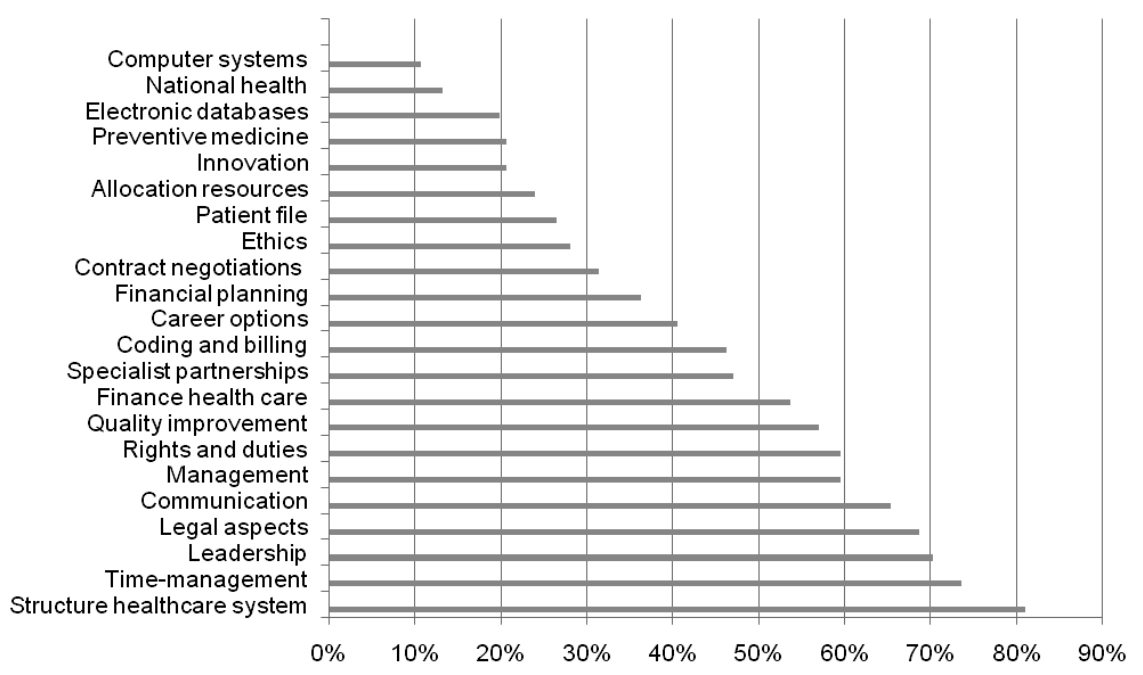

Figure 1. Preferred training topics

On the question regarding the preferred training method, "workshop" was most frequently selected ( $n=96)$, whereby a workshop is defined as a course in which interactive (group) assignments are used to translate theory into practice. The other preferred training method was coaching and feedback from supervisors $(n=71)$. The other methods were chosen less frequently: interactive training $(n=49)$, case-based training $(n=40)$, discussion groups $(n=22)$, lectures ( $n=22)$ and web-based training ( $n=21)$. With respect to the instructor of choice, the specialists preferred 'extramural instructors or experts' $(n=111)$ and 'medical specialists' ( $n=95)$, while a third chose 'hospital managers' ( $n=45)$.

Hundred twenty-one specialists marked at least one of the options on the ideal timespan and period of a training. Fourteen of them filled out more than one answer. The preferred duration for the training was 1-5 hours during a month ( $\mathrm{n}=29$ times), 5-10 hours during 


\section{Chapter 5}

a day ( $n=20$ times) or 10-20 hours during a year ( $n=18$ times). On the question of when during the medical program the training should take place, the respondents answered during residency as the most frequent option ( $n=114)$. Fifty six per cent $(68 / 121)$ felt that the training should take place after qualification as a specialist while 35\% (42/121) felt that it should take place during the undergraduate medical training.

Finally, we also examined if there was a relationship between the perceived need for management training and gender, specialty, PhD degree holder, previous experience with management tasks and/or training and the number of years of clinical experience. No significance influence was found, the p-values of all these variables were $>0.05$.

\section{DISCUSSION}

In this article we set out to investigate how medical specialists perceived the managerial competencies of their residents and if they felt that medical residents need training in health care management. We also investigated what medical specialists thought a management course for medical residents should consist of.

The specialists rated the management competency of their residents overall as moderate (mean=2.95; SD=0.41), with the highest competency ratings in updating their medical knowledge, handling received feedback effectively, using evidence based medicine (EBM) to allocate resources and knowing when they were eligible for (additional) medical training. They gave the lowest scores for their knowledge on the organization of the healthcare system and the organization of their specialist department and for their ability to negotiate their working conditions and their ability to code and bill their work.

When we compared these scores to the results of our previous research on how residents perceived their own management competencies there were remarkable similarities (15). The residents rated their overall competency slightly better with a mean of 3.41 (SD 0.37). They perceived their knowledge and skills on almost the same subjects as mentioned above to be weak or strong. They gave the highest scores to updating their medical knowledge, handling received feedback effectively and allocating resources based on EBM. The areas in which they rated their competency to be lowest were in how to negotiate on their working conditions, knowledge on how their specialist department is organized, knowledge of the requirements as a specialist and how the Dutch healthcare system is organized. This comparison suggests that residents and specialists agree on the problematic areas of management competencies among Dutch medical residents. 
The domains in which they experienced a shortcoming in knowledge and skills are imperative, since negotiating skills are not only essential when debating work conditions but also in several other settings, for example in contract negotiations, patient interactions, nurse-physician collaborations and when deliberating with colleagues. Comprehension of how the healthcare system is structured and funded is important because without this knowledge it will be impossible to reform, economize and improve the current system. The measured shortcoming in knowledge of the national healthcare system also indicates a potential deficit in the Dutch basic medical education (15).

We also investigated if there were any variables that influenced the way in which the specialists rated the residents. Having a doctorate degree (PhD) was the only variable which had an overall positive influence on how the specialists rated their residents managerial competency. We don't have an explanation for this, but it is possible that specialists who have a PhD are more research oriented and possess a different mindset.

Ninety-four per cent of the specialists agreed on the statement that there is a need for management training among their residents. This is higher than the percentage of residents that agreed on that statement (85\%) (16). Knowing this and the fact that the specialists also rated the overall competence of the residents lower than the residents themselves, may suggest that specialists consider the managerial role to be more important and difficult than the residents do. This could be due to the fact that specialists have a better understanding of what the physician managers' role entails.

The preferred method of instruction was a workshop with a specialist or extramural expert as training instructor. This matched the preferences of the residents in our previous study (16). With regard to the topics that should be taught in a health care management course, the most frequently chosen topics by the specialists were knowledge of the healthcare system, time management, leadership and legal aspects of medical errors. The residents themselves chose negotiation skills, specialist partnerships, knowledge of the healthcare system and career opportunities (16). A closer look at the topics selected by the residents, shows that except for the topic "organization of the healthcare system" the predominant focus of their choices was on their future positions as medical specialists, while the preferred topics of the specialists focused more on the needs for daily patient care. In the literature review we saw however, that the most frequently taught subjects were: quality assurance, management related topics, finance related topics, legal issues, personnel, organizational skills and time management (11). None of the topics mentioned 


\section{Chapter 5}

in the review matched those mentioned by the residents, while the specialists in this study also mentioned time management and legal issues as important items. Nonetheless, both specialists and residents agreed on the fact that the training should take place during residency, although there was little consensus on the timespan of the training (16). This was similar to the findings in the international literature (11).

There are some limitations worth mentioning in this study. To begin with, the response rate of $43.3 \%$ was not as high as we aimed for, even though we sent two reminders. However, as can be seen in Table 1, when we compare the sample of responding specialists to the data available on all Dutch medical specialists, we see that the group of responding specialists is a good representation of the male : female ratio on national level. Also, the percentages of responding specialties seem to reflect the proportions of medical specialties in the Netherlands (18). Although we did not find information on all characteristics, this information does reduce the chance of response bias.

This study only included collaborating hospitals in one region, so it is possible that specialists in other hospitals in the Netherlands have a different opinion on the management competencies of their residents. However, this is unlikely since there is still no formal management training being applied in any of the Dutch medical residency programs.

\section{CONCLUSIONS}

This study of (Dutch) specialists' perceptions of residents practice management skills and knowledge shows that they rate their residents' overall competency as physician managers to be moderate. There are a number of areas where the specialists feel that the residents lack adequate managerial knowledge or skills. Furthermore, 94\% of the respondents agreed that there is a need for management training among their residents. This study largely confirms our earlier findings on the perceived management competencies of residents and strengthens our statement that a course in medical management should be considered as a mandatory part of the curricula for residents. 


\section{REFERENCES}

1. Royal College of Physicians and Surgeons of Canada. CanMEDS: better standards, better physicians, better care: Royal College of Physicians and Surgeons of Canada; 2011 [updated 2011; cited 2012 06-02-2012]. Available from: http://www.royalcollege.ca/ public/resources/aboutcanmeds.

2. Essex B, Jackson RN. Moneymed: a game to develop management skills in general practice. J R Coll Gen Pract. 1981 Dec;31(233):735-9. PubMed PMID: 7338867. Pubmed Central PMCID: 1972233. Epub 1981/12/01. eng.

3. Aluise JJ. The physician as manager. "What" and HOW" OF PRACTICE MANAGEMENT EDUCATION. J Fam Pract. 1977 Feb;4(2):30511. PubMed PMID: 65441. Epub 1977/02/01. eng.

4. Cordes DH, Rea DF, Rea J, Vuturo A. A program of management training for residents. Acad Med. 1989 Jan;64(1):45-6. PubMed PMID: 2914065. Epub 1989/01/01. eng.

5. Lawson JG, McConnell JW. Teaching practice management in a family practice residency. J Med Educ. 1976 Oct;51(10):858-60. PubMed PMID: 972380. Epub 1976/10/01. eng.

6. Reisman A, Mathur K, Mulcahy E. The Case Western Reserve University practice management game: a painless way for physicians to learn managerial skills. J Health Adm Educ. 1984 Winter;2(1):65-74. PubMed PMID: 10299547. Epub 1984/12/06. eng.

7. Griffiths R. The National Health Service Management Inquiry. London: Department of Health and Social Security, 1983.

8. Horsley S, Roberts E, Barwick D, Barrow S, Allen D. Recent trends, future needs: management training for consultants. J Manag Med. 1996;10(2):47-53. PubMed PMID: 10162757. Epub 1995/12/09. eng.
9. Walker R, Morgan P. Involving doctors in management. A survey of the management development career needs of selected doctors in NHS Wales. J Manag Med. 1996;10(1):31-52. PubMed PMID: 10162925. Epub 1995/12/09. eng.

10. O'Neil E. Four Leadership Cornerstones for Health Care San Fransisco: Center for the Health Professions; 2005 [updated 2009; cited 2012 06-02-2012]. Available from: http://futurehealth.ucsf.edu/ Public/Publications-and-Resources/ Content.aspx?topic=Four_Leadership_ Cornerstones_for_Health_Care.

11. Busari JO, Berkenbosch L, Brouns JW. Physicians as managers of health care delivery and the implications for postgraduate medical training: a literature review. Teach Learn Med. 2011 Apr;23(2):186-96. PubMed PMID: 21516608. Epub 2011/04/26. eng.

12. Ringsted C, Hansen $T L$, Davis $D$, Scherpbier A. Are some of the challenging aspects of the CanMEDS roles valid outside Canada? Med Educ. 2006 Aug;40(8):807-15. PubMed PMID: 16869928. Epub 2006/07/28. eng.

13. Lieberman L, Hilliard RI. How well do paediatric residency programmes prepare residents for clinical practice and their future careers? Med Educ. 2006 Jun;40(6):539-46. PubMed PMID: 16700769. Epub 2006/05/17. eng.

14. Busari JO, Verhagen EA, Muskiet FD. The influence of the cultural climate of the training environment on physicians' self-perception of competence and preparedness for practice. BMC Med Educ. 2008;8:51. PubMed PMID: 19025586. Pubmed Central PMCID: 2596784. Epub 2008/11/26. eng. 


\section{Chapter 5}

15. Berkenbosch L, Brouns JW, Heyligers I, Busari JO. How Dutch medical residents perceive their competency as manager in the revised postgraduate medical curriculum. Postgrad Med J. 2011 Oct;87(1032):680-7. PubMed PMID: 21693572. Epub 2011/06/23. eng.

16. Brouns JW, Berkenbosch L, Ploemen-Suijker FD, Heyligers I, Busari JO. Medical residents perceptions of the need for management education in the postgraduate curriculum: a preliminary study. Int J Med Educ. 2010;1:7682. Epub November 12, 2010. eng.

17. Daugird AJ, Spencer DC. The perceived need for physician management training. J Fam Pract. 1990 Mar;30(3):348, 51-2. PubMed PMID: 2307950. Epub 1990/03/01. eng.

18. Ministerie van Volksgezondheid Welzijn en Sport. Overzicht zorgverleners per specialisme 2012. Available from: https://www.bigregister.nl/doc/pdf/ Overzicht\%20zorgverleners\%20per\%20 specialisme_34664.pdf. 


\section{APPENDIX 1}

\section{Questionnaire}

Statements regarding the competency 'manager'

On a scale of 1 to 5, choose the response you feel to be most accurate regarding your residents'knowledge or skills on the following topics.

$1=\mid$ totally agree

$2=1$ agree

$3=$ Neutral

$4=1$ disagree

$5=1$ totally disagree

The resident finds a balance between patient care and personal development in his work.

- Residents are well aware of how to create career opportunities.

- Residents know how to negotiate on personal ambitions (working part-time, PhD project)

- Residents know how to handle their personal financial situation and what they can expect in the future.

- Residents know how to negotiate on their salary and their working conditions.

- Residents are adept at estimating time requirements for daily tasks and time management and as a result, they are capable of finishing their job requirements on time.

- Residents are capable of setting priorities between providing patient care and practice requirements, such as administrative tasks.

- Residents know how to handle feedback from their supervisors

- Residents are capable of giving feedback to their colleagues.

The resident functions effectively in the health care setting

- Residents know how the Dutch healthcare system is organised and financed

- Residents know how their specialty's department is organised and financed

- Residents know what will be expected of them when they become a specialist (leadership, administrative tasks, meetings, finance)

- Residents know how to function in their position as a leader for other medical personnel (nurses etc.)

- Residents know how to manage their ward effectively

- Residents know how to deal with conflicts at their workplace

- Residents know which rights and duties they have to fulfil being a doctor (for example, health law) 


\section{Chapter 5}

- Residents know what has to be reported in a medical file to avoid legal problems

- Residents know how to deal with medical mistakes they made themself

- Residents know how to deal with medical mistakes made by others

- Residents stand up for their patient, when they feel that the amount of care he/she receives isn't enough, even when they have to challenge their supervisor

- Residents know how to lead or participate in a committee or meeting

- Residents are adequately prepared for the future to make decisions on the employment of potential colleagues

The resident allocates finite healthcare resources appropriately

- Residents allocate healthcare resources (additional research, treatments) based on evidence-based medicine, guideline or protocol

- Residents take into account when allocating health care resources that they are finite (waiting lists).

- Residents take the costs of healthcare resources into account when allocating them.

- Residents are actively involved in preventive healthcare (for example giving advice on lifestyle)

The resident uses information technology appropriately to deliver health care optimal and to maintain and keep up medical knowledge

- Residents participate actively in evaluating and improving systemic quality processes (e.g. improving patient safety).

- Residents know how to use information technology in patient care appropriately (e.g., work with electronic medical file and online databases)

- Residents know where they can find medical resources (books, internet, databases) to keep up their medical knowledge

- Residents know when they are eligible for (additional) medical training

- Residents know how to reimburse and code their work (coding and billing).

- There is not sufficient time given to management responsibilities and management training at my work place.

\section{Needs assessment}

- Residents need training in medical management. Answers: Yes, No

- Management training will improve the residents' competency as a manager Answer: Yes, No 
- The residents need training/teaching in the following topic(s).. (multiple answers possible)

Answers: Career options, Financial Planning, Negotiation skills e.g. contract negotiation, Time management, Health Care System, Specialist Partnerships, Leadership, Juridical Aspects of Medical Mistakes, Medical Law and Duty, Communication, Medical Cost-effectiveness of Diagnosis and Treatment, Medical Computer Systems, Electronic Medical Databases,Medical Ethics, Preventive health care, Development of innovations, Quality processes, Coding and billing, Practice management, The residents don't need training, Other (please specify)

- Residents should receive training which uses the following method..(multiple answers possible)

Answers: Lectures, Workshop, Discussion Groups, Interactive training, Case-Based training, Web-Based course, Feedback-based training by supervisors, Residents don't need training, Other (please specify)

- $\quad$ Residents should receive their management training from the following instructor... (multiple answers possible)

Answers: Physician, Extramural Expert, Hospital Manager, They don't need training, Other (please specify)

- Residents should receive training that lasts..

\begin{tabular}{|l|l|l|l|l|l|l|}
\hline & $1-5$ & $5-10$ & $10-20$ & $20-30$ & $30-40$ & $>40$ \\
\hline Hours on a day & & & & & & \\
\hline Hours per week & & & & & & \\
\hline Hours per month & & & & & & \\
\hline Hours per years & & & & & & \\
\hline
\end{tabular}

- Timing of training...

Answers: During medical school, During pre-residency period e.g. Senior House Officer, During residency, When working as a specialist, There is no need for management training 


\section{Chapter 5}

\section{Personal Characteristics}

- Gender:

- Male

- Female

- Age:

- Work experience

- I work in the following specialty (e.g. paediatrics):

- Years of work experience as a specialist (e.g. 2 years) :

- Do you have a PhD:

- Yes

- No

- Besides Medicine I also undertook a training/curriculum/course which contributes to my functioning as a Manager:

- No, I have not undertaken such training

- Yes, I undertook the following training/curriculum/course (please specify):

- I have experience which can contribute to my functioning as a manager:

- No, I don't have such experience

- Yes, I have the following experience.. (for example chair(wo)man of a committee):

- At my current workplace, focused time has been spent on the management role of physicians..

- No

- Yes, namely (please specify):

- I currently work at:

- Teaching (Academic) hospital

- General hospital 




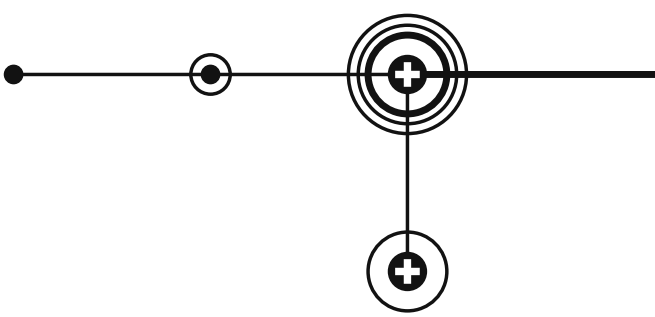

\section{Chapter 6}

Medical residents' perceptions of

their competencies and training

needs in health care management:

an international comparison.

Berkenbosch L, Schoenmaker SG, Ahern S, Søjnæs C, Snell L, Scherpbier A, Busari JO BMC Medical Education 2013, 13:25
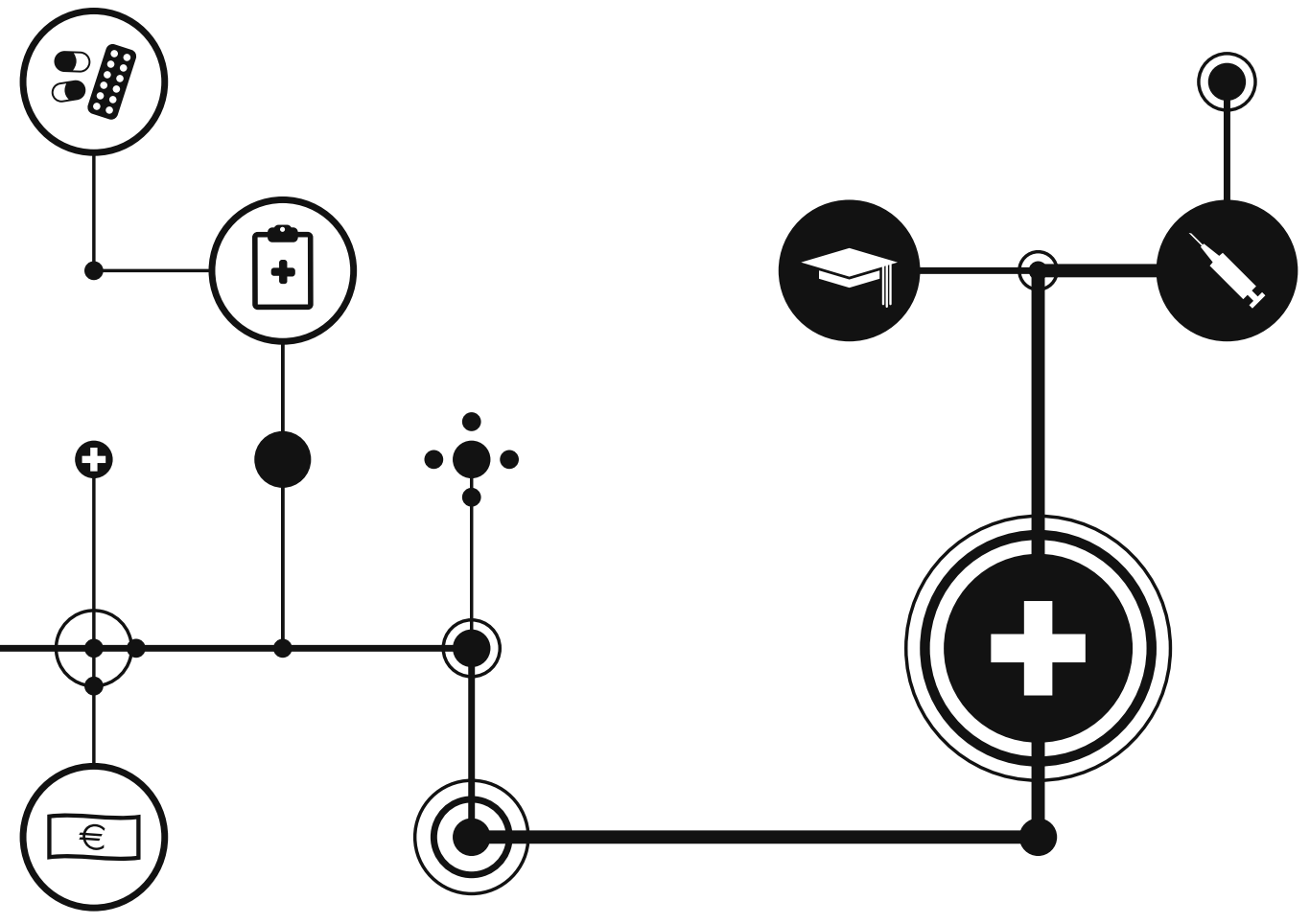


\section{Chapter 6}

\section{ABSTRACT \\ Background}

Previous research has shown that Dutch medical residents feel inadequate in certain management areas: 85\% had a need for management training and reported preferences on the format of such training. Our objective was to explore if the perceived deficiencies and needs among Dutch residents were similar to those of their peers in other countries, and if a longer duration of the incorporation of the CanMEDS competency framework into curricula as well as management training had an influence on these perceptions.

\section{Methods}

Medical residents from Denmark, Canada and Australia were approached for participation. The questionnaire used to survey the perceptions of Dutch residents was slightly modified, translated into English and sent by email to all international participants.

\section{Results}

Response rates were; Denmark 719/2105 (34\%), Canada 177/500 (35\%) and Australia 194/1213 (16\%) respectively. The Danish as well as the Canadian residents rated their negotiating skills poorly. In Australia the residents found their knowledge on how their specialist department was organized to be insufficient, while residents in the Netherlands rated their knowledge on how the healthcare system was organized as inadequate. In all of the countries, more than $70 \%$ of the residents reported a perceived need for management training.

\section{Conclusions}

A majority of the residents in all countries felt the need for specific training in developing their management competencies. The adoption of the CanMEDS framework alone seems to be insufficient in meeting residents' perceived educational needs in this area. 


\section{BACKGROUND}

Until now, learning by doing has been the predominant method of training in management competencies for most practicing physicians. In the 1970s some authors proposed that physicians should not only be trained as medical experts, but also as medical managers. Lawson et al (1976) wrote: "Times and methods are changing. Gone are the days when the physician might be paid in kind rather than cash. Gone, too, are the days when one could get by without accounting for profit and loss, when one could be less careful about the source, amount, and use of one's income. The running of a physician's office has become a complex business venture" (1). At the same time, some of the first management training programs were introduced for both staff physicians and trainees (1, 2). These proliferated into the 1990s as more physician management training programs emerged (3-8). In 1996 the Royal College of Physicians and Surgeons of Canada defined the Managers Role as one of seven key competencies in the CanMEDS framework needed for medical education and practice (9). A few years later, the Accreditation Council for Graduate Medical Education in the USA identified that Systems-Based Practice was one of the six core competencies for practicing medicine (10). In 2005 the CanMEDS competencies were officially introduced in the Netherlands as the framework for residency training programs (11), however there is still no formal national curriculum that focuses on the development of management competencies.

In 2009 a literature review of management skill development in postgraduate medical training revealed 40 articles, of which eleven were needs assessments among medical students, residents, fellows or program directors. The general conclusion was that management training was necessary in both the undergraduate and postgraduate training of medical doctors. Twenty-six articles gave a description of existing management courses, which were all different in format and content; all were evaluated positively (12). In a separate study that investigated the perceived competence and educational needs in health care management of Dutch medical residents, the residents perceived their competencies in certain important medical management areas to be inadequate. More than half of the respondents did not feel confident in their (contract) negotiating skills and lacked sufficient knowledge of how the Dutch healthcare system and the respective specialist practices were financed and organized. About one-third gave neutral ratings on their negotiation and leadership skills and of their knowledge of the legal aspects of healthcare (13). It was also found that $85 \%$ of the residents reported a need for management training (14). 


\section{Chapter 6}

\section{Current situation of management training in postgraduate medical education}

The Royal College of Physicians and Surgeons of Canada (RCPSC) developed the CanMEDS Framework with its seven core competencies in the 1990s; the framework was implemented nationally in 1996 (9). As residency training in Canada is university-based, any formal Manager Role education is done by the individual programs or the university. The RCPSC instituted a Manager Role 'Train-the-Trainer' (TTT) Program to assist residency program directors and university curriculum planners design and implement programs to help residents learn this role. The goals of the $T \pi$ addressed curriculum design as applied to the development of Manager Role and developed knowledge in the areas of health care systems, resource management, career development, quality improvement, leadership and change management (15).

The framework was incorporated in Australia in 2006, into the Australian Curriculum Framework for Junior Doctors but provides no formal learning strategies or outlined mechanisms for the formal assessment of the managers' competency (16).

In 2003, the CanMEDS Framework was adopted in Denmark and in 2005 a formal and mandatory training program was implemented for medical residents covering areas of leadership, collaboration and health care administration to support several of the roles including the manager role (17). The training program is divided into three courses stretched over nine days. The first course is conducted at the beginning of the specialist training and covers subjects and issues from the physician's work to illustrate and apply rules and theoretical knowledge about the organization and management at local and regional level. The second and third courses run in the second half of the specialist training. The second course involves issues of health policy, health economics and organizational issues at national, European and international level and the third course covers subjects and issues around leadership, cooperation and organization at local, regional and national level with the doctor as the central actor (18).

So far our research findings on management and leadership training in postgraduate medical education indicate that there is a need for specific training in this area among Dutch medical residents. However, it is unclear whether the perceived deficiencies and needs in management training among Dutch medical residents are similar to those of their peers in other countries. As a result we decided to explore whether the length of incorporation of the CanMEDS framework and the availability or not of management training programs in the postgraduate medical curriculum, influences the perceived management competencies and needs of medical residents in Denmark, Canada and Australia. 


\section{METHODS \\ Designing the survey}

A questionnaire that was designed in 2009 to survey Dutch residents' management competencies and needs was translated into English and modified to suit the target groups in the different countries (13,14). For example, we deleted the item on coding and billing in Australia since the junior doctors there do not take part in that administrative process. The final questionnaire consisted of 28 statements about the perceived management competency of junior doctors, which covered four areas of practice management namely: 1. the balance between patient care and personal development, 2. effectively operating within the health care context, 3. allocating healthcare resources appropriately and 4. using information technology to deliver optimal healthcare. The respondents were asked to rank their perceived level of competence on a 5-point Likert-scale, with 1: completely disagreeing, and 5: completely agreeing with a statement. There were seven items which assessed how they perceived their need for management education (training variables). This section not only investigated the need for management training, but also the preferred topics, the preferred method of instruction, when the training should take place and the preferred duration of training.

Finally there were six questions about the demographic characteristics of the junior doctors (background variables) i.e. age, gender, years since graduation, current specialty, previous management experience (e.g. in a committee, or previous job) and previous management education (e.g. a management course). We were interested in finding out whether some of these background variables were associated with the junior doctors' perceptions of their management competencies and management education needs.

\section{Data collection}

Similar to the Dutch study, we made use of an opportunity (convenience) sampling to select our target population, as it was deemed unfeasible to conduct national surveys in these countries due to logistical and time constraints. We emailed the questionnaire to all junior doctors in Denmark that participated in the mandatory courses of pedagogics and communication by the Centre for Clinical Education since 2005. In Australia, hospital based Medical Education Officers forwarded an email to all the junior doctors of eight health services in the state of Victoria. In Canada the questionnaire was forwarded to all residents at McGill University through their respective specialty programs. As the study was a webbased survey (using the Survey Monkey web application) links to the questionnaire were sent to the participants by email. The survey was completed anonymously. The survey was online for six weeks; two reminders (in Canada one) were sent. 


\section{Chapter 6}

Prior to starting the survey, we sought for and obtained ethical approval from the McGill Faculty of Medicine Institutional Review Board and the ethical committees of the eight health services in Australia. In Denmark ethical approval is only necessary for biomedical research, for our research project it was therefore not required.

\section{Data analysis}

Analysis was performed using SPSS, version 17. Descriptive statistics were used to present the demographic distribution of the participants. An explorative factor analysis was performed to identify if there were underlying clusters of items (scales) in the questionnaire. Cronbach's alpha analysis was used to test the reliability of the resulting scales. For the final scales, scale scores were obtained by calculating the mean score of the corresponding items. Whether the residents' perceptions as expressed by these scale variables were influenced by background variables was investigated using multiple regression analysis. The scale variables formed the dependent variables in the analysis and the background variables were the independent variables. In order to reduce the number of (dummy) variables, the following background variables were selected: Gender, Years since graduation from medical school, Management training and Management experience. Specialty (surgical vs. non-surgical) was not selected as a background variable since previous research indicated that this characteristic had no significant influence on the perceived management competency (13). Gender was defined $0=$ Male, and $1=$ Female. Years since graduation was expected to have a skewed distribution and was therefore converted into a logarithmic variable. Management training was defined as $\mathrm{O}=\mathrm{No}$ and $1=$ Yes, except for Denmark where no management training was defined as 0 , residents who followed the first mandatory course as 1, residents who followed the first and second course as 2, and residents who followed all three courses as 3. Management experience was defined $0=\mathrm{No}$ and $1=$ Yes.

The relationship between the perceived need for management training and the background variables mentioned above were investigated by analyzing the corresponding cross tables using Pearson's Chi-square test to assess the significance of the association. Because years since graduation is a continuous variable, logistic regression was used to assess the effect on the perceived need for management training.

\section{RESULTS}

In Denmark 2105 residents were approached to participate in the survey. Of this total, 719 questionnaires were returned (response rate 34.2\%). In Canada 183 out of 500 questionnaires were returned (36.8\%) and in Australia 197 out of 1213 surveys (16.2\%) 
were returned. In the Netherlands 177 of 506 residents (35.0\%) responded to the survey (19). The dropout rate (failure to complete the survey) was $8.9 \%(n=64)$ in Denmark, 10.9\% $(n=20)$ in Canada, 9.6\% in Australia $(n=19)$ and 5.1\% ( $n=9)$ in the Netherlands. There were no reasons given for not completing the questionnaire. In Denmark 39 respondents were already specialists and excluded from further analysis.

\section{Residents' characteristics}

The mean age of the Danish residents was 34.2 years (SD 4.3), the mean age of the Canadian, Australian and Dutch residents was 29.2 years (SD 3.9), 27.2 years (SD 3.8) and 30.3 years (SD 3.0) respectively. In Denmark 36.3\% of the respondents were male, $50 \%$ in Canada $43.3 \%$ in Australia and in the Netherlands 33.3\%. The average number of years since graduation from medical school was 6.0 years (SD 4.2) for the Danish residents and 3.2 years (SD 2.7), 2.5 years (SD 2.5) and 4.9 years (SD 2.8) for the Canadian, Australian and Dutch residents respectively. Eighty-seven percent of the Danish respondents had participated in management training, in comparison to $13.4 \%$ of the Canadian respondents, $14.6 \%$ of the Australian respondents and $15.5 \%$ of the Dutch respondents. Thirty-eight percent of the Danish residents reported to have some previous experience in a management or leadership function. This percentage was $56.1 \%$ for the Canadian residents, $43.8 \%$ of the Australian residents and $58.3 \%$ of the Dutch residents (Table 1 ).

\section{Explorative Factor Analysis}

The questions which did not occur in every survey were removed and for the 26 remaining common competency items the data from the four countries was clustered, using a random $25 \%$ ( $n=180$ ) sample of the Danish data to create an evenly spread influence from all four countries. An explorative factor analysis (EFA) was performed using 3-5 factors consisting of principal components analysis and oblique rotation. After removal of ambiguous items (loading difference less than 0.1) and low loading items (loading less than 0.4), the EFA was repeated. Using these indications two items were removed, and for the remaining set of 24 items a satisfactory 5 -factor solution was obtained (explained variance equal to $65 \%$ ). Table 2 shows the resulting loadings for this solution (loadings $<0.1$ not shown), the numbers which are bold and underlined are indicating subsets of items associated with each factor (scale). Based on the content of their corresponding items, the five scales were indicated as following: "Management and Leadership", "Organization and Finance", "Operational Management", "Professional Ethics" and "Career Planning (and negotiation skills)" respectively. The reliability (Cronbach's alpha) of each scale amounted to 0.90, 0.76, $0.84,0.85$ and 0.67 respectively. 


\section{Chapter 6}

Table 1. Residents' characteristics

\begin{tabular}{|c|c|c|c|c|c|}
\hline Country & & $\begin{array}{l}\text { Netherlands } \\
\quad(n=168)\end{array}$ & $\begin{array}{c}\text { Denmark } \\
(n=625)\end{array}$ & $\begin{array}{l}\text { Australia } \\
(n=178)\end{array}$ & $\begin{array}{l}\text { Canada } \\
(n=163)\end{array}$ \\
\hline \multirow[t]{2}{*}{ Gender (Number(\%)) } & Male & $56(33.3)$ & $227(36.3)$ & $77(43.3)$ & $81(49.7)$ \\
\hline & Female & $112(66.7)$ & $398(63.7)$ & $101(56.7)$ & $82(50.3)$ \\
\hline Age (years) (Mean (SD)) & & $30.3(3.0)$ & $34.2(4.3)$ & $27.2(3.8)$ & $29.2(3.9)$ \\
\hline \multirow[t]{29}{*}{ Specialty (Number(\%)) } & Anesthesiology & $15(8.9)$ & $45(7.2)$ & $4(2.2)$ & $6(3.7)$ \\
\hline & Clinical biochemistry & $1(0.6)$ & $10(1.6)$ & & $1(0.6)$ \\
\hline & Clinical genetics & $3(1.8)$ & & & \\
\hline & Clinical microbiology & & $8(1.3)$ & & $1(0.6)$ \\
\hline & Clinical pharmacology & & $6(1.0)$ & & \\
\hline & Dermatology & $6(3.6)$ & $11(1.8)$ & $1(0.6)$ & $2(1.2)$ \\
\hline & ENT medicine & $3(1.8)$ & $10(1.6)$ & & $9(5.5)$ \\
\hline & Emergency department & $4(2.4)$ & & $40(22.5)$ & $7(4.3)$ \\
\hline & General medicine & & $87(13.9)$ & $22(12.4)$ & $34(20.7)$ \\
\hline & Geriatrics & & $6(1.0)$ & $6(3.4)$ & \\
\hline & Forensic medicine & & $3(0.5)$ & & \\
\hline & Internal medicine & $24(14.3)$ & $166(26.6)$ & $16(9.0)$ & $39(23.8)$ \\
\hline & Intensive care & & & $5(2.8)$ & $1(0.6)$ \\
\hline & Medical rehabilitation & $1(0.6)$ & & $4(2.2)$ & \\
\hline & Neurology (surgery) & $7(4.2)$ & $36(5.8)$ & $4(2.2)$ & $1(0.6)$ \\
\hline & Nuclear medicine & & $8(1.3)$ & & \\
\hline & Obstetrics\&Gynecology & $31(18.5)$ & $26(4.2)$ & $6(3.4)$ & $6(3.7)$ \\
\hline & Occupational medicine & & $3(0.5)$ & $1(0.6)$ & \\
\hline & Ophthalmology & $5(3.0)$ & $10(1.6)$ & & $1(0.6)$ \\
\hline & Orthopedic surgery & $5(3.0)$ & $37(5.9)$ & $6(3.4)$ & $7(4.3)$ \\
\hline & Pathology and cytology & $5(3.0)$ & $9(1.4)$ & & $3(1.8)$ \\
\hline & Pediatrics & $36(21.4)$ & $23(3.7)$ & $5(2.8)$ & $10(6.1)$ \\
\hline & Psychiatry & $2(1.2)$ & $50(8.0)$ & $8(4.5)$ & $11(6.7)$ \\
\hline & Public health & & $6(1.0)$ & & $1(0.6)$ \\
\hline & Quality\&Safety & & & $2(1.1)$ & \\
\hline & Radiology & $8(4.8)$ & $19(3.0)$ & & $6(3.7)$ \\
\hline & Surgery & $4(2.4)$ & $33(5.3)$ & $32(18.0)$ & $13(7.9)$ \\
\hline & Urology & $3(1.3)$ & $13(2.1)$ & $1(0.6)$ & $3(1.8)$ \\
\hline & Not-stated* & $5(3.0)$ & & $15(8.4)$ & $1(0.6)$ \\
\hline $\begin{array}{l}\text { Years since graduation } \\
\text { (Mean (SD)) }\end{array}$ & & $4.9(2.8)$ & $6.0(4.2)$ & $2.5(2.5)$ & $3.2(2.7)$ \\
\hline Previous management & Yes & $26(15.5)$ & $545(87.2)$ & $26(14.6)$ & $22(13.5)$ \\
\hline Training (Number(\%)) & No & $142(84.5)$ & $80(12.8)$ & $152(85.4)$ & $141(86.5)$ \\
\hline Previous management & Yes & $98(58.3)$ & $240(38.4)$ & $78(43.8)$ & $91(55.8)$ \\
\hline experience (Number(\%)) & No & $70(41.7)$ & $385(61.6)$ & $100(56.2)$ & $72(44.2)$ \\
\hline
\end{tabular}

*Not-stated: the question was not answered or the answer was incomprehensible 
Table 2. Resulting scales of the Explorative Factor Analysis

\begin{tabular}{|c|c|c|c|c|c|}
\hline \multirow[b]{2}{*}{ Items } & \multicolumn{5}{|c|}{ Scales* } \\
\hline & 1 & 2 & 3 & 4 & 5 \\
\hline Time management & .894 & .103 & & & \\
\hline Patient care vs. Practice requirements & .806 & & & & \\
\hline Patient care vs. Personal life & .683 & & & & \\
\hline Leadership skills & .527 & .118 & .246 & -.211 & \\
\hline Handling received feedback & .494 & -.173 & .271 & -.243 & \\
\hline Managing a ward & .477 & -.103 & .291 & -.286 & \\
\hline Using information technology & .449 & -.191 & .333 & -.158 & \\
\hline Organisation \& finance healthcare system & .137 & .881 & .142 & & .171 \\
\hline Organisation \& finance specialist department & & .866 & & & \\
\hline Requirements as specialist & & .630 & & -.148 & -.209 \\
\hline Allocating resources based on costs & -.188 & & .903 & & \\
\hline Allocating resources based on finiteness & & & .834 & & \\
\hline Allocating resources based on EBM & .172 & & .683 & -.123 & \\
\hline Advocating for patients & .223 & -.112 & .525 & -.225 & \\
\hline Responding to mistakes made by others & -.109 & & -.140 & -.956 & \\
\hline Responding to mistakes made by myself & & & & -.865 & \\
\hline Legal rights and duties & .215 & & & -.586 & -.121 \\
\hline Proper use of medical records & .272 & & .135 & -.513 & -.115 \\
\hline Dealing with conflicts & .239 & -.138 & .181 & -.482 & \\
\hline Improving quality processes & -.120 & .107 & .173 & -.457 & -.146 \\
\hline Negotiating personal ambitions & & & & -.104 & -.831 \\
\hline Create career opportunities & .104 & & .190 & & -.691 \\
\hline Negotiate working conditions & -.138 & .245 & -.287 & & -.623 \\
\hline Personal financial management & .284 & & .158 & & -.521 \\
\hline
\end{tabular}

*Scale 1: Management and Leadership, Scale 2: Organization and Finance, Scale 3: Operational Management, Scale 4: Professional Ethics, Scale 5: Career planning (and negotiation skills)

\section{Perceived levels of knowledge and skills}

In general, residents from Denmark gave their own management competencies a mean score of 3.54 (SD 0.40). The Canadian residents rated their management competencies with an average of 3.35 (SD 0.51), the Australian residents had an average score of 3.45 (SD 0.42) and the Dutch residents 3.39 (SD 0.37). The mean overall scores per scale can be found in Table 3. 


\section{Chapter 6}

Table 3. Perceived levels of knowledge and skills

\begin{tabular}{|c|c|c|c|c|}
\hline & \multicolumn{4}{|c|}{ Mean (standard deviation) } \\
\hline & Denmark & Canada & Australia & Netherlands \\
\hline Mean & $3.54(0.40)$ & $3.35(0.51)$ & $3.45(0.42)$ & $3.39(0.37)$ \\
\hline Mean scale 1 & $3.76(0.48)$ & $3.74(0.58)$ & $3.88(0.45)$ & $3.65(0.47)$ \\
\hline Time management & $3.43(1.00)$ & $3.51(1.00)$ & $3.67(0.87)$ & $3.59(0.89)$ \\
\hline Patient care vs. Practice requirements & $3.49(0.84)$ & $3.50(0.88)$ & $3.90(0.67)$ & $3.40(0.90)$ \\
\hline Patient care vs. Personal life & $3.79(0.87)$ & $3.64(0.84)$ & $3.80(0.78)$ & $3.40(0.89)$ \\
\hline Leadership skills & $3.79(0.76)$ & $3.83(0.84)$ & $3.67(0.74)$ & $3.54(0.70)$ \\
\hline Handling received feedback & $3.88(0.65) \dagger$ & $3.84(0.79)$ & $3.98(0.61) \dagger$ & $3.92(0.55) \dagger$ \\
\hline Managing a ward & $3.88(0.64) \dagger$ & $3.93(0.72) \dagger$ & $3.92(0.55) \dagger$ & $3.78(0.70)$ \\
\hline Using information technology & $4.11(0.69) \dagger$ & $4.01(0.83) \dagger$ & $4.23(0.64) \dagger$ & $3.94(0.87) \dagger$ \\
\hline Mean scale 2 & $3.46(0.71)$ & $2.93(0.77)$ & $2.78(0.78)$ & $2.40(0.65)$ \\
\hline $\begin{array}{l}\text { Organisation \& finance healthcare } \\
\text { system }\end{array}$ & $3.55(0.84)$ & $3.23(0.98)$ & $2.86(0.97)^{*}$ & $2.55(0.84)$ \\
\hline Organisation \& finance specialist dep. & $3.42(0.89)$ & $2.66(0.97)^{*}$ & $2.59(0.92)^{*}$ & $2.11(0.77)^{*}$ \\
\hline Requirements as specialist & $3.39(0.93)$ & $2.92(0.96)$ & $2.88(0.98)$ & $2.53(0.81)^{*}$ \\
\hline Mean scale 3 & $3.55(0.51)$ & $3.74(0.64)$ & $3.40(0.62)$ & $3.75(0.49)$ \\
\hline Allocating resources based on costs & $3.28(0.86)$ & $3.47(0.88)$ & $3.16(0.86)$ & $3.42(0.86)$ \\
\hline $\begin{array}{l}\text { Allocating resources based on } \\
\text { finiteness }\end{array}$ & $3.39(0.71)$ & $3.71(0.82)$ & $3.46(0.86)$ & $3.65(0.70)$ \\
\hline Allocating resources based on EBM & $3.76(0.76)$ & $3.81(0.68)$ & $3.44(0.82)$ & $3.90(0.58)$ \\
\hline Advocating for patients & $3.76(0.76)$ & $3.95(0.81) \dagger$ & $3.54(0.80)$ & $4.03(0.60) \dagger$ \\
\hline Mean scale 4 & $3.55(0.53)$ & $3.28(0.66)$ & $3.52(0.58)$ & $3.51(0.48)$ \\
\hline $\begin{array}{l}\text { Responding to mistakes made by } \\
\text { others }\end{array}$ & $3.38(0.83)$ & $3.07(0.90)$ & $3.29(0.89)$ & $3.33(0.80)$ \\
\hline $\begin{array}{l}\text { Responding to mistakes made by } \\
\text { myself }\end{array}$ & $3.69(0.77)$ & $3.38(0.83)$ & $3.59(0.83)$ & $3.53(0.75)$ \\
\hline Legal rights and duties & $3.80(0.73)$ & $3.29(0.96)$ & $3.66(0.69)$ & $3.49(0.75)$ \\
\hline Proper use of medical records & $3.82(0.76)$ & $3.43(0.91)$ & $3.76(0.81)$ & $3.62(0.74)$ \\
\hline Dealing with conflicts & $3.33(0.85)$ & $3.56(0.88)$ & $3.54(0.73)$ & $3.72(0.64)$ \\
\hline Improving quality processes & $3.25(0.94)^{*}$ & $2.94(0.97)$ & $3.29(0.96)$ & $3.38(0.87)$ \\
\hline Mean scale 5 & $3.27(0.67)$ & $2.74(0.79)$ & $3.18(0.65)$ & $3.16(0.63)$ \\
\hline Negotiating personal ambitions & $3.10(0.98)^{*}$ & $2.58(1.00)^{*}$ & $3.11(0.93)$ & $3.38(0.86)$ \\
\hline Create career opportunities & $3.71(0.82)$ & $2.89(1.02)$ & $3.30(0.82)$ & $3.42(0.85)$ \\
\hline Negotiate working conditions & $2.51(0.97)^{*}$ & $2.23(0.91)^{*}$ & $2.75(0.93)^{\star}$ & $2.45(0.87)^{\star}$ \\
\hline Personal financial management & $3.75(0.92)$ & $3.26(1.09)$ & $3.54(0.89)$ & $3.36(0.94)$ \\
\hline
\end{tabular}

*Three lowest scores per country, † Three highest scores per country. 
The three lowest rated items from the Danish residents were "negotiating working conditions" 2.51 (SD 0.97), "negotiating personal ambitions" 3.10 (SD 0.98) and "improving quality processes" 3.25 (SD 0.94). For the Canadian residents the three lowest rated items were "negotiating working conditions" 2.13 (SD 0.91), "negotiating personal ambitions" 2.58 (SD 1.00) and "organization specialist department" 2.66 (SD 0.97). The three lowest rated items for the Australian residents were "organization of a specialist department" 2.59 (SD 0.92), "negotiating working conditions" 2.75 (SD 0.93) and "organization of the healthcare system" 2.86 (SD 0.97). The Dutch residents three lowest rated items were "organization of the healthcare system" 2.11 (SD 0.77), "negotiating working conditions" 2.45 (SD 0.87) and "requirements as a specialist" 2.53 (SD 0.81).

The three items the Danish residents rated highest were "using information technology" 4.11 (SD 0.69), "handling received feedback" 3.88 (SD 0.65) and "managing a ward" 3.89 (SD 0.64). The three highest rated items among the Canadian residents were "using information technology" 4.01 (SD 0.83), "standing up for patients" 3.95 (SD 0.81) and "managing a ward" 3.93 (SD 0.72). The three highest rated items for the Australian residents were "using information technology" 4.23 (SD 0.65), "handling received feedback" 3.98 (SD 0.61) and "managing a ward" 3.92 (SD 0.55). The three highest rated items for the Dutch residents were "standing up for patients" 4.03 (SD 0.60), "using information technology" 3.94 (SD 0.87 ) and "handling received feedback" 3.92 (SD 0.55), as can be seen in table three.

\section{Multiple regression analysis per country}

Denmark

As is shown in Table 4 there were three variables, which had a significant influence on the overall perceived management competencies of the Danish residents. The first variable was "gender" ( $b=-.108, p=.001)$, the male residents gave themselves on average significantly higher scores in comparison to their female counterparts. The second variable was "previous management experience" ( $b=.181, p=.000)$, where the residents with previous management experience gave themselves significant higher ratings than their colleagues without such experience. The third factor was "previous management course" $(b=.082$, $\mathrm{p}=.001)$, where the residents with more training scored on average increasingly higher (mean of no training 3.40 (SD 0.38); mean of one training 3.55 (SD 0.37); mean of two training courses 3.57 (SD 0.38) and the residents who participated in all three training courses had a mean of 3.83 (SD 0.27)). These three variables were also of significant influence in the factor "Organization and Finance" (gender $b=-.148, p=.016$, experience $b=.281, p=.000$ and training $b=.121, p=.010$ ). In the factor "Management and Leadership" the variable gender had a significant influence (b-.139, p=.001), as did the variable training (b.070, $p=.027$ ). In the factor "Operational Management" the variables experience and training were of 
Chapter 6

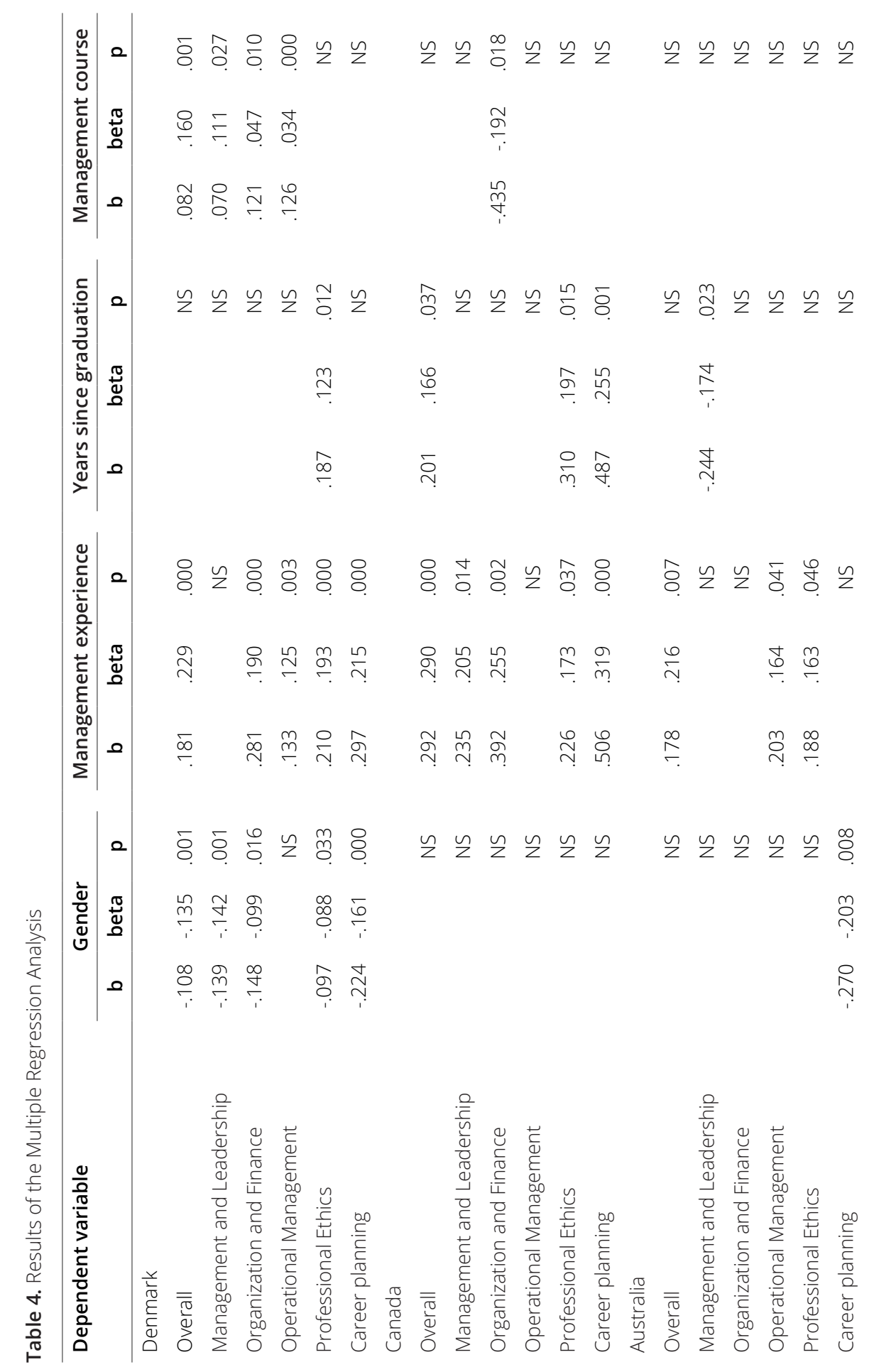


International comparison

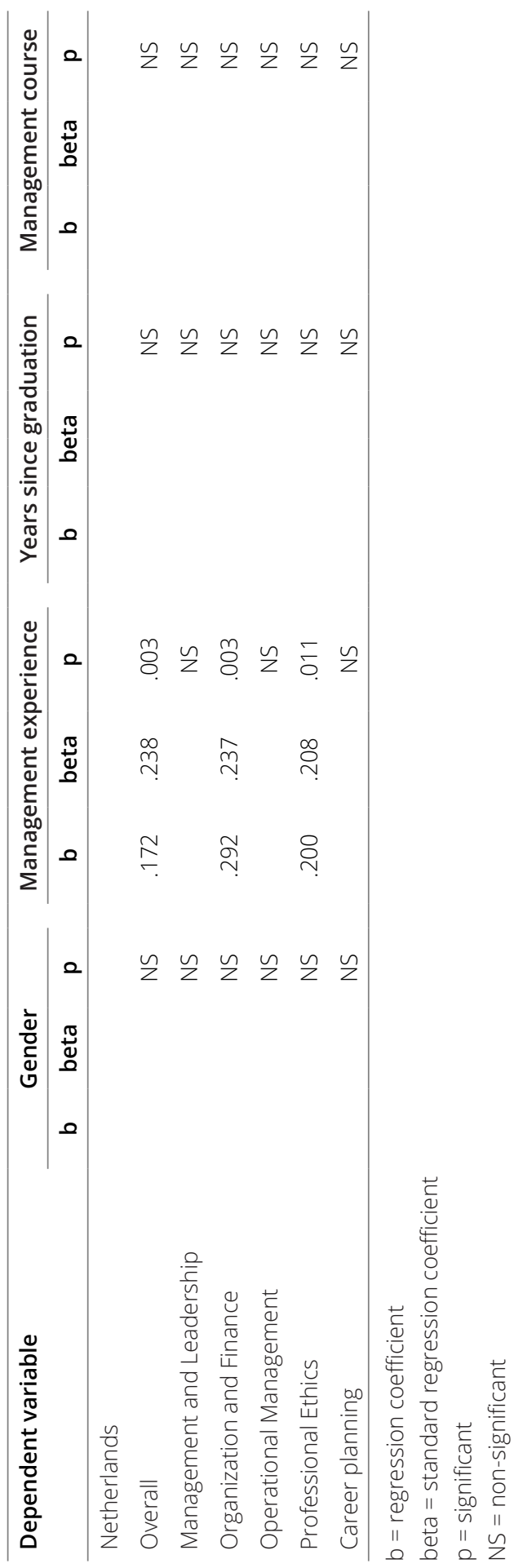




\section{Chapter 6}

significant influence on the average ratings of the residents $(b=.133, p=0.002$ and $b .126$, $\mathrm{p}=.000$ respectively). In the factor "Professional Ethics" gender, experience and years since graduation had a significant influence ( $b-.097, p=.033, b .210, p=.000$ and b.187, $p=.012$ respectively). And in the last factor "Career Planning" the variables gender and previous management experience were of significant influence $(b=-.224, p=.000$ and $.297, p=.000$ respectively).

\section{Canada}

The two variables which had a significant positive influence on the overall mean scores of the Canadian residents were "previous management experience" $(b=.292, p=0.000)$ and "years since graduation" ( $b=.201, p=0.037)$. These two variables were also of influence in the factors "Professional Ethics"(experience $b=.226, p=0.037$ and graduation $b=.310, p=0.015$ ) and in "career planning"(experience $b=.506, p=0.000$ and graduation $b=.487, p=0.001$ ). In the factor "Management and leadership" only previous management experience had a significant influence $(b=-.235, p=0.014)$. In the factor "Organization and Finance" previous management experience had a positive significant influence ( $b .392, p=0.002$ ), but a previous management course had a negative significant influence $(-.435, p=0.018)$.

\section{Australia}

The only variable which had an influence on the average overall score was "previous experience" ( $b=.178, p=0.07)$; residents who had previous management experience gave themselves on average higher scores. This effect was also seen in the factors "operational management" ( $b=.203, p=0.041)$ and professional ethics $(b=.188, p=0.046)$. In the factor "management and leadership", residents who had more years since graduation gave on average lower ratings than their colleagues with fewer years since graduation $(b=-.244$, $p=0.023$ ). In the factor "career planning" female residents gave themselves lower scores on average than their male counterparts ( $b=-.270, p=0.008)$.

\section{The Netherlands}

In the Netherlands only the variable previous experience had an influence on the average ratings of the residents $(b=.172, p=0.003)$, the residents who had this experience rated themselves on average higher. This effect was also found in the factors Organization and Finance $(b=0.292, p=0.003)$ and Professional ethics" $(b=.200, p=0.011)$ (13).

\section{Needs assessment}

More than fifty percent of the residents from all four countries felt that there wasn't sufficient attention being given to management training in their current residency program. The vast 
majority of residents in all four countries had a need for management training (Denmark 84.7\%, Canada 83.5\%, Australia 76.8\% and the Netherlands 85.3\%). When we analyzed the different subcategories in Denmark we saw that $84.6 \%$ of Danish residents who had not received any training yet, had a need for management training. The percentages of residents who perceived a need for additional management training after a first training course was $87.0 \%$, after two training courses $81.2 \%$ and after all three training courses $78.9 \%$ respectively.

The top three preferred topics for a management training program differed between countries except for "negotiation skills" which was in the top three of preferred topics in all four countries. Two topics that were least preferred in all countries included knowledge of "computer systems" and "electronic databases". The favorite method of instruction was the same for Canada (70.6\%), Australia (68.5\%) and the Netherlands (84.7\%), namely a workshop. The residents from Denmark preferred a case based method (63.6\%). The majority of all residents chose "physicians" or "extramural experts (e.g. a lawyer)" as preferred instructors for such programs. The hospital manager was chosen least frequently in all four countries.

The preferred length of each training differed between Denmark, Canada and Australia from one hour to a half day. The preferred frequency of the sessions among those respondents varied between once every month or every half-year. In the Netherlands however, the preferred length of training and training frequency was investigated using open questions. The respondents' preferred duration of the training ranged from 1 to 400 hours, with a mean of 17 hours. The length of the program that they preferred most was one that was spread over days ( $n=42$ times) or years ( $n=43$ times). A training period spread over months ( $n=19$ times) or weeks ( $n=2$ times) was not a preferred choice (20). The majority of all residents chose the postgraduate period as being the most suitable period for management training rather than during medical school or after specialization (Denmark 87.3\%, Canada 85.3\%, Australia 75.7\%, the Netherlands 95.3\%) (Table 5).

\section{Influences on the perceived need for management training per country} Denmark

Gender was a significant influence on the perceived need for management training. Significantly more female residents had a need for management training than their male counterparts ( $p=.004)$. Previous management training ( $p=.291)$ and previous management experience $(p=.206)$ were not a significant influence on the need for management training. Also, the years since graduation was not a significant influence on the perceived need for management training $(p=.131)$. 


\section{Chapter 6}

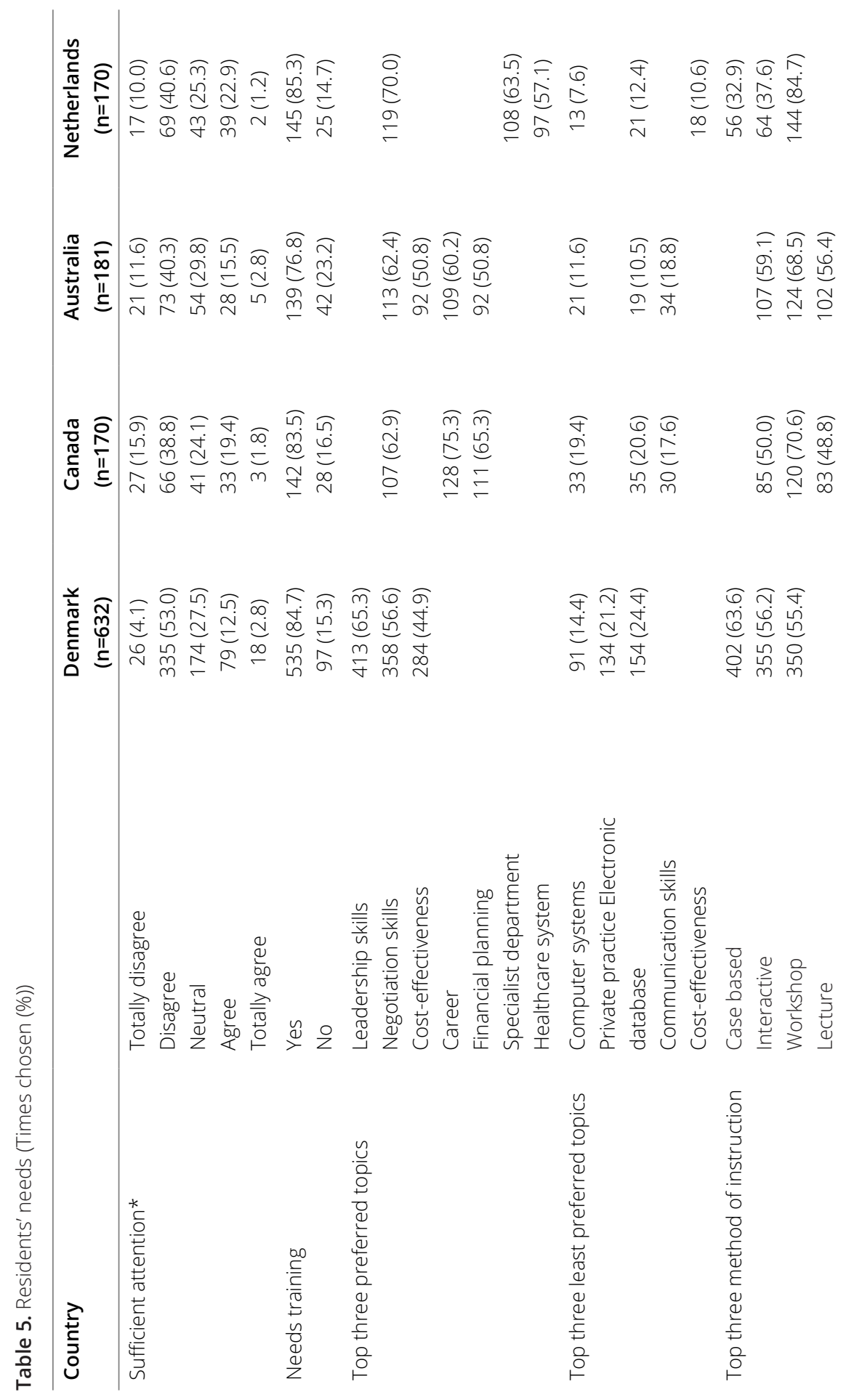


International comparison

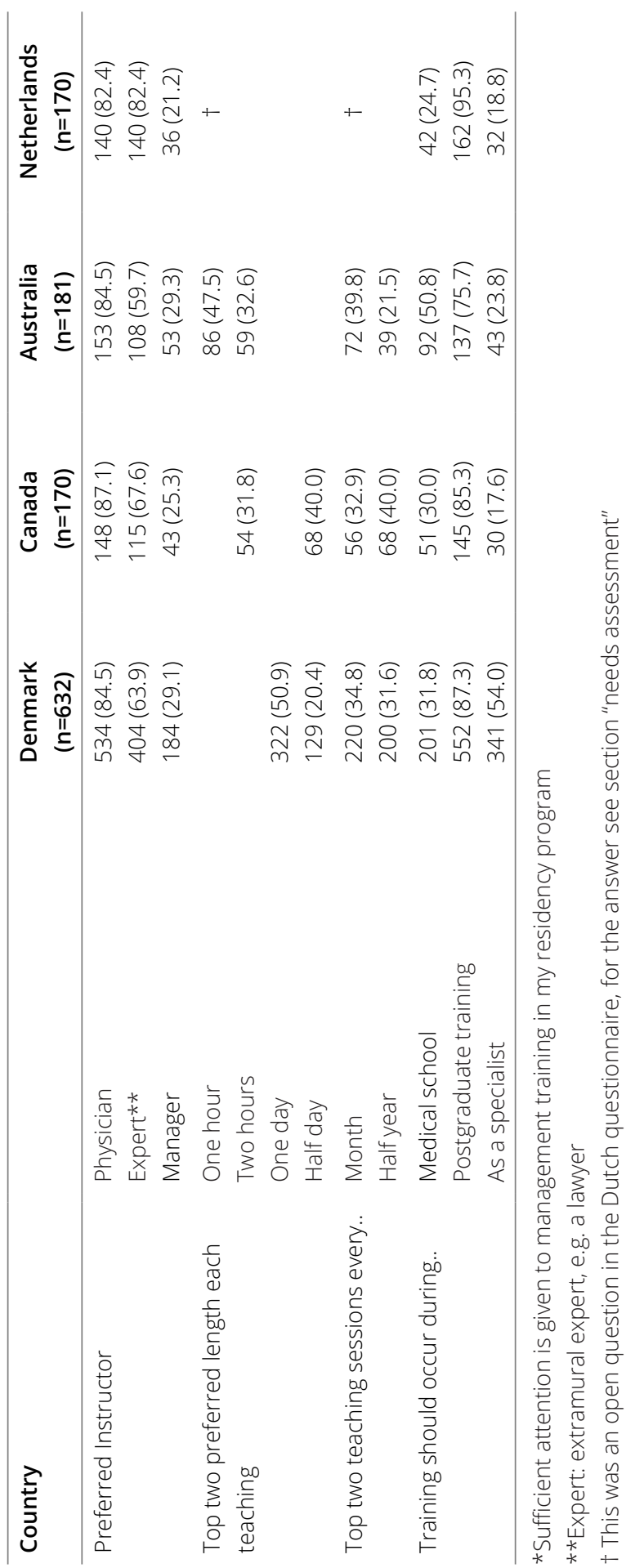




\section{Chapter 6}

Canada

Gender, previous management training and previous management experience were not a significant influence on the residents need for management training ( $p>$.05). The years since graduation did have a significant influence, the more time had passed the less need there was for management training $(b=-2.52, p=.000)$.

\section{Australia}

Female residents had on average a significant greater need for management training than their male counterparts $(p=.015)$. Previous management training was not a significant influence, residents who did not have previous management experience had a significant greater need for management training than their colleagues who did have such experience $(p=.007)$. Logistic regression showed that the more years since graduation passed the more need residents felt for a management training $(b=1.86, p=.009)$.

\section{The Netherlands}

Gender was not an influence on the perceived need for management training ( $p=.283)$. Neither was previous management training $(p=.263)$, previous management experience $(p .=256)$ or the years since graduation $(p=.798)(20)$.

\section{DISCUSSION}

In this study we investigated whether the perceived deficiencies and needs among Dutch residents were similar to those of their peers in other countries and if a longer incorporation of the CanMEDS framework and management training had an influence on the residents' perceptions of their management competency.

We used a questionnaire that measured the perceived management competencies of residents from Denmark, Canada, the Netherlands and Australia and found out that on the average, residents from Canada scored lowest in their perceived competencies. In addition, the Canadian residents had lesser number of years of clinical experience post graduation than their Danish and Dutch counterparts and multiple regression analysis showed that this factor significantly influenced the average perception of their management competencies. This finding was remarkable however, since the CanMEDS framework emerged from Canada and had been implemented in their postgraduate training program about 10 years prior to its implementation in the other countries included in our survey. The Canadian respondents scored especially low, in comparison to the residents from the 
other countries, on the items in the factors Career Planning and Professional Ethics. Our assumption is that this may be due to the fact that the general guidelines for postgraduate training programs set up by the RCPSC are subject to the interpretation of the different program directors and how they subsequently translate these guidelines into specific educational activities. It is possible for example, that residents do not receive any training in these areas, because some program directors may feel that residents will learn this on the job, or that they may get more training in their senior years. Why the Dutch residents gave higher ratings than their colleagues in Canada is not completely clear, since they too do not receive any mandatory management training during medical school as well as during the postgraduate training. An explanation for the higher ratings from the Australian junior doctors could be that in some universities a number of hours are spent on topics such as health services management and health economics [personal communication: S. Ahern, Medical Director of Postgraduate Medical Council of Victoria, Australia].

The residents from Denmark gave themselves on average the highest scores, which could be due to the mandatory management training, which all residents in Denmark receive. We saw in our results that the more training they received, the higher their average score was (mean no training 3.40 (SD 0.38), mean one training 3.55 (SD 0.37), mean two training courses 3.57 (SD 0.38) mean three training courses 3.83 (SD 0.27)). Moreover the medical students in Denmark also receive a three-week course on Medical Sociology where topics such as "knowledge of how the healthcare system is organized and financed", "management technologies", "quality development" and "health policies" are being addressed (19).

The item "negotiating working conditions" was in the top three of lowest perceived competencies in all four countries. "Knowledge of how their respective specialist department is organized and financed" was in the top three of lowest scored items in Canada, Australia and the Netherlands while the other items in the respective top three category differed per country. These differences can, for example, be attributed to the structure of the health care systems the residents were working in, or to the education they received in (medical) school. These differences should be accounted for when developing and designing a management training in the different countries.

The same can be said about the residents preferred topics for a future management course. The topics differed per country except for "negotiation skills" which was in the top three of preferred topics in all of the countries. Since the majority of the residents from all four countries rated their negotiation skills lowly and chose it as a preferred topic for a management course, it suggests that this topic is a subject residents want to know more about and that it is a need which is felt in all participating countries. 


\section{Chapter 6}

Most importantly, the majority of the residents from all four countries felt a need for (more) management training. In Denmark, despite the extra attention that was given to the managers' role during the postgraduate training, the average need for additional management training remained high. The different subcategories showed that the percentage of Danish residents who had not received any training yet and had a need for management training was $84.6 \%$. The percentages of residents who had an additional management training need and received one, two or all three training courses was $87.0 \%$, $81.2 \%$ and $78.9 \%$ respectively. An explanation for the increase in percentage after the first training could be that their interest in the subject is being raised after their first management course and that awareness arises of their knowledge gap in this area.

The favorite method of instruction was the same for Canada, Australia and the Netherlands, namely a workshop. The residents from Denmark preferred a case based method. The majority of all residents chose "physicians" as the preferred instructor for a managementtraining program. The preferred length of each training differed between Denmark, Canada and Australia from one hour to a half day. The preferred frequency of sessions among the respondents from those three countries was once every month or every half year.

We acknowledge that there is little room left for additional content in most postgraduate medical curricula and that including yet another element, namely medical management, into these busy programs may be difficult. However we think that since the manager's role has been identified as a key competency in the four participating countries, the training programs in those countries need to design courses to develop this competency. Also, the extent to which these skills would need to be taught may differ for instance by the resident's number of years in training or their personal interest. Nevertheless, our research showed that the majority of the residents felt a need for a basic understanding of medical management.

As we mentioned earlier in our methods section, there were constraints e.g. logistical and time that influenced our approach and choice for convenience sampling. As this could have resulted in our survey population being biased, we need to interpret our findings with caution. For example, the response rate was not as high as we had hoped for in all four countries and particularly low in Australia, despite the two reminders we sent. We assume that the low response rates could have been due to the increasing amount of emails and questionnaires that residents receive, which may have resulted in a lack of time and interest in the residents to respond. We know this to be especially true for the Australian residents, as they regularly receive surveys from their own health services. Furthermore, our use of convenience sampling in the Netherlands, Australia and Canada may have resulted in 
a selection of samples that were not fully representative of the situation among all the residents at a national level in the respective countries. In other words, our findings in the district of Victoria may not necessarily be representative of a national view or of the view of residents in other districts. However, we do expect some degree of generalizability in the results since all countries have similar frameworks (CanMEDS) in their national health services, which have been used to develop their respective professional training programs. Finally, caution should be exercised when interpreting these results as we measured the perceived management competencies of the residents in our survey, and it is possible that the scores could have been different if objective assessment methods had been used.

\section{CONCLUSION}

In conclusion, the incorporation of the CanMEDS framework alone does not seem to be enough to improve the perceived management competencies among medical residents. The majority of the residents from all four countries had a need for management training, despite the duration of the incorporation of the CanMEDS framework and whether or not management training was provided in their programmes. Furthermore, receiving formal management training seemed to positively influence perceived management competencies. While we acknowledge that any recommendation for additional management training within the medical curriculum would undoubtedly be at the cost of the attention given to development of other professional competencies, there is sufficient evidence to suggest that the introduction of formal management training in postgraduate training programmes should be made mandatory, and that these should be adjusted to the specific needs of the residents in every country. 


\section{REFERENCES}

1. Lawson JG, McConnell JW. Teaching practice management in a family practice residency. J Med Educ. 1976 Oct;51(10):858-60. PubMed PMID: 972380. Epub 1976/10/01. eng.

2. Aluise JJ. The physician as manager. "What" and how" of practice management education. J Fam Pract. 1977 Feb;4(2):30511. PubMed PMID: 65441. Epub 1977/02/01. eng.

3. Piatt JP, Bartley $\mathrm{DL}$, Jacobson $A D$, Rimsza ME. Practice management training for pediatric residents. Am J Dis Child. 1991 Mar;145(3):299-301. PubMed PMID: 2003479. Epub 1991/03/01. eng.

4. Sims KL, Darcy TP. A leadershipmanagement training curriculum for pathology residents. Am J Clin Pathol. 1997 Jul;108(1):90-5. PubMed PMID: 9208984. Epub 1997/07/01. eng.

5. Brooks JP. Suggestions for management training of residents. Physician Exec. 1996 Mar;22(3):26-8. PubMed PMID: 10155972. Epub 1996/02/07. eng.

6. Farnsworth JR, Weiss RL. A mentorbased laboratory management elective for residents. Am J Clin Pathol. 1999 Feb;111(2):156-60. PubMed PMID: 9930135. Epub 1999/02/04. eng.

7. Cordes DH, Rea DF, Rea J, Vuturo A. A program of management training for residents. Acad Med. 1989 Jan;64(1):45-6. PubMed PMID: 2914065. Epub 1989/01/01. eng.

8. Winkelman JW, Brugnara C. Management training for pathology residents. II. Experience with a focused curriculum. Am J Clin Pathol. 1994 May;101(5):564-8. PubMed PMID: 8178761. Epub 1994/05/01. eng.
9. Royal College of Physicians and Surgeons of Canada. CanMEDS: better standards, better physicians, better care 2012 [cited 2012 September 2012]. Available from: http:// www.royalcollege.ca/portal/page/portal/rc/ canmeds.

10. Accreditation Council for Graduate Medical Education. Competency Requirements 2002 [cited 201220 September]. Available from: http://www.acgme.org/acWebsite/irc/ irc_complntro.asp.

11. Reenen RRd, C.; Schelfhout-van Deventer, $V$. Modernisering medische vervolgopleidingen: nieuw kaderbesluit CCMS (Dutch): Koninklijke Nederlandsche Maatschappij tot bevordering der Geneeskunst; 2009. Available from: http:// knmg.artsennet.nl/artikel/Moderniseringmedische-vervolgopleidingennieuwkaderbesluit-CCMS.htmReenen.

12. Busari JO, Berkenbosch L, Brouns JW. Physicians as managers of health care delivery and the implications for postgraduate medical training: a literature review. Teach Learn Med. 2011 Apr;23(2):186-96. PubMed PMID: 21516608. Epub 2011/04/26. eng.

13. Berkenbosch L, Brouns J, Busari JO. How Dutch medical residents perceive their competency as manager in the revised postgraduate medical curriculum. Postgrad Med J. 2011 Oct;87(1032):680-7. PubMed PMID: 21693572. Epub 2011/06/23. eng.

14. Brouns J, Berkenbosch L, D. P-SF, Heyligers I, Busari JO. Medical residents perceptions of the need for management education in the postgraduate curriculum: a preliminary study. International Journal of Medical Education. 2010;1:76-82. 
15. Royal College of Physicians and Surgeons of Canada. Train-the-Trainer workshop resource binders 2007-2011 [cited 2012 20 September]. Available from: http:// www.royalcollege.ca/portal/page/portal/rc/ canmeds/resources/workshops.

16. Confederation of Postgraduate Medical Education Councils. Australian Curriculum Framework for Junior Doctors (ACF) 2006 [cited 201220 September]. Available from: http://www.cpmec.org.au/Page/australiancurriculum-framework-for-junior-doctorsacf-menu.

17. Specialist Commission $\mathrm{MoH}$. The future specialist (Danish). Copenhagen: Ministry of Health, 2000.

18. Ministry of Health. Vejledning om generelle kurser i speciallægeuddannelsen (Danish) 2011 [cited 201220 September]. Available from: https://www.retsinformation.dk/ Forms/R0710.aspx?id=136870.

19. University of Copenhagen. studieordning for kandidatuddannelsen i medicin (Danish) 2009 [cited 201220 September]. Available from: http://medicin.ku.dk/om_ uddannelsen/studieordninger/2009kandidatstudieordning_pr._01.02.12.pdf/. 



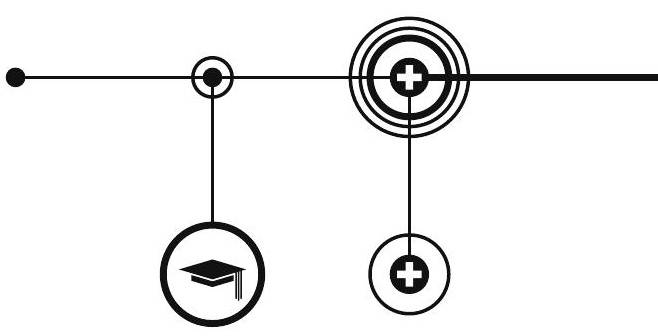

\section{Chapter 7}

\section{A pilot study of a practice management training module for medical residents}

Berkenbosch L, Muijtjens AMM, Zimmermann LJI, Heyligers I, Scherpbier A, Busari JO Accepted for publication in BMC Medical Education

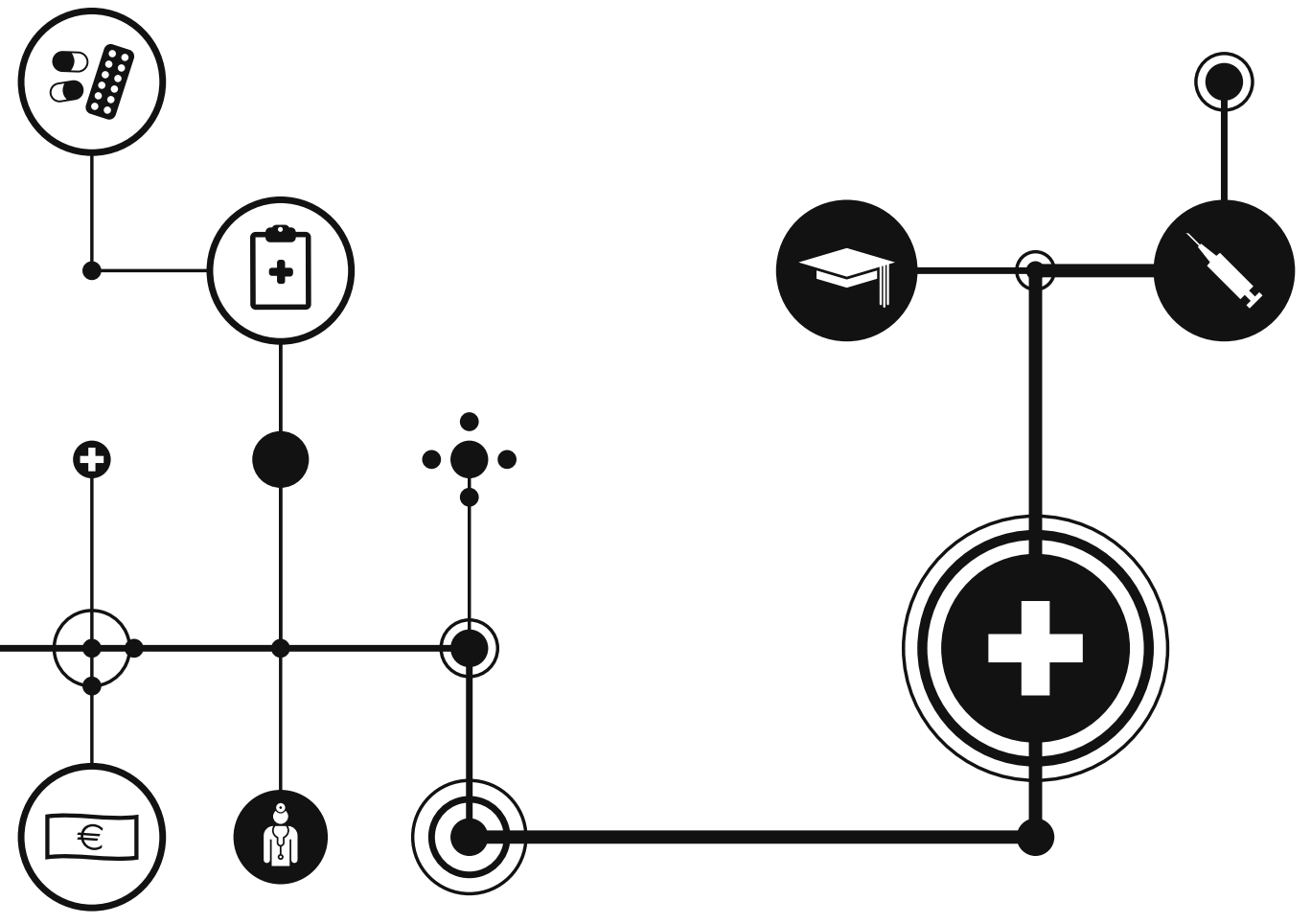




\section{Chapter 7}

\section{ABSTRACT \\ Background}

In 2005 a competency based curriculum was introduced in the Dutch postgraduate medical training programs. While the manager's role is one of the seven key competencies, there is still no formal management course in most postgraduate curricula. Based on a needs assessment we conducted, several themes were identified as important for a possible management training program. We present the results of the pilot training we performed to investigate two of these themes.

\section{Methods}

The topics "knowledge of the healthcare system" and "time management" were developed from the list of suggested management training themes. Fourteen residents participated in the training and twenty-four residents served as control. The training consisted of two sessions of four hours with a homework assignment in between. 50 True/false-questions were given as pre- and post-test to both the test and control groups to assess the level of acquired knowledge among the test group as well as the impact of the intervention. We also performed a qualitative evaluation using evaluation forms and in-depth interviews.

\section{Results}

All fourteen residents completed the training. Six residents in the control group were lost to follow up. The pre- and post-test showed improvement among the participating residents in comparison to the residents from the control group, but this improvement was not significant. The qualitative assessment showed that all residents evaluated the training positively and experienced it as a useful addition to their training in becoming a medical specialist.

\section{Conclusion}

Our training was evaluated positively and considered to be valuable. This study supports the need for mandatory medical management training as part of the postgraduate medical curriculum. Our training could be an example of how to teach two important themes in the broad area of medical management education. 


\section{BACKGROUND}

Today's doctors differ from their predecessors and work in a different health care environment. The physician of a century ago for example, was usually male and always available. He took decisions about his patients alone and rarely was there joint deliberation with colleagues within his own or other specialties. Nowadays, physicians practice their profession as part of a team across multiple disciplines and decisions are made within the context of multidisciplinary guidelines and institutional frames of reference. In addition, more doctors are working part-time, are on the payroll of hospitals and women are increasingly taking on the professional role as physicians $(1,2)$.

In the Netherlands, as in some other countries, the healthcare system and parts of the social security system are undergoing a transformation, moving from a framework of price regulation to one of regulated market forces (3-5). Due to this transition, physicians are to a greater extent than before, compelled to take part in negotiations with insurers and hospital management (2). The role for physicians as medical managers is in this context of increasing importance. On the first of January 2005 a new competency based curriculum was introduced in the postgraduate medical training programs of Dutch medical residents (6). The new curriculum was based on seven competencies that residents were expected to possess upon graduation (i.e. medical expert, communicator, collaborator, manager, health advocate, professional and scholar) and is derived from the CanMEDS framework from Canada (7). Although the CanMEDs competencies were introduced in 2005 and the manager's role is gaining increased importance, there is still no formal national curriculum in the Netherlands that teaches this role.

Hence, we decided to investigate if there was a need for management training among residents in the Netherlands and if so, what such training program should look like. We started by performing a literature review to find out what already had been written on the topic (8) and we performed a survey and needs assessment among Dutch medical residents and specialists on the perceived management competencies of junior doctors and their training needs (9-11). The most important results of these projects are summarized in Table 1.

We updated our literature search to see if new articles on management curricula had been published since 2010. We used the same search strategy as for the earlier literature review (8). We found nine new articles describing a management program designed for medical residents (12-20). In combination with our previous literature review a total of 32 articles described management training programs which focused on medical residents. Most of 


\section{Chapter 7}

Table 1. Overview of previously performed research by the authors

\begin{tabular}{|c|c|}
\hline Research project & Most important findings \\
\hline Literature review[8] & $\begin{array}{l}\text { - } 40 \text { articles on medical management were found } \\
\text { - } 24 \text { articles described management curricula } \\
\text { - The curricula differed in timing, length, content and teachers, but were all } \\
\text { evaluated positively } \\
\text { - Topics most taught: financial concepts, management concepts, quality } \\
\text { assurance, legal issues, personnel issues and organizational skills/time } \\
\text { management }\end{array}$ \\
\hline $\begin{array}{l}\text { Perceived } \\
\text { competencies by } \\
\text { residents[10] }\end{array}$ & $\begin{array}{l}\text { - Neutral perceptions on: negotiating personal ambitions, possessing } \\
\text { adequate leadership skills, knowledge of the legal aspects of healthcare } \\
\text { and knowing how to deal with medical errors } \\
\text { - Inadequate perceptions on: contract negotiating skills and knowledge of } \\
\text { how the healthcare system and specialists departments are financed } \\
\text { and organized }\end{array}$ \\
\hline $\begin{array}{l}\text { Needs assessment } \\
\text { among residents[11] }\end{array}$ & $\begin{array}{l}\text { - 85\% reported a need for management training } \\
\text { - Training preferences: during residency, interactive, by physician or } \\
\text { extramural expert, topics: negotiation skills, specialist partnerships, the } \\
\text { health care system, career opportunities and leadership }\end{array}$ \\
\hline $\begin{array}{l}\text { Competencies and } \\
\text { needs of residents } \\
\text { perceived by } \\
\text { specialists[9] }\end{array}$ & $\begin{array}{l}\text { - Inadequate perceptions on residents abilities: contract negotiating skills, } \\
\text { knowledge of the healthcare system and specialist department. } \\
\text { - 94\% reported a need for management training among residents } \\
\text { - Training preferences: during residency, interactive, by physician or } \\
\text { extramural expert, topics: the health care system, time management, } \\
\text { leadership, legal aspects of medical errors and communication. }\end{array}$ \\
\hline
\end{tabular}

these curricula were developed based on previous literature and personal experience. Only five programs were based on a needs assessment, four among the residents themselves (21-24) and one among their supervisors (25). There was no consensus regarding the content, the timing in the overall curriculum, the length of individual training sessions, or the total duration of management training programs. Of the 32 programs described, several courses had subjective evaluations, but only eight had objective pre- and/or posttests to evaluate the effect of the training (Table 2). None used in-depth interviews as a qualitative approach to evaluate the training courses.

Based on the findings from our previous research, we decided to design and develop a management training program for medical residents. Our goal was 1) to develop a management course on the basis of a list of items suggested by residents and specialists, 2) to evaluate the objective and perceived impact of the course on the residents, and 3) to compare the knowledge of the healthcare system between residents and specialists. 
Table 2. Overview pre-posttest designs in the literature

\begin{tabular}{|c|c|c|c|c|}
\hline & $\begin{array}{l}\text { Number of items } \\
\text { (design) }\end{array}$ & $\begin{array}{l}\text { Reliability } \\
\text { reported }\end{array}$ & Timing of posttest & $\begin{array}{l}\text { Contro } \\
\text { group }\end{array}$ \\
\hline Crites & 12 (true/false) & No & $\begin{array}{l}\text { Immediately after } \\
\text { completion }\end{array}$ & No \\
\hline Babitch & 5 (unknown) & No & $\begin{array}{l}\text { Immediately after } \\
\text { completion }\end{array}$ & No \\
\hline Essex & 65 (true/false) & No & $\begin{array}{l}\text { Immediately and one } \\
\text { month after completion }\end{array}$ & Yes \\
\hline Hemmer & 20 (unknown) & No & Before last session & No \\
\hline Lopresti & $\begin{array}{l}40 \text { (multiple choice and } \\
\text { "pick N" questions) }\end{array}$ & Yes & Unknown & Yes \\
\hline Turley & 50 (multiple choice) & No & Unknown & No \\
\hline Kerfoot & 26 (multiple choice) & Yes & $\begin{array}{l}\text { Immediately and five } \\
\text { weeks after completion }\end{array}$ & Yes \\
\hline David & 10 (true/false) & No & Unknown & Yes \\
\hline
\end{tabular}

\section{METHODS}

\section{Topic selection}

Medical management is a broad subject and it is impossible to cover all areas in one training session. We therefore designed a training module and chose two themes from the list of suggested areas by the residents and specialists, namely knowledge of the healthcare system and time management. We chose these topics since we wanted to combine a theoretical topic (knowledge of the healthcare system) with a skill (time management). Also these topics were indicated as important in the literature review as well as in the needs assessments (Table 1).

\section{Instructors selection}

To meet the preferences of the residents we wanted the instructors to be physicians as well as content experts. Members of the board of directors of the two participating hospitals (Atrium Medical Centre, Heerlen and Maastricht University Medical Centre, Maastricht) were approached to participate in the course as teachers. A member of the board of directors from each hospital offered to be an instructor on the topic "Knowledge of the healthcare system". One of the divisional directors of the Atrium Medical Centre offered to be the instructor on "Time management". 


\section{Chapter 7}

\section{Participants}

In the two participating hospitals, residents in Paediatrics, Obstetrics and Gynaecology (ObGyn), Orthopaedic Surgery and Internal Medicine were approached for participation in the management training to obtain a representative group of residents from surgical- as well as non-surgical specialties. To implement an interactive learning approach, as was preferred in the needs assessments, we wanted no more than 15 participants in each group.

\section{Format of the training}

The format of the course was set up to meet the requirements of the inter-disciplinary educational standards that apply in the south-east region of the Netherlands. The first session during week one, consisted of a two hours lecture on the concepts of the organization and financing of the healthcare system on national level and a two hours lecture on the general concepts of time management. Both sessions used a PowerPoint presentation as a general guideline to cover the most important subjects, but the instructors invited the participants to ask questions and bring their own thoughts on the subject to the table to create an interactive learning environment.

The residents received two homework assignments. With the first assignment they were invited to solve a simulated problem in the healthcare system and to present their solutions in a PowerPoint presentation. For the other assignment the residents received the documentation of a real staff meeting from one of the hospitals. They were asked to prepare themselves individually for the next session where a staff meeting would be simulated to teach them on time management and skills to effectively participate in and chair a staff meeting. Lectures and literature were provided to support the residents in their assignments.

After three weeks the second and final session of four hours took place. In the first hour the residents presented their solutions on the assigned problem in the healthcare system. Then another hour was spent on teaching them the micro concepts of the healthcare system, namely the organization and financing of hospitals and specialists departments. The session was concluded with a simulated staff meeting.

\section{Evaluation}

Training course

Feedback from the residents was received through evaluation forms and in-depth interviews. The anonymous evaluation form consisted of five statements querying the 
residents on their assessment of each presentation. They were asked to rate the sessions on a 1-5 Likert scale (1=very poor; $5=$ =very good) on the following points: the communication skills of the presenter, the extent to which the theoretical framework was clearly explained, the translation of theory into practice, the quality of the PowerPoint presentation and the overall usefulness of the presentation. In addition they were invited to rate the choice of the selected topics in the training, the quality of homework assignments, the provided literature, and the overall added value of the course. There was also an open area where they could leave their additional comments.

With the in-depth interviews we tried to gain further insight in the positive aspects of the training and the areas for improvement. A selection of residents (based on demographic information) and all three teachers were invited to further explain in a 20-minute telephone interview, their views on the management training. LB conducted the semi-structured interviews after the last training session. The interviews were guided by 12 questions covering the most important topics (strengths, points for improvement, topic selection, time per topic, format of the training, teachers, homework assignments and the literature). Participants were assured of anonymity and confidentiality and received the transcript of their interview by e-mail with the request to correct them if necessary.

\section{Knowledge}

To evaluate the effectiveness of the training a knowledge test consisting of 50 true/falsequestions on the subject "knowledge of the health care system" was set up by the two instructors on that topic. Scores were expressed as the percentage correctly answered questions. The residents were also requested to complete an additional questionnaire to obtain information on background variables such as a resident's work experience in years, if the resident attended management training before and if the resident had previous management experience.

\section{Procedures}

Ethical approval

Prior to starting the (pilot)training we sought for ethical approval from the hospital's research and ethics committee. They ruled that ethical approval was not required according to the Dutch Medical Research (Human Subjects) Act.

\section{Pilot}

We first conducted a pilot training from March till April 2012 at the Atrium Medical Centre. Eleven residents ( 6 from ObGyn, 1 from Internal Medicine and 4 from Orthopaedic 


\section{Chapter 7}

Surgery) participated in the pilot training. Based on the analysis of the feedback (eleven evaluation forms and four in-depth interviews) we received about the pilot training, minor modifications were performed on the main format of the training workshop. For example, the homework assignment on the staff meeting was cancelled and the time schedule per subject was adjusted. The residents wanted more time (3 hours per session) on knowledge of the healthcare system and less on time-management and participating in or leading (staff)meetings (1 hour per session).

\section{The definite training}

The definite training ran from April till May 2012 at the Maastricht University Medical Centre. Again residents from Paediatrics, ObGyn, Orthopaedic Surgery and Internal Medicine were approached for participation. We also set up a group of medical residents from the same disciplines who served as a control for comparison. The assignment to experimental or control group was determined by the residents' availability, largely determined by their work schedule during the study period (i.e. convenience sampling). All program directors agreed to have their residents' join in and facilitated participation as much as possible. Consent was sought for and obtained from all participating residents.

Two weeks before the start of the training the participating residents and the residents in the control group were asked to fill in the 50 item questionnaire of knowledge testing (pretest). At the same time medical specialists of Pediatrics, Orthopedics, Internal Medicine and ObGyn received the test to explore whether their knowledge of the healthcare system was gained over time through work experience. Immediately after the training, the participating residents filled in the evaluation forms. In the weeks after completion of the training, four in-depth interviews were performed among the participating residents and three among the teachers. After two months the knowledge test was again send by email to the participating residents and the residents in the control group (post-test) (see Figure 1).

\section{DATA ANALYSIS}

Analysis was performed using SPSS, version 17. Descriptive statistics were used to present the demographic distribution of the participants of this study. The reliability (Cronbach's alpha) of the 50 true/false questions test was calculated using the pre-test data of all medical residents (intervention as well as control group). Whether the scores on the posttest were influenced by participating in the management course or not, was investigated 


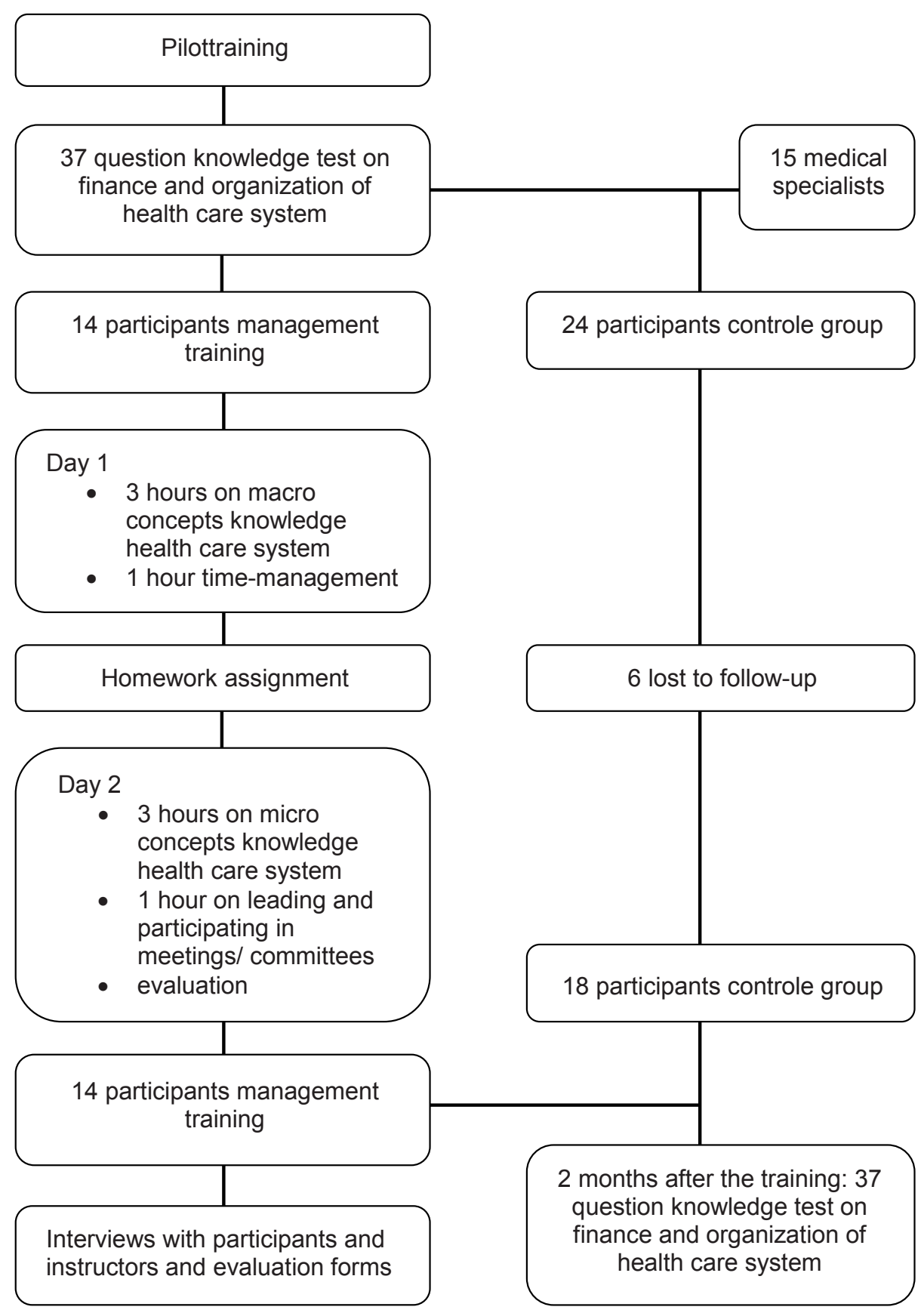

Figure 1. Flowchart pilot training 


\section{Chapter 7}

using multiple regression analysis. The posttest score was the dependent variable in the analysis and training (0: control, 1: intervention), the pre-test score, and work experience were the independent variables. For ease of interpretation and numerical stability the centered version of the pre-test score, score pre-test - mean score pre-test, was used as independent variable in the regression analysis. Work experience was defined in years. We used an independent t-test to see if medical specialists had on average a significant higher score than the residents by comparing the pre-test results of all residents to the test results of the medical specialists. The in-depth interviews were transcribed verbatim. To classify these unstructured data into coding categories author LB created a coding dictionary by which all interviews were analyzed. Descriptive statistics were used to present these data.

\section{RESULTS}

\section{Final version of the knowledge test}

The original test consisted of 50 true/false questions. In the reliability analysis, questions that did not positively contribute to the reliability were candidates to be removed. The coverage of the domain of the test was also taken into consideration when deciding on removing items. Using these indications 13 items were removed, resulting in a satisfactory alpha of .702 for the remaining set of 37 items in the final version of the test.

\section{Characteristics (table 3)}

Fourteen residents (2 from ObGyn, 5 from Internal Medicine, 5 from Orthopaedic Surgery and 2 from Paediatrics) participated in our final training. The control group consisted of 24 medical residents (3 Orthopaedic Surgery, 5 Paediatrics, 9 Internal Medicine, 7 ObGyn). The fourteen residents who participated in the course completed all sections of training and evaluation. Of the 24 residents in the control group six were lost to follow-up (3 ObGyn, 3 Orthopedic Surgery) and did not complete the post-test. There were no reasons given for not completing the post-test.

The group of medical specialists consisted of 6 Paediatricians, 5 Internists and 4 Gynaecologists. The participating residents had on average 5.6 years of work experience. The residents from the control group had on average 4.8 years of experience, while the medical specialists had an average of 20.3 years experience. Of the participating residents, one resident had previous management training while two residents had previous management experience. In the control group two residents had previous management experience and two residents had previous management training. Five of the 15 medical specialists had previous management training and 8 specialists had previous management 
Table 3. Characteristics

\begin{tabular}{|c|c|c|c|}
\hline & $\begin{array}{l}\text { Participating } \\
\text { residents }(n=14)\end{array}$ & $\begin{array}{l}\text { Residents in control } \\
\text { group }(n=24)\end{array}$ & $\begin{array}{c}\text { Medical } \\
\text { specialists }(n=15)\end{array}$ \\
\hline \multicolumn{4}{|l|}{ Specialisation } \\
\hline - Orthopedical surgery & 5 & 3 & 0 \\
\hline - Paediatrics & 2 & 5 & 6 \\
\hline - Internal Medicine & 5 & 9 & 5 \\
\hline · Gynaecology & 2 & 7 & 4 \\
\hline Work Experience (years) & 5.6 & 4.8 & 20.3 \\
\hline Previous training & $N=1,7.1 \%$ & $N=2,8.3 \%$ & $N=5,33.3 \%$ \\
\hline Previous experience & $N=2,14.2 \%$ & $N=2,8.3 \%$ & $N=8,53.3 \%$ \\
\hline Average score pretest & $66.41 \%$ (SD 6.2) & 67.94\% (SD 9.7) & $71.23 \%$ (SD 8.1) \\
\hline Average score posttest & $72.97 \%$ (SD 5.7) & $71.22 \%$ (SD 5.2) & \\
\hline
\end{tabular}

experience. The residents in the intervention group scored on average $66.41 \%$ (SD 6.2) questions correct on the pre-test. The residents in the control group scored on average $67.94 \%$ (SD 9.7) correct. The specialists answered on average $71.23 \%$ (SD 8.1) of the questions correct. On the post-test the scores for the residents in the intervention and control groups were $72.97 \%$ (SD 5.7) and $71.22 \%$ (SD 5.2), respectively. Although the specialists had on average a higher score than the residents the difference, $4.06 \%$, was not significant ( $p=0.072$ ) using independent t-test analysis.

\section{Multiple regression analysis}

None of the independent variables had a significant influence on the post-scores. The score difference between intervention and control at post-intervention time was equal to $2.3 \%$ ( $p=0.30$; standard regression coefficient $(\mathrm{src})=0.21$ ), the effect of the pre-test score on the post-test score was equal to 0.27 ( $p=0.094$; src=0.33), and the effect of work experience was 0.11 ( $p=0.82$; src=0.05).

\section{Evaluation forms}

On a 1-5 Likert-scale (1=very poor; $5=$ very good) the items were assessed as follows:

- The average quality of the sessions: 4.21 (SD 0.45)

- The choice of the selected topics in this training: 4.09 (SD 0.30)

- The added value of the course: 4.27 (SD 0.65)

- The quality of the provided literature: 3.41 (SD 0.58)

- $\quad$ The homework assignments: 3.82 (SD 0.98)

The overall grade with which the residents rated the training was on average (on a scale 


\section{Chapter 7}

from 1-10) a 7.66 (range 6-9). There were also some additional comments written on the evaluations forms. Two residents stated that they had too little basic knowledge of the subjects to fully appreciate the training. Two residents stated that this training filled a gap in their current postgraduate medical training. Three residents thought that the homework assignments were too broad, they advised to limit the assignments so that the presentations of the assignments wouldn't take up as much time during the sessions. Five residents wrote that they would have liked even more opportunities for debate during the sessions.

\section{In-depth interviews}

Four residents (1 ObGyn, 1 pediatrics, 1 orthopedics, 1 internal medicine) and the three instructors participated in the in-depth interviews.

\section{Residents}

All four residents stated that they had appreciated the training, some positive points they named were:

- "The teachers used an interactive approach." (resident 1)

- "It fills a gap in our current postgraduate medical training." (resident 2)

- "I would like to have another session, my interest is piqued." (resident 3)

There were also some points for improvement. Three out of four residents said that too much basic knowledge was expected as resident 1 stated: "I had heard of some basic concepts and perhaps I should have asked more but occasionally it really was like Chinese to me." Also three out of four residents said they liked the fact that they had received some literature before the start of the training, but two out of those three said that the amount had been too much and that they rather would have received two short overview articles.

All four residents appreciated the topics that were chosen, although resident 4 said that he would maybe split the topics up. "The topics are well chosen, but they do not fit in the same course. Time management is more suitable for first year medical residents and the organization and financing of health care is better appreciated by senior residents". We also asked them if they had missed a topic in this training course. Two out of four said that they would like to have heard more about the organization and financing of specialist partnerships.

They all liked the format of the training and they would preserve the two sessions as "it is too much information for one day." (resident 1 and 4). They also appreciated the homework assignment in which they had to solve a simulated problem in the healthcare system and 
present their solutions, "it is a trigger for some interesting discussions" (resident 4), and " $a$ homework assignment serves as a big stick to ensure that you delve into the material" (resident 1).

There was some discussion on the question if they had liked the fact that all teachers were also physicians. Two out of three said yes, because "they were better able to empathize with the bustle of the day and estimate what material was interesting for us." One said yes on time-management, but he didn't think it was of added value on the topic organization and financing of the health care system. And one said no, "because their stories sometimes seemed a bit biased."

\section{Teachers}

All three teachers agreed on the topics that were being taught. An additional comment was: "There are many other important issues to consider, but in the limited time we had these topics were adequate and relevant" (teacher 2).

If they had to pick another topic, two out of three said that they thought that the residents probably wanted to know more about specialist partnerships.

They all wanted to keep the current format, "it is too much information for one day" (teacher 3) and teacher 2 stated that "this format encouraged residents to get involved with the material" The two teachers on the subject "knowledge of the organization and financing of the health care system" stated that they had expected a higher level of basic knowledge from the participating residents.

\section{DISCUSSION}

In this study, we set out to design and develop a management training module for medical residents. We also wanted to evaluate the objective and subjective impact of the course on the residents, and to compare the objective knowledge of the healthcare system between residents and specialists.

We developed a training course in which two management topics were taught, namely "the organization and financing of the health care system in the Netherlands" and "time management". We used a pre- and post-knowledge test to see if the knowledge of the participating residents on the "organization and financing of the health care system" had significantly improved after participating in the training in comparison to the residents in the control group. Although the difference between the percentages of correctly answered 


\section{Chapter 7}

questions on the pre- and post-test was greater for the participating residents (6.56\%) in comparison to the residents from the control group (3.28\%), the difference was not significant. This can be explained by three possible causes. First of all our research groups were small and probably too small to detect a significant difference. To detect a large effect with a power of $80 \%$ and a significance level of 5\% at least 26 persons had to take part in the participating group as well as in the control group. Due to time and resource limitations, we weren't able to provide those numbers. Secondly, the knowledge test was based on the Powerpoint presentations the teachers had prepared, but due to a lack of basic knowledge of the residents on the topics and due to the vivid discussions (which were encouraged), the teachers did not complete their Powerpoint presentations. Although the residents received the Powerpoint presentations by email, it is possible that they did not pick up on all information that was available. Finally it is also possible that the knowledge the residents gained from this training was not retained as well as we had hoped for. Of the eight management training programs described in the literature, which also used objective pre- and posttests, four programs found a significant increase in knowledge $(13,14,25,26)$. Three out of those four programs had a research population of less than 35 participants $(14,25,26)$. The other four programs described an increase in knowledge, but this increase was either not significant, or not tested for significance.

The 15 medical specialists did not significantly score better on the knowledge test than the residents. Even though the specialists had relatively more work experience, management experience and previous management training in comparison to the residents. This could suggest that work experience alone is not enough to gain knowledge on this subject. But the group of participating specialists and residents was again too small to give a definite answer to this question or to perform sub analyses on the variables management experience and management training.

The evaluation of the participants' perceptions showed that all residents appreciated the training. Some of them stated that it had filled a gap in their current specialist training and others said that they would have liked even more education on these subjects. Residents and teachers agreed on the topics that were chosen for this course, but some suggested that specific knowledge on how specialist partnerships in the Netherlands are organized and financed would also be of value, especially to those who are almost at the end of their specialist training. This evaluation suggests that two sessions of four hours isn't enough to adequately teach all aspects of medical management and to satisfy the residents educational needs on this matter. Besides "specialist partnerships" the needs assessment and literature review we earlier performed showed that topics as negotiation 
skills, career opportunities, legal issues and leadership skills are also deemed important $(8,9,11)$. At least two other training modules would be necessary to teach all these subjects. Our suggestions would be to divide the topics into subjects suitable for junior medical residents and for residents who are more advanced in their specialist training program. In the literature, of the 32 training programs described, 21 used a subjective evaluation of which 20 (14,15,17,19,20,22,27-40) were positive and one was neutral (13). Based on our own evaluation and the evaluations in the literature we also suggest that medical management training should be mandatory since we feel that all doctors should have a basic knowledge of these subjects and residents seem to have a need for it.

\section{CONCLUSION}

We recognize that most postgraduate medical curricula are already quite full and that there is little room left for additional content, namely medical management. However we think that since the managers role has been identified as a key competency in the Netherlands but also in many other countries (US, Canada, Australia), the training programs in those countries need to design courses to develop this competency. This paper has described how we developed and evaluated a management training module, which taught the topics "organization and financing of the health care system" and "time management". This training was evaluated positively and considered to be of added value by the participants. This training is an example of how to systematically develop, design and evaluate management training courses for medical residents. Based on this and our previous research experience in this area, we recommend that medical management training should be a mandatory part of the postgraduate medical curriculum. 


\section{REFERENCES}

1. Groenewegen PP, Hansen JJHHI, Bekke S. Professies en de toekomst: veranderende verhoudingen in de gezondheidszorg: Springer; 2007.

2. The Royal Dutch Medical Association (KNMG). Medical Professionalism 2007 [cited 2013 may 11 2013]. Available from: http://knmg.artsennet.nl/Publicaties/ KNMGpublicatie/Medical-professionalismKNMG-manifesto-2007.htm.

3. Leu RE, Rutten FFH, Brouwer W, Matter P, Rütschi C. The Swiss and Dutch Health Insurance Systems: Universal Coverage and Regulated Competitive Insurance Markets. The Commonwealth Fund, 2009.

4. Thomson S, Osborn R, Squires D, Reed SJ. International Profiles of Health Care Systems, 2011. The Commonwealth Fund, 2011.

5. Rosenau PV, Lako CJ. An experiment with regulated competition and individual mandates for universal health care: the new Dutch health insurance system. Journal of health politics, policy and law. 2008 Dec;33(6):1031-55. PubMed PMID: 19038869.

6. Reenen van R, Rooyen den C, Schelfhoutvan Deventer $\mathrm{V}$. Modernisering medische vervolgopleidingen: nieuw kaderbesluit CCMS (Dutch): The Royal Dutch Medical Association (KNMG); [cited 2013 May 11 2013]. Available from: http://knmg. artsennet.nl/artikel/Moderniseringmedische-vervolgopleidingennieuwkaderbesluit-CCMS.htm.

7. Royal College of Physicians and Surgeons of Canada. The CanMEDS Framework 2005 [cited 2013 May 11 2013]. Available from: http://www.royalcollege.ca/portal/page/ portal/rc/canmeds/framework.
8. Busari JO, Berkenbosch L, Brouns JW. Physicians as managers of health care delivery and the implications for postgraduate medical training: a literature review. Teach Learn Med. 2011 Apr;23(2):186-96. PubMed PMID: 21516608. Epub 2011/04/26. eng.

9. Berkenbosch L, Bax $M$, Scherpbier $A$, Heyligers I, Muijtjens AM, Busari JO. How Dutch medical specialists perceive the competencies and training needs of medical residents in healthcare management. Medical teacher. 2013 Apr;35(4):e1090-102. PubMed PMID: 23137237.

10. Berkenbosch L, BrounsJW, Heyligers I, Busari JO. How Dutch medical residents perceive their competency as manager in the revised postgraduate medical curriculum. Postgrad Med J. 2011 Oct;87(1032):680-7. PubMed PMID: 21693572. Epub 2011/06/23. eng.

11. Brouns JW, Berkenbosch L, Ploemen-Suijker FD, Heyligers I, Busari JO. Medical residents perceptions of the need for management education in the postgraduate curriculum: a preliminary study. Int J Med Educ. 2010;1:7682. Epub November 12, 2010. eng.

12. Doezema D, McLaughlin S, Sklar DP. An approach to fulfilling the systemsbased practice competency requirement. Academic emergency medicine : official journal of the Society for Academic Emergency Medicine. 2002 Nov;9(11):13559. PubMed PMID: 12414495.

13. Kerfoot BP, Conlin PR, Travison T, McMahon GT. Web-based education in systems-based practice: a randomized trial. Archives of internal medicine. 2007 Feb 26;167(4):3616. PubMed PMID: 17325297. 
14. Turley CB, Roach R, Marx M. Systems survivor: a program for house staff in systems-based practice. Teaching and learning in medicine. 2007 Spring;19(2):128-38. PubMed PMID: 17564540.

15. Allen E, Zerzan J, Choo C, Shenson D, Saha S. Teaching systems-based practice to residents by using independent study projects. Academic medicine : journal of the Association of American Medical Colleges. 2005 Feb;80(2):125-8. PubMed PMID: 15671314

16. Kasuya RT, Nip IL. A retreat on leadership skills for residents. Academic medicine : journal of the Association of American Medical Colleges. 2001 May;76(5):554. PubMed PMID: 11346606.

17. Voss JD, Nadkarni MM, Schectman JM. The Clinical Health Economics System Simulation (CHESS): a teaching tool for systems- and practice-based learning. Academic medicine : journal of the Association of American Medical Colleges. 2005 Feb;80(2):129-34. PubMed PMID: 15671315.

18. David RA, Reich LM. The creation and evaluation of a systems-based practice/ managed care curriculum in a primary care internal medicine residency program. The Mount Sinai journal of medicine, New York. 2005 Sep;72(5):296-9. PubMed PMID: 16184291.

19. Jones K, Lebron RA, Mangram A, Dunn E. Practice management education during surgical residency. American journal of surgery. 2008 Dec;196(6):878-81; discussion 81-2. PubMed PMID: 19095103.
20. Kuo AK, Thyne SM, Chen HC, West DC, Kamei RK. An innovative residency program designed to develop leaders to improve the health of children. Academic medicine : journal of the Association of American Medical Colleges. 2010 Oct;85(10):1603-8. PubMed PMID: 20703151.

21. Chan S. Management education during radiology residency: development of an educational practice. Academic radiology. 2004 Nov;11(11):1308-17. PubMed PMID: 15561581

22. Crites GE, Schuster RJ. A preliminary report of an educational intervention in practice management. BMC medical education. 2004 Sep 20;4:15. PubMed PMID: 15380023. Pubmed Central PMCID: 520819.

23. Gill JB, Schutt RC, Jr. Practice management education in orthopaedic surgical residencies. The Journal of bone and joint surgery American volume. 2007 Jan;89(1):216-9. PubMed PMID: 17200329.

24. Maggi JD, Stergiopoulos V, Sockalingam S. Implementing a new physician manager curriculum into a psychiatry residency training program: the change process, barriers and facilitators. The Psychiatric quarterly. 2008 Mar;79(1):21-31. PubMed PMID: 18157639.

25. Essex B, Jackson RN. Moneymed: a game to develop management skills in general practice. The Journal of the Royal College of General Practitioners. 1981 Dec;31(233):735-9. PubMed PMID: 7338867. Pubmed Central PMCID: 1972233.

26. LoPresti L, Ginn P, Treat R. Using a simulated practice to improve practice management learning. Family medicine. 2009 Oct;41(9):640-5. PubMed PMID: 19816827. 


\section{Chapter 7}

27. Hemmer PR, Karon BS, Hernandez JS, Cuthbert C, Fidler ME, Tazelaar HD. Leadership and management training for residents and fellows: a curriculum for future medical directors. Archives of pathology \& laboratory medicine. 2007 Apr;131(4):6104. PubMed PMID: 17425393.

28. Babitch LA. Teaching practice management skills to pediatric residents. Clinical pediatrics. 2006 Nov;45(9):846-9. PubMed PMID: 17041173.

29. Bayard M, Peeples CR, Holt J, David DJ. An interactive approach to teaching practice management to family practice residents. Family medicine. 2003 Oct;35(9):622-4. PubMed PMID: 14523656.

30. Horowitz RE, Naritoku W, Wagar EA. Management training for pathology residents: a regional approach. Archives of pathology \& laboratory medicine. 2004 Jan;128(1):59-63. PubMed PMID: 14692810.

31. Aluise JJ. The physician as manager. "What" and HOW" OF PRACTICE MANAGEMENT EDUCATION. The Journal of family practice. 1977 Feb;4(2):305-11. PubMed PMID: 65441.

32. Amin AN. A business of medicine curriculum for medical students. Medical education. 2005 May;39(5):510-1. PubMed PMID: 15842690.

33. Cordes DH, Rea DF, Rea J, Vuturo A. A program of management training for residents. Academic medicine : journal of the Association of American Medical Colleges. 1989 Jan;64(1):45-6. PubMed PMID: 2914065.

34. Kaur N, Singh $T$. Introducing medical students to health care management. Medical education. 2009 Nov;43(11):10901. PubMed PMID: 19799732.

35. Lawson JG, McConnell JW. Teaching practice management in a family practice residency. Journal of medical education. 1976 Oct;51(10):858-60. PubMed PMID: 972380.
36. Mirowitz SA. Development and assessment of a radiology core curriculum in health care policy and practice. Academic radiology. 2000 Jul;7(7):540-50. PubMed PMID: 10902963.

37. Sims KL, DarcyTP.Aleadership-management training curriculum for pathology residents. American journal of clinical pathology. 1997 Jul;108(1):90-5. PubMed PMID: 9208984.

38. Stergiopoulos V, Maggi J, Sockalingam S. Teaching the physician-manager role to psychiatric residents: development and implementation of a pilot curriculum. Academic psychiatry : the journal of the American Association of Directors of Psychiatric Residency Training and the Association for Academic Psychiatry. 2009 Mar-Apr;33(2):125-30. PubMed PMID: 19398625.

39. Yu-Chin R. Teaching administration and management within psychiatric residency training. Academic psychiatry : the journal of the American Association of Directors of Psychiatric Residency Training and the Association for Academic Psychiatry. 2002 Winter;26(4):245-52. PubMed PMID: 12824127.

40. Scott HM, Tangalos EG, Blomberg RA, Bender CE. Survey of physician leadership and management education. Mayo Clinic proceedings Mayo Clinic. 1997 Jul;72(7):65962. PubMed PMID: 9212770. 




\section{Chapter 8}

\section{BACKGROUND}

The process of health care delivery and professional training of medical doctors has recently been the subject of much debate. The different stakeholders in the healthcare system are demanding more of physicians than just being medical experts. Patients want doctors who also know how to communicate, hospitals want doctors who can collaborate in multidisciplinary teams, universities want great teachers for their medical students and insurance companies want doctors who allocate scarce resources with care. Among other medical institutions, the Royal College of Physicians and Surgeons of Canada (RCPSC) concluded that physicians need to be trained in a more elaborate set of competencies. They decided on seven key competencies which all modern physicians should possess and described these in the CanMEDS framework. These competencies are: medical expert, communicator, collaborator, manager, health advocate, scholar and professional (1). The Netherlands adopted this framework as the foundation of their postgraduate medical curricula when they too realized the need for a different kind of doctor (2).

The role as manager is one of the seven key competencies described by the CanMEDS framework. As managers, physicians have to organize their practices, decide on allocating resources, contribute to the effectiveness of the healthcare system and serve in leadership roles as appropriate. In the modern, complex and demanding healthcare environment, those responsibilities are becoming increasingly difficult. However, we felt that this important competency did not receive as much attention in the postgraduate curricula as some of the other competencies. A tentative literature search showed no published attention in the Netherlands on this subject. Those findings formed the base for our two main research aims:

- To find out what is known about the managers role in the international literature and to investigate if these findings also apply to the Dutch situation.

- To design and develop a medical management training intervention based on the findings resulting from the research that will be necessary to complete aim 1.

In this chapter the main findings of the studies are summarized and discussed. We discuss the limitations of the studies and propose recommendations for future research. Finally, practical implications with respect to management education in the postgraduate medical curriculum are considered. 


\section{LITERATURE REVIEW}

As mentioned above, before starting this PhD project we performed a literature search to investigate how much attention is given to the manager role in Dutch medical education. We found little information on the subject in the Netherlands, which made us wonder how much importance was given to the subject, not only in the Netherlands but also worldwide. We therefore started by performing an international literature review, described in Chapter 2 (3). The review revealed mostly information from the USA and Canada. Of the 40 articles we found, 37 originated from the USA or Canada. It appeared that there was much more (published) attention in North-America concerning this competency than in the rest of the world. Another notable finding were the specialties that published these articles. The majority of the articles came from family medicine $(n=8)$, pathology $(n=8)$ and another eight originated in university settings. The possible explanations for this finding were that many primary care physicians have to set up and run their own clinics and thus have a greater need to be well equipped with managerial skills and knowledge. Pathologists may also have a greater interest in managerial competencies since they run laboratories and are therefore involved in managerial issues like laboratory design, analysis of work flow, choice of instrumentation, quality control, indicators of productivity and sometimes even budgeting and staff planning (4-7). The relatively large amount of articles from university settings suggests that the manager role is considered to be an important competency, worth spending educational time on (8-12).

Eleven of the reviewed articles concerned needs-assessments (10,13-22). The assessments were taken from program directors, fellows, residents and medical students. There was no consensus on the managerial topics that should be taught or on the educational method that should be used. All of the articles however concluded that management education was essential and needed.

Of the 26 articles that described curriculum designs to teach managerial skills, only five were based on a needs assessment (13-16,23). So the method of choice, the addressed topics and the length of the training courses were mostly based on the expert opinion of the curriculum designer. Most of the curricula were given in the residency period and the most commonly taught topics were financial concepts (13 programs), management concepts (13 programs), quality management (13 programs), legal affairs (12 programs), personnel issues (12 programs), and organizational skills and time management (12 programs). Ten articles evaluated the effects of their training intervention $(8,14,15,24-30)$. All articles reported improvement in the participants' managerial knowledge. However, five articles used subjective pre- and post-self-assessments tests and most study populations were small (max $n=60$ ). Moreover, only one of the questionnaires used was evaluated for 


\section{Chapter 8}

internal consistency. Despite the differences in the educational methods used, all curricula which were assessed received positive evaluations (6,8-10,14,15,18,23-27,29,31-36).

Overall, the literature review produced little definite conclusions since there were only few needs assessments, most of the curricula were designed on expert opinion and showed no internal consistency and there were only five objective knowledge assessments after completion of the training $(14,15,24,26,28)$. However, the needs-assessments that were performed and the subjective evaluations of the management curricula all showed that management education was deemed important.

\section{PERCEIVED MANAGERIAL COMPETENCIES AND EDUCATIONAL NEEDS}

We developed a questionnaire to gain insight in the experienced managerial competencies of Dutch medical residents and if they perceived a need for management education. We designed the questionnaire based on our results from our literature review and on the definition of the implemented CanMEDS framework for the manager's role $(3,37)$. The combination of these two sources gave us the tools to develop a questionnaire in which we intended to address all the important items of the manager's role.

The results described in Chapter 3 concerned the medical residents perceived competencies (38). The respondents assessed themselves by ranking their perceived competency, using a number of managerial examples, on a five point Likert scale. An example of such a statement was: "I know how to manage my ward effectively". The following characteristics were recorded: age, gender, years of work experience, specialty, hospital (university vs. district teaching hospitals), previous management experience and previous management education, to assess if any of them had a significant influence on their perceived management competency.

We approached 506 medical residents to participate and one hundred and seventy-seven questionnaires were returned (response rate 35\%). The participants rated their overall perceived managerial competency as moderate (mean 2.59; SD 0.37). The abilities in which they felt most competent were "updating their medical knowledge", "handling received feedback", "using information technology", "protecting patients' interests" and "allocating resources based on evidence-based medicine". In the Dutch basic medical curriculum much attention is given to evidence-based medicine and how to use the associated search strategies. There is also a lot of emphasis on providing and receiving feedback, so these results were in line with what we expected. The abilities they felt least competent in were 
"negotiating on working conditions" and "coding and billing", together with their knowledge of the "organization and financing of the healthcare system", "organization and financing of the specialist department", and "requirements as a specialist".

General knowledge of the organization and financing of the healthcare system at micro and macro level is not being addressed in the basic medical curriculum. It therefore came as no surprise that these knowledge items had the lowest scores. Nevertheless they are important topics as a good understanding of these issues is required if you would like to engage in renewing and cost-saving healthcare practices. The residents scored their coding and billing abilities and their contract negotiating skills also as low. A large number of patients are seen and therefore coded and billed by residents in the Netherlands. This should therefore be done well as this may otherwise have adverse effects on the clinical departments' financial situation. Effective negotiating skills are also necessary in many different clinical settings and not only when negotiating over a contract. They are also important in patient contacts, nurse-physician interactions and in deliberations with peers.

Previous management experience was the only characteristic that had an influence on their overall perceived competency. Residents with such experience rated themselves on average higher than their peers without such experience. This could suggest that extracurricular managerial activities improved their managerial competencies, but since we only measured perceived competencies, this remains uncertain. A previous management course or more work experience had no significant influence. This suggests that those alone are not sufficient enough to increase the residents' perceived management competencies.

The questionnaire described above contained another element, namely a needsassessment. In Chapter 4 we explored if Dutch medical residents had a need for management education and if so, what such training should look like (39). The results showed that $85 \%$ of the responding residents reported a need for management training. Half of the residents agreed that there was not enough attention for managerial tasks during their postgraduate training.

The preferred topics for management training were negotiation skills, knowledge of specialist partnerships and of the organization and financing of the health care system and career opportunities. A workshop was the preferred training method and the residents' preferred medical specialists and external experts such as lawyers as training instructors. There was a wide spread in the preferred length of the program. It ranged from 1 to 400 hours, with a mean of 17 hours. The residency period was deemed the most suitable timing for management training. Gender, number of years of clinical experience, specialty, training location and prior experience with management training and/or tasks were not of 


\section{Chapter 8}

influence on the need for management training. These results were consistent with our findings in the existing literature. They also confirmed our hypothesis that many Dutch residents perceive a lack in managerial knowledge and would like to receive management training.

Since our goal was to ultimately develop a management training that would meet the needs of today's doctors, we wanted to examine the problem from different perspectives. As described in Chapter 5, we investigated if medical specialists felt that their residents lacked specific management skills or knowledge. We also investigated what medical specialists thought a management course for residents should entail (40).

A different survey was defined for the medical specialists based on the previous questionnaire for residents. We approached 298 medical specialists to participate in the survey, 129 questionnaires were returned (response rate 43\%). The specialists gave the lowest rating to their residents' knowledge of the organization and financing of a specialist department, organization and financing of the healthcare system, coding and billing, requirements as a specialist and to the skill "negotiating working conditions". The highest ratings were given to their competency to update their medical knowledge, handling received feedback and allocating resources based on evidence-based medicine. Of the participating specialists, 94\% reported a need for management training for their residents. Most specialists chose knowledge of the healthcare system, time management, leadership, and legal aspects of medical errors as the topics residents should be trained in. A workshop was the preferred educational method. External experts or medical specialists were their instructors of choice. The respondents regarded the residency period as the most appropriate timing for such training. No significant influence was found between the characteristics of the specialists and their perceived need for management training.

When we compared these results to the results of our research on how residents perceived their own management competencies, there were many similarities. The residents and the specialists exactly agreed on the items they perceived the residents to be least and most competent at. They also had the same preferences for the timing, method and instructors for a possible management training. The specialists and residents only differed on the topics that such training should deal with. Although they agreed on knowledge of the health care system, the residents mentioned that they would like to develop their negotiation skills and learn more about their career options, while the specialists considered time management, leadership and the legal aspects of medical errors to be more important. This difference can possibly be explained by the fact that residents are still planning their future and feel that they would be better prepared if they had more negotiation skills and knowledge on 
career options. Meanwhile specialists are already in that position and consider skills that would help them in daily practice to be more important.

So far our research findings indicated that there was a need for management and leadership training among Dutch medical residents. The results of our literature review suggested that this need was also felt abroad, although the review was mostly based on literature from the United States of America (3). In Chapter 6 we explored the perceived deficiencies and needs of medical residents in other countries a little further (41). We were also interested in finding out whether the length of incorporation of the CanMEDS framework and the availability or not of mandatory management training programs, influenced the perceived management competencies and needs of the medical residents. The questionnaire that was designed to previously survey the Dutch medical residents was translated into English. It was sent by email to junior doctors in Denmark, Australia and Canada. The CanMEDS framework was developed in Canada and implemented nationally in 1996 (1). Residency program directors got assistance from the RCPSC in the design and implementation of programs to help residents learn the manager's role. It was up to the individual universities however how much time and effort was spent on this role and there were no mandatory elements that had to be taught (42). In Australia, the framework was incorporated in 2006, however there were no defined learning strategies or established methods for the assessment of the managers' competency (43). The CanMEDS framework was adopted in 2003 in Denmark and in 2005 a national mandatory training program which covered areas of leadership, collaboration and health care administration was introduced (44). The program consists of three courses. The first course covers topics and problems from physicians' daily practice to illustrate and apply knowledge about the organization and management at local and regional level. The second course involves issues of health policy, health economics and organizational issues at national, European and international level. The third course covers leadership, co-operation and organization at local, regional and national level with the doctor as central actor (45). With these three countries and their different focuses on the manager's role we felt that an interesting comparison could be made.

Eventually, 719 questionnaires from the 2105 residents who were approached in Denmark were returned (34.2\%). The response rate in Canada was 36.8\% (183/500). In Australia 197 of 1213 sent surveys were returned (16.2\%). As mentioned in Chapter 2 and 3, in the Netherlands 177 of 506 residents (35.0\%) responded to the survey (38,39). In general, residents from Denmark gave their own management competencies the highest mean score (3.54, SD 0.40), followed by the Australian residents (3.45, SD 0.42), the Dutch residents (3.39, SD 0.37) and the Canadian residents (3.35, SD 0.51). The items the residents 


\section{Chapter 8}

Table 1. Highest and lowest rated items per country

\begin{tabular}{lll}
\hline Countries & Highest rated items & Lowest rated items \\
\hline Denmark & "using information technology" & "negotiating working conditions" \\
& "handling received feedback" & "negotiating personal ambitions" \\
"managing a ward" & "improving quality processes" \\
Canada & "using information technology" & "negotiating working conditions" \\
& "advocating for patients" & "negotiating personal ambitions" \\
Australia & "managing a ward" & "organization specialist department \\
& "using information technology" & "organization of a specialist department" \\
& "handling received feedback" & "negotiating working conditions" \\
The Netherlands & "managing a ward" & "organization of the healthcare system \\
& "using information technology" & "organization of the healthcare system" \\
& "handling received feedback" & "requirements as a specialist". \\
\hline
\end{tabular}

from the four countries rated on average the highest and the lowest are shown in table 1. It is noticeable that all residents rated their skill "negotiation working conditions" as one of their weakest perceived competencies. Also negotiating personal ambitions, knowledge of the organization and financing of the health care system and of specialist departments are named more than once.

In Denmark there were three variables, which had a significant influence on the overall perceived management competency. Males rated themselves on average higher, residents with more management experience rated themselves higher and residents with more management training rated themselves also increasingly higher. In Canada there were two factors of significant positive influence namely previous management experience and the number of years since graduation. In Australia and in the Netherlands only the characteristic "previous management experience" was of significant influence. Residents which such experience rated themselves on average higher.

More than $75 \%$ of the residents from all four countries felt a need for management training (Denmark 84.7\%, Canada 83.5\%, Australia 76.8\% and the Netherlands 85.3\%). The topic "negotiation skills" was in the top three of preferred subjects for a potential management training of all four countries. Also personal financial planning, career options and costeffectiveness were named more than once. A workshop was in three out of four countries the preferred method of training. The majority of the residents chose the postgraduate period as being the most suitable period for management training. There was little consensus about the length of the training or how often the training would have to take place. The residents from Canada had the lowest mean score on how they perceived their management competency. A longer implementation of the CanMEDS framework 
did therefor not seem to positively influence the perceived competency. It also did not seem to influence their need for management training. The residents from Denmark gave themselves on average the highest scores on perceived competency, which may be the result of the mandatory management training, as we found that the more training they had received the higher their average score was. It also seemed to influence their need for management training, since the percentage of residents which felt a need for training was $84.6 \%$ among the residents who had not received any training yet, after one training the percentage went up to $87.0 \%$, but then progressively decreased after two (81.2\%) and three (78.9\%) training sessions. An explanation for the increase in the perceived need after one training session could be that their interest is sparked and knowledge gaps exposed.

The results of this research project suggested that there were similarities between the perceptions and needs of the participating residents from these four different countries in the field of medical management. There was some consistency in the topics they felt they lacked knowledge or skills in. There was also agreement on some of the aspects of a possible management training. The differences suggest however that there is no single training that would suit the needs of all residents worldwide. Every country would need to take into account for example, that which is already being taught in the basic medical curriculum. Despite the differences though, the most important conclusion for us was that the majority of residents from all four countries felt a need for (more) management training.

\section{MANAGEMENT TRAINING COURSE}

In Chapter $\mathbf{7}$ we describe the development, implementation and evaluation of a module of a management-training course that we designed (46). Our goals with this project included setting up a well-founded training course that was based on the results of previous research, to evaluate the subjective and objective impact of the course on medical residents management competencies and to compare the knowledge of the healthcare system between residents and specialists.

Since medical management is a broad subject however, we realized that is was impossible to cover all areas identified from our research in a single training session. We therefore chose two topics from the list of suggested themes in our studies and which seemed to recur in the preferences of both the Dutch residents and specialists $(3,39,40)$. We chose knowledge of the healthcare system and time management not only because they 


\section{Chapter 8}

were named important in the literature review as well as in the needs assessments, but also because we wanted to combine a theoretical topic with a skill to create a balanced training course. Also based on the preferences of the questioned residents and specialists, we chose an interactive learning approach in the form of lectures with group-based discussions and case-based assignments. We selected the preferred choice of content experts who were also physicians as instructors for the course. The format of the training comprised of two training sessions and was based on the requirements of the interdisciplinary educational standards that apply in the south-east region of the Netherlands. The first meeting consisted of a two hours lecture on the concepts of the organization and financing of the healthcare system on national level and 1.5 hours on the general concepts of time-management. The second meeting was divided into two sessions. The first session comprised of a first half where residents presented their homework-assignments and a second half where the micro-concepts of the healthcare system, namely the organization and financing of hospitals were taught. The second session was concluded with a workshop on how to organize and lead (staff) meetings.

The module was evaluated using subjective evaluation forms, in depth-interviews and through a pre- and post-knowledge test on the organization and financing of the healthcare system. We also gave this test to a (control) group of residents who did not participate in the training and to a number of specialists to see whether knowledge of the healthcare system was gained over time and/or through work experience. The results showed more improvement based on the delta percentages of correctly answered questions on the preand post-test of the participating residents (6.56\%) in comparison to the control group (3.28\%). However, the difference was not significant. This could be explained by a number of possible causes. First of all our study population was possibly too small to detect a significant difference. Due to a shortage in time and resources, we weren't able to provide larger numbers. Secondly, the knowledge test covered more material than we were able to address during the training sessions. The lively discussions took up more time than we expected and there was also a greater lack in basic knowledge among the residents on these topics than we anticipated. Finally, it is also possible of course that the training was not as effective as we hoped for.

The medical specialists did not have significantly higher scores on the knowledge test than the residents. This could suggest that work experience alone, is not sufficient to gain the desired amount of knowledge on the organization and financing of the healthcare system.

The residents gave high ratings to the training through the evaluation forms as well as during the in-depth interviews. Some said that it had filled a gap in their specialist 
training and many would have liked even more educational time spent on these topics. The residents were satisfied with the topics chosen for this management training. The most common suggestion for an additional topic was "knowledge of the organization and financing of specialist departments". This evaluation suggests that the need for management training isn't fulfilled with just one training session. Besides the suggested topic "specialist partnerships", the needs-assessments and literature review showed that topics as negotiation skills, career opportunities, legal issues and leadership skills were also considered essential. These topics can be subdivided into subjects suitable for junior medical residents and for residents who are more advanced in their specialist training. We feel that an educational structure like the one being used in Denmark, namely several courses divided over the years of specialist training would be an appropriate way to teach these different subjects to residents.

\section{GENERAL CONCLUSIONS}

Overall the findings from the six studies support the need for additional training in medical management in postgraduate medical education. Chapters 2 and 6 provided evidence that not only Dutch medical residents feel this need, but that it is a perception shared by other trainees in other countries too $(3,41)$. Chapters 2 and 5 show that among others medical specialists support this view $(3,40)$. We also investigated specific information required for developing well-founded management training programs. Surprisingly Dutch medical residents and specialists had matching perspectives on the format and content of the training, while in our international study the residents agreed on the timing and format for such training but had different views on the preferred topics (39-41). We think that the differing contents of the basic medical curricula within the different countries may have been responsible for this. The management training we implemented was received with enthusiasm and inspires to move forward with this concept.

\section{LIMITATIONS}

In our questionnaire-based studies the biggest limitations were that the questionnaires were only administered to a part of the total resident population in the Netherlands but also abroad, the low response rates and the fact that we were measuring perceived needs and competencies instead of objective data. As argued in Chapters 3 to 6 it is possible that by measuring subjective data we are not getting an accurate view of the management capabilities of the medical residents. We were aware of this limitation and we tried to 


\section{Chapter 8}

overcome this problem by making use of the concept of triangulation. By approaching Dutch medical residents, medical specialists and foreign medical residents we tried to find, and found, a consistency in our results (39-41).

The low response rates formed another limitation. We speculated that the low rates could be due to the increasing amount of emails and questionnaires that residents receive, which may have resulted in a lack of time and interest to respond. Due to the low response rates and the fact that we only administered the questionnaires to a part of the total resident population, it is hard to extrapolate the results to all residents of the Netherlands, Canada, Denmark or Australia. However, we do feel that it is fair to say that the results consistently suggest a need for management training. The main limitation of our study described in Chapter 7 were the small groups of participants. Because of the small number of participants, it was hard to formulate definite conclusions. Unfortunately, due to time and resource limitations, we weren't able to provide bigger participants groups (46).

\section{VALORIZATION}

The manager's role is named a key competency for modern physicians by many different medical institutions around the world. Some even argue that truly innovative, cost-saving and care-improving changes are only possible when doctors take up their role as managers and leaders and initiate or enable such initiatives $(47,48)$. Our research underlines that a need is felt among residents and specialists that modern doctors should be trained in this competency. So although we acknowledge that the postgraduate curricula of medical residents are already quite full, we still feel that every doctor should receive some education regarding this role.

By developing a management course based on a literature review and several needsassessments we tried to create a well-founded training. Although participants were enthusiastic some questions still remained. We have no definitive answer to the question if our training improved the participants' knowledge on the subjects that were addressed. To find this answer the training and knowledge test would have to be re-executed to create a larger study population. As we already argued in Chapter 7, we feel that a single training course isn't enough to teach every aspect of the manager's role. At least two other courses would be necessary to teach subjects as "knowledge of specialist departments", "negotiation skills", "career opportunities", "legal issues" and "leadership skills". Our suggestion would be to divide these topics into subjects which should be taught to junior medical residents, and subjects that should be taught to residents who are more advanced. Future research 
projects could investigate if these subjects would raise the same amount of enthusiasm as the topics that were taught in our training. One could also examine again if there would be knowledge retention on the subjects after the training. A pre- and post-knowledge test is possible for topics as legal issues and knowledge of specialist departments but an improvement in skills would be harder to test.

Three training sessions would provide residents with some basic knowledge of medical management and leadership. This introduction to the manager's role may spark the interest of some residents who would want to learn more about this competency. A possibility, which some hospitals already offer, would be to create "internships" for residents who have such an interest $(49,50)$. Through these internships residents will gain practical experience and they will have an opportunity to examine if management and leadership is a subject in which they want to further develop themselves. This would not only be an advantage for the resident himself/herself but also for medical departments who will gain physicians who are also motivated and well educated leaders and managers.

Finally, this PhD project focused primarily on the residency period. It may therefor be interesting in future studies to investigate if medical students also already feel a need for management education and how this should be implemented in the basic medical curriculum. 


\section{REFERENCES}

1. Frank JR, Danoff D. The CanMEDS initiative: implementing an outcomes-based framework of physician competencies. Medical teacher. 2007 Sep;29(7):642-7. PubMed PMID: 18236250.

2. Scheele F, Teunissen P, Van LuijkS, Heineman $E$, Fluit $L$, Mulder $H$, et al. Introducing competency-based postgraduate medical education in the Netherlands. Medical teacher. 2008;30(3):248-53. PubMed PMID: 18484450.

3. Busari JO, Berkenbosch L, Brouns JW. Physicians as managers of health care delivery and the implications for postgraduate medical training: a literature review. Teaching and learning in medicine. 2011 Apr;23(2):186-96. PubMed PMID: 21516608.

4. Brugnara C, Fenton T, Winkelman JW. Management training for pathology residents. I. Results of a national survey. American journal of clinical pathology. 1994 May;101(5):559-63. PubMed PMID: 8178760.

5. Goldberg-Kahn B, Sims KL, Darcy TP. Survey of management training in United States and Canadian pathology residency programs. American journal of clinical pathology. 1997 Jul;108(1):96-100. PubMed PMID: 9208985.

6. Sims KL, DarcyTP. Aleadership-management training curriculum for pathology residents. American journal of clinical pathology. 1997 Jul;108(1):90-5. PubMed PMID: 9208984.

7. Winkelman JW, Brugnara C. Management training for pathology residents. II. Experience with a focused curriculum. American journal of clinical pathology. 1994 May;101(5):564-8. PubMed PMID: 8178761.
8. Junker JA, Miller T, Davis MS. Practice management: a third-year clerkship experience. Family medicine. 2002 Feb;34(2):87-9. PubMed PMID: 11874029.

9. Kaur $N$, Singh $T$. Introducing medical students to health care management. Medical education. 2009 Nov;43(11):10901. PubMed PMID: 19799732.

10. Patel MS, Lypson ML, Davis MM. Medical student perceptions of education in health care systems. Academic medicine : journal of the Association of American Medical Colleges. 2009 Sep;84(9):1301-6. PubMed PMID: 19707077.

11. Stulc JP. An economics course in medical school? The Journal of the Kentucky Medical Association. 1999 Jul;97(7):317-8. PubMed PMID: 10412260.

12. Suzewits J. Medical student education in practice management. Family medicine. 2003 Nov-Dec;35(10):697-8. PubMed PMID: 14603397.

13. Chan S. Management education during radiology residency: development of an educational practice. Academic radiology. 2004 Nov;11(11):1308-17. PubMed PMID: 15561581.

14. Crites $G E$, Schuster RJ. A preliminary report of an educational intervention in practice management. BMC medical education. 2004 Sep 20;4:15. PubMed PMID: 15380023. Pubmed Central PMCID: 520819.

15. Essex B, Jackson RN. Moneymed: a game to develop management skills in general practice. The Journal of the Royal College of General Practitioners. 1981 Dec;31(233):735-9. PubMed PMID: 7338867. Pubmed Central PMCID: 1972233. 
16. Maggi JD, Stergiopoulos V, Sockalingam S. Implementing a new physician manager curriculum into a psychiatry residency training program: the change process, barriers and facilitators. The Psychiatric quarterly. 2008 Mar;79(1):21-31. PubMed PMID: 18157639.

17. Daugird AJ, Spencer DC. The perceived need for physician management training. The Journal of family practice. 1990 Mar;30(3):348, 51-2. PubMed PMID: 2307950.

18. Sockalingam S, Stergiopoulos V, Maggi J. Residents' perceived physician-manager educational needs: a national survey of psychiatry residents. Canadian journal of psychiatry Revue canadienne de psychiatrie. 2008 Nov;53(11):745-52. PubMed PMID: 19087468.

19. Lusco VC, Martinez SA, Polk HC, Jr. Program directors in surgery agree that residents should be formally trained in business and practice management. American journal of surgery. 2005 Jan;189(1):11-3. PubMed PMID: 15701483.

20. Lyss-Lerman P, Teherani A, Aagaard E, Loeser H, Cooke M, Harper GM. What training is needed in the fourth year of medical school? Views of residency program directors. Academic medicine : journal of the Association of American Medical Colleges. 2009 Jul;84(7):823-9. PubMed PMID: 19550170.

21. Tobin M, Edwards JL. Are psychiatrists equipped for management roles in mental health services? The Australian and New Zealand journal of psychiatry. 2002 Feb;36(1):4-8. PubMed PMID: 11929434.
22. Williford LE, Ling FW, Summitt RL, Jr., Stovall TG. Practice management in obstetrics and gynecology residency curriculum. Obstetrics and gynecology. 1999 Sep;94(3):476-9. PubMed PMID: 10472882.

23. Stergiopoulos V, Maggi J, Sockalingam S. Teaching the physician-manager role to psychiatric residents: development and implementation of a pilot curriculum. Academic psychiatry : the journal of the American Association of Directors of Psychiatric Residency Training and the Association for Academic Psychiatry. 2009 Mar-Apr;33(2):125-30. PubMed PMID: 19398625.

24. Babitch LA. Teaching practice management skills to pediatric residents. Clinical pediatrics. 2006 Nov;45(9):846-9. PubMed PMID: 17041173.

25. Bayard M, Peeples CR, Holt J, David DJ. An interactive approach to teaching practice management to family practice residents. Family medicine. 2003 Oct;35(9):622-4. PubMed PMID: 14523656.

26. Hemmer PR, Karon BS, Hernandez JS, Cuthbert C, Fidler ME, Tazelaar HD. Leadership and management training for residents and fellows: a curriculum for future medical directors. Archives of pathology \& laboratory medicine. 2007 Apr;131(4):6104. PubMed PMID: 17425393.

27. Horowitz RE, Naritoku W, Wagar EA. Management training for pathology residents: a regional approach. Archives of pathology \& laboratory medicine. 2004 Jan;128(1):59-63. PubMed PMID: 14692810.

28. LoPresti L, Ginn P, Treat R. Using a simulated practice to improve practice management learning. Family medicine. 2009 Oct;41(9):640-5. PubMed PMID: 19816827. 


\section{Chapter 8}

29. Piatt JP, Bartley DL, Jacobson AD, Rimsza ME. Practice management training for pediatric residents. American journal of diseases of children. 1991 Mar;145(3):299-301. PubMed PMID: 2003479.

30. Taylor ML, Mainous AG, 3rd, Blue AV, Carek PJ. How well are practice management curricula preparing family medicine residents? Family medicine. 2006 Apr;38(4):275-9. PubMed PMID: 16586175.

31. Aluise JJ. The physician as manager. "What" and HOW" OF PRACTICE MANAGEMENT EDUCATION. The Journal of family practice. 1977 Feb;4(2):305-11. PubMed PMID: 65441.

32. Amin AN. A business of medicine curriculum for medical students. Medical education. 2005 May;39(5):510-1. PubMed PMID: 15842690

33. Cordes DH, Rea DF, Rea J, Vuturo A. A program of management training for residents. Academic medicine : journal of the Association of American Medical Colleges. 1989 Jan;64(1):45-6. PubMed PMID: 2914065.

34. Lawson JG, McConnell JW. Teaching practice management in a family practice residency. Journal of medical education. 1976 Oct;51(10):858-60. PubMed PMID: 972380.

35. Mirowitz SA. Development and assessment of a radiology core curriculum in health care policy and practice. Academic radiology. 2000 Jul;7(7):540-50. PubMed PMID: 10902963.

36. Yu-Chin R. Teaching administration and management within psychiatric residency training. Academic psychiatry : the journal of the American Association of Directors of Psychiatric Residency Training and the Association for Academic Psychiatry. 2002 Winter;26(4):245-52. PubMed PMID: 12824127
37. Royal College of Physicians and Surgeons of Canada. The CanMEDS Framework 2005 [cited 2013 May 11 2013]. Available from: http://www.royalcollege.ca/portal/page/ portal/rc/canmeds/framework.

38. Berkenbosch L, Brouns JW, Heyligers I, Busari JO. How Dutch medical residents perceive their competency as manager in the revised postgraduate medical curriculum. Postgraduate medical journal. 2011 Oct;87(1032):680-7. PubMed PMID: 21693572.

39. Brouns JW, Berkenbosch L, Ploemen-Suijker FD, Heyligers I, Busari JO. Medical residents perceptions of the need for management education in the postgraduate curriculum: a preliminary study. Int J Med Educ. 2010;1:7682. Epub November 12, 2010. eng.

40. Berkenbosch L, Bax M, Scherpbier A, Heyligers I, Muijtjens AM, Busari JO. How Dutch medical specialists perceive the competencies and training needs of medical residents in healthcare management. Medical teacher. 2013 Apr;35(4):e1090-102. PubMed PMID: 23137237.

41. Berkenbosch L, Schoenmaker SG, Ahern S, Sojnaes C, Snell L, Scherpbier AJ, et al. Medical residents' perceptions of their competencies and training needs in health care management: an international comparison. BMC medical education. 2013;13:25. PubMed PMID: 23406436. Pubmed Central PMCID: 3577427.

42. Royal College of Physicians and Surgeons of Canada. Train-the-Trainer workshop resource binders [cited 2014 01-01]. Available from: http://www.royalcollege.ca/ portal/page/portal/rc/canmeds/resources/ workshops\#manager_workshop. 
43. Confederation of Postgraduate Medical Education Councils. Australian Curriculum Framework for Junior Doctors (ACF) 2008 [cited 2014 01-01]. Available from: http:// www.cpmec.org.au/Page/australiancurriculum-framework-for-junior-doctorsacf-menu.

44. Health SCMo. The future specialist (Danish). Copenhagen: 2000.

45. Health Mo. Vejledning om generelle kurser i speciallægeuddannelsen (Danish) 2011. Available from: https://www.retsinformation. $\mathrm{dk} /$ Forms/R0710.aspx?id=136870.

46. Berkenbosch L, Muijtjens AMM, Zimmermann LJI, Heyligers I, Scherpbier A, Busari JO. A pilot study of a practice management training module for medical residents. 2014.

47. Porter ME, Teisberg EO. How physicians can change the future of health care. JAMA : the journal of the American Medical Association. 2007 Mar 14;297(10):1103-11. PubMed PMID: 17356031.

48. Swanwick T, McKimm J. What is clinical leadership...and why is it important? The clinical teacher. 2011 Mar;8(1):22-6. PubMed PMID: 21324068.

49. Catharina hospital. Management en supervisie (Dutch) Eindhoven [cited 2014 01-01]. Available from: http://www. opleidingsetalage.nl/nc/opleidingen/ opleiding/347-management-en-supervisie. html.

50. Groene Hart Ziekenhuis. Management en Organisatie [cited 2014 01-01]. Available from: http://www.opleidingsetalage.nl/nc/ opleidingen/opleiding/1342-algemenepediatrie-kopie.html. 



\section{Chapter 8}

\section{ACHTERGROND}

De verwachtingen ten aanzien van de gezondheidszorg en van de praktiserende arts zijn de laatste decennia veranderd. De maatschappij wil meer dan alleen een bekwaam medisch specialist. Een moderne arts moet bijvoorbeeld ook communicatief vaardig zijn. Hij moet niet alleen goed met zijn patiënten kunnen communiceren maar ook met collegae van andere disciplines aangezien zorg steeds meer geleverd wordt in een multidisciplinaire setting. Doordat de kosten van de gezondheidzorg exponentieel zijn toegenomen, wordt er tevens steeds meer van artsen gevraagd om kostenbewust te zijn. Ze moeten de baten tegen de kosten op laten wegen wanneer zij bijvoorbeeld beslissingen moeten nemen over het te verrichten aanvullend onderzoek.

Aan het einde van de vorige eeuw waren er een aantal medische instellingen die erkenden dat hun opleidingen niet meer voldeden aan de eisen van de maatschappij. In Amerika was het de ACGME (de raad die verantwoordelijk is voor de accreditatie van de medische postdoctorale opleidingen in Amerika) die vijf competenties vastlegde, buiten die van medisch expert, die alle moderne artsen zouden moeten bezitten en waar dus aandacht aan besteed zou moeten worden gedurende de opleiding. In Canada werd het CanMEDs raamwerk geïntroduceerd als pijler van de medische (vervolg) opleidingen. Dit raamwerk beschrijft zeven kerncompetenties die artsen zouden moeten beheersen. Deze competenties overlappen met de competenties die beschreven zijn door de ACGME. Deze zeven competenties zijn: medisch handelen, communicatie, samenwerking, kennis en wetenschap, maatschappelijk handelen, organisatie en professionaliteit. In Nederland ontstond hetzelfde besef en in 2005 werd het CanMEDS raamwerk geïmplementeerd als basis voor de medische (vervolg)opleidingen.

De competentie "organisatie", beschrijft de arts als een leider in het zorgproces die er op toeziet dat de patiëntenzorg zo goed mogelijk verloopt. Daarnaast moet hij ook het voortouw nemen in nieuwe initiatieven die zowel verbeteringen in de kwaliteit van de gezondheidszorg moeten bewerkstelligen als ook kostenbesparingen. Deze competentie lijkt in de huidige complexe gezondheidzorg belangrijker dan ooit. Voor ons gevoel was er echter minder aandacht in de vervolgopleiding voor deze competentie dan voor enkele andere beschreven kerncompetenties. We besloten daarom om hier meer onderzoek naar te verrichten. De twee belangrijkste doelen van dit proefschrift waren:

- Om te onderzoeken wat er over dit onderwerp bekend is in de internationale literatuur en hoe deze bevindingen in verhouding staan met de situatie in Nederland. 
- Om een managementtraining te ontwerpen en te implementeren gebaseerd op de resultaten die verkregen zouden worden door het benodigde onderzoek voor doel 1.

In dit gedeelte van het proefschrift zal er een Nederlandse samenvatting gegeven worden van het onderzoek dat beschreven wordt in de hoofdstukken 2 tot en met 7.

\section{SAMENVATTING}

In hoofdstuk 2 geven we een samenvatting van de actuele literatuur aangaande medisch management en leiderschap. Er werden 40 relevante artikelen gevonden. Een van de meest opvallende bevindingen was het feit dat 37 van de 40 artikelen uit Noord-Amerika kwamen. Er leek dus veel meer (gepubliceerde) aandacht te zijn voor dit onderwerp in NoordAmerika dan in de rest van de wereld. Daarnaast viel het ook op dat er een beperkt aantal specialismen waren die voor het gros van de publicaties hadden gezorgd. Dit waren de huisartsgeneeskunde, het specialisme pathologie en verschillende onderwijsinstellingen. Een verklaring hiervoor kan zijn dat de betreffende specialismen in de dagelijkse praktijk meer te maken krijgen met management gerelateerde zaken dan andere specialismen. Dat onderwijsinstellingen over dit onderwerp publiceren kan betekenen dat het onderwerp binnen deze instituten steeds belangrijker wordt bevonden.

De artikelen die wij vonden beschreven onder andere de percepties van de eigen ervaren managementcompetentie onder artsen, needs-assessments en trainingen die deze competentie onderwezen. Een belangrijke conclusie die uit de literatuurstudie getrokken kon worden was dat artsen zich over bepaalde aspecten van deze competentie niet vaardig voelden en dat het merendeel hier graag in onderwezen zou willen worden. De managementtrainingen die beschreven werden vertoonden vaak onderlinge overlap, maar verschilden te veel van elkaar om een conclusie te kunnen trekken over hoe een managementtraining er uit zou moeten zien. Echter, ondanks de bestaande verschillen tussen de trainingen werd in al deze artikelen geconcludeerd dat de deelnemers enthousiast waren en een training op dit gebied nuttig vonden.

In hoofdstuk 3 en 4 beschrijven we hoe we onderzochten of Nederlandse artsassistenten behoefte hebben aan management training en hoe zij oordelen over hun eigen management competenties. Wij maakten daarvoor gebruik van een vragenlijst die wij opstuurden naar 506 arts-assistenten. Honderdzevenenzeventig arts-assistenten vulden de vragenlijst in. De arts-assistenten hadden onvoldoende vertrouwen in hun (contract) onderhandelingsvaardigheden, en in hun kennis over de organisatie en financiering van 


\section{Chapter 8}

de Nederlandse gezondheidszorg. De assistenten hadden het meeste vertrouwen in hun vermogen om met feedback om te gaan, hun vermogen om met informatietechnologie om te gaan en hun vaardigheid in het toewijzen van schaarse middelen (diagnostiek, medicatie etc.) op basis van evidence-based medicine (EBM).

In het tweede deel van de vragenlijst werd een needs-assessment afgenomen. Vijfentachtig procent van de arts-assistenten gaf daarin aan dat zij behoefte hadden aan management training. De onderwerpen die zij daarin graag aan bod zouden zien komen waren onderhandelingsvaardigheden, kennis over de financiering en organisatie van maatschappen, kennis van de financiering en organisatie van de gezondheidszorg en loopbaanplanning. De onderwijsmethode die hun voorkeur had was een workshop en deze zou gegeven moeten worden door medisch specialisten of externe inhoudsdeskundigen zoals juristen of economen. Het beste moment voor een management training volgens deze groep arts-assistenten zou gedurende de opleiding tot specialist zijn.

In hoofdstuk 5 hebben we hetzelfde onderzoek herhaald onder medisch specialisten om een zo compleet mogelijk beeld te krijgen van de mening van artsen ten aanzien van deze competentie bij arts-assistenten. Wij vroegen hen naar hun mening over de competenties van hun arts-assistenten op het gebied van medisch management en of zij dachten dat arts-assistenten hierin onderwezen zouden moeten worden. Tweehonderd achtennegentig specialisten werden via een e-mail uitgenodigd om deel te nemen. Honderd negenentwintig specialisten $(43,3 \%)$ vulden de vragenlijst in. Ze beoordeelden de competentie van hun arts-assistenten op het gebied van contractonderhandelingen, kennis van de organisatie en financiering van de gezondheidszorg en van maatschappen als onvoldoende. Ze gaven arts-assistenten de hoogste cijfers in hun vaardigheid om hun kennis up-to-date te houden, in het toewijzen van schaarse gezondheidsgoederen op basis van EBM en in het omgaan met feedback.

Vierennegentig procent van de specialisten gaf aan dat zij vonden dat assistenten onderwezen zouden moeten worden op het gebied van medisch management. De onderwerpen die aan bod zouden moeten komen waren timemanagement en de organisatie en financiering van de gezondheidszorg. De aanbevolen trainingsmethode was een workshop gegeven tijdens de opleiding tot specialist door een externe expert .

De hierboven beschreven onderzoeken toonden aan dat Nederlandse arts-assistenten zich onvoldoende bekwaam voelen op bepaalde gebieden van medisch management en dat het overgrote merendeel behoefte heeft aan onderwijs op dit gebied. De 
ondervraagden medisch specialisten onderschrijven dit beeld. We waren vervolgens benieuwd of we dezelfde resultaten zouden verkrijgen als we het onderzoek zouden uitvoeren onder arts-assistenten in het buitenland. Tevens waren we benieuwd naar de invloed van een langere implementatie tijd van het CanMEDS raamwerk in de opleiding en of een verplichte management training van invloed is op de ervaren competentie en behoefte aan (meer) management onderwijs. In hoofdstuk 6 beschrijven we de resultaten van dit onderzoeksproject. Arts-assistenten uit Denemarken, Canada en Australië werden benaderd voor deelname. De vragenlijst die we in Nederland hadden gebruikt werd enigszins aangepast, in het Engels vertaald en per email verstuurd aan alle internationale deelnemers. De respons rates in de deelnemende landen waren in Denemarken 719/2105 (34\%), in Canada 177/500 (35\%) en in Australië 194/1213 (16\%). De Deense evenals de Canadese arts-assistenten beoordeelden met name hun onderhandelingsvaardigheden als onvoldoende en in Australië vonden de assistenten hun kennis over hoe maatschappen werden georganiseerd en gefinancierd onvoldoende. In alle landen gaven meer dan 75\% van de arts-assistenten aan dat zij behoefte hadden aan managementtraining.

Een langere implementatieduur van het CanMEDS raamwerk leek de ervaren managementcompetentie niet te verbeteren en zorgde ook niet voor een afname in de behoefte aan onderwijs op dit gebied. Verplicht management onderwijs, zoals in Denemarken het geval is, leek wel een positieve invloed te hebben op de ervaren managementcompetentie en zorgde op de langere termijn voor een afname in onderwijsbehoefte op dit gebied.

In hoofdstuk 7 beschrijven we de managementtraining die we ontwierpen en organiseerden op basis van de onderzoeksresultaten uit de voorgaande hoofdstukken. Medisch management is een zeer breed onderwerp en naar ons idee daarom onmogelijk om in één training volledig te behandelen. We identificeerden daarom twee onderwerpen die belangrijk waren bevonden in de literatuurstudie en in de needs-assessments onder zowel de arts-assistenten als de medisch specialisten. De onderwerpen "kennis van het gezondheidszorgsysteem" (organisatorisch en financieel) en "timemanagement" werden uitgewerkt. Na een trial onder 11 arts-assistenten, werd de definitieve training aan 14 arts-assistenten gegeven. Het doel van de training was om te zien of hun kennis na de training ten aanzien van het gezondheidszorgsysteem significant was toegenomen. Om dit vast te kunnen stellen ontwierpen wij daarom een toets met kennisvragen over het gezondheidszorgsysteem die de arts-assistenten zowel voor als na de training moesten invullen. Een controle groep van 24 arts-assistenten vulden op dezelfde momenten dezelfde vragenlijst in om met zekerheid vast te kunnen stellen dat de eventuele 


\section{Chapter 8}

kennistoename werd veroorzaakt door de managementtraining. Een ander doel was om de training te laten beoordelen door de deelnemende arts-assistenten door middel van evaluatieformulieren en diepte-interviews.

De training bestond uit twee sessies van vier uur. Tussen de sessies zat een periode van drie weken, waarin de arts-assistenten konden werken aan een huiswerkopdracht. Alle veertien arts-assistenten voltooide de training. Zes arts-assistenten uit de controlegroep waren lost-to-follow-up. De pre- en postkennistest liet een grotere verbetering in kennis onder de deelnemende arts-assistenten zien in vergelijking met de arts-assistenten uit de controlegroep. Deze verbetering was echter niet significant. Alle deelnemende artsassistenten evalueerden de training positief en gaven aan dat zij de training als een nuttige aanvulling hadden ervaren op hun opleiding tot medisch specialist.

\section{CONCLUSIE}

De studies die wij hebben uitgevoerd suggereren dat er een duidelijke behoefte aan medisch managementonderwijs bestaat onder (Nederlandse) arts-assistenten. Opvallend genoeg hadden arts-assistenten en medisch specialisten een vrijwel identieke mening over de opzet en inhoud van zo'n training. De managementtraining die wij ontwierpen en implementeerde werd met enthousiasme ontvangen en nodigt uit tot een verdere ontwikkeling hiervan. 




\section{Chapter 8}

Ik ben ontzettend blij dat ik na een periode van hard werken dit proefschrift mag verdedigen. Ik had dit nooit voor elkaar gekregen zonder de steun en bijdragen van een heel aantal mensen.

Als eerste wil ik daarvoor dr. Busari bedanken. Ik kon vanaf het begin het enthousiasme voor het onderwerp met u delen. Toen ik echter de eerste versie van mijn eerste artikel van u terug kreeg, vrijwel geheel met rode pen aangestreept, had ik zo mijn twijfels dat het ooit goed zou komen. Dankzij uw aanwijzingen, positieve aanmoedigingen en voorliefde voor het stellen van strakke deadlines is het uiteindelijk toch helemaal goed gekomen. Dat zetje in de rug had ik af en toe nodig en dat voelde u goed aan. Niet alleen heeft u mij begeleid in de ontwikkeling naar een zelfstandig wetenschapper, ook in de kliniek heeft u mij het nodige bijgebracht. Voor al deze lessen wil ik u bedanken.

Ide, jouw nuchtere aard in combinatie met een sterk doorzettingsvermogen, zorgden er mede voor dat dit onderzoek van de grond kon komen. Je was op een oprechte en gezellige manier betrokken, wat ik ook zeer waardeerde op de congressen waar we zijn geweest.

Luc, door jouw uitgebreide ervaring in het onderzoeksveld kon je met een enkel woord direct de gevoelige plek van een onderzoek benoemen en een oplossing aandragen. Ik hoop deze prettige samenwerking de komende jaren voort te mogen zetten in de kliniek.

Albert, ik moest er in het begin erg aan wennen dat ik in een vergadering het woord moest nemen en de vergadering moest leiden. Maar je had helemaal gelijk, op die manier werd het nog meer "mijn" onderzoek en mijn leerproces. Ik ben je zeer dankbaar voor de altijd snelle reacties, het meedenken en het feit dat alles altijd mogelijk was.

Uiteraard wil ik ook alle onderzoekspartners bedanken. Mark en Suzanne, bedankt voor jullie harde werk en positieve inzet, zonder jullie was het niet gelukt. Linda, Charlotte en Susannah, bedankt voor de fijne internationale samenwerking. Fraukje, bedankt voor het meedenken en de gezelligheid. Arno, bedankt dat ik met mijn pagina-lange (letterlijk) statistische vragen bij jou terecht kon en je de tijd wilde nemen om mij hierin verder te onderwijzen. Ook wil ik alle arts-assistenten en specialisten uit zowel Nederland als het buitenland bedanken voor hun deelname, zonder jullie was er geen onderzoek geweest.

Naast mijn onderzoeksteam wil ik ook graag mijn paranimfen bedanken. Judith, vanaf de eerste dag dat we elkaar leerden kennen voelden we een klik. Zonder jou was dit boekje 
wellicht nooit tot stand gekomen omdat mijn eerste ervaringen met het wetenschappelijk onderzoek dan vast niet zo positief waren geweest. Samen op congres, samen cocktails drinken en samen kleding bestellen tijdens de lange uren achter de computer, het maakte dat ik iedere dag met plezier naar het ziekenhuis ging.

Caroline, ook wij hebben inmiddels een behoorlijke geschiedenis samen. Als eerste natuurlijk bij ons dispuut, waarbij onze band hechter werd toen we allebei na onze studie in Maastricht bleven wonen en aan een promotietraject begonnen. Je begreep mijn sores en ik kon altijd bij je terecht voor advies of een opbeurende lunch, diner of avondje uit. Ik ben heel blij dat ik op termijn weer bij jullie beide in de buurt kom wonen (Maastrickie!).

Ook wil ik Marieke, Nienke, Annemarie, Merel, Max en Rudo in het bijzonder bedanken voor hun adviezen en niet aflatende steun in de mooie, maar vooral ook wat moeilijkere tijden. Met name het laatste jaar is een behoorlijke achtbaan geweest en zonder jullie waren er heel wat minder mooie momenten geweest.

Nick, ik vind het ontzettend tof dat je de kaft van mijn proefschrift wilde ontwerpen. Nu heb ik eindelijk een echte "Liefhebber" in huis!

Naast al deze lieve vrienden wil ik ook mijn collega's van de afgelopen jaren bedanken, mijn collega's bij GGD West-Brabant, het St. Antonius Ziekenhuis in Nieuwegein en het Atrium Medisch Centrum in Heerlen. Jullie vertrouwen en gezelligheid hebben er toe bijgedragen dat alles een stukje lichter voelde en ik er echt voor durfde te gaan.

Mijn (schoon)familie wil ik graag bedanken voor hun niet aflatende interesse in mijn welzijn en het onderzoek. De herhaalde vraag "wanneer is de verdediging nou?", zorgde ervoor dat ik de nodige druk bleef voelen om mijn onderzoek tijdig af te ronden :). Mijn ouders wil ik daarbij in het bijzonder bedanken voor de onvoorwaardelijke steun, die ik niet alleen afgelopen jaren, maar mijn hele leven heb gevoeld.

En tot slot wil ik natuurlijk Gerard bedanken, mijn grote liefde. Het is moeilijk om in woorden uit te drukken wat jij voor mij betekent en hoe ik mij door jou gesteund voel in alles wat ik doe. Ik ben ontzettend trots op je en kijk uit naar alles wat wij samen nog gaan beleven. 


Lizanne Berkenbosch was born on the 9th of May 1985 in Berkel-Enschot. She studied medicine at the Maastricht University from 2004-2010. During medical school she also participated in the elective "International Track in Medicine" for which she engaged in several internships abroad, besides taking classes like "Globalization and Inequality". After obtaining her medical degree in September 2010, she started her PhD at the Maastricht University at the School of Health Professions Education. During this period she combined her PhD studentship with her job as a resident-not-in-training (ANIOS) at two Pediatric Departments; namely at the Atrium Medical Centre in Heerlen and at the St. Antonius Hospital in Nieuwegein. She also held a job as a school doctor at the Community Health Service of West-Brabant.

In June 2014, Lizanne started her specialty training within Pediatrics at the Maastricht University Medical Centre. She also participates in several committees promoting management and leadership education in the Dutch postgraduate medical curriculum. 
